\title{
A expressão de genes relacionados à plasticidade sináptica durante o sono REM após exposição a um ambiente enriquecido
}

Dissertação apresentada ao Instituto de

Psicologia da Universidade de São

Paulo para a obtenção de título de

Mestre em Neurociências e

Comportamento

Orientador: Prof. Dr. Koichi Sameshima

Co-orientadora: $\mathrm{Dr}^{\mathrm{a}}$. Elida Paula

Benquique Ojopi

São Paulo

2009 
AUTORIZO A REPRODUÇÃO E DIVULGAÇÃO TOTAL OU PARCIAL DESTE TRABALHO, POR QUALQUER MEIO CONVENCIONAL OU ELETRÔNICO, PARA FINS DE ESTUDO E PESQUISA, DESDE QUE CITADA A FONTE.

Catalogação na publicação

Biblioteca Dante Moreira Leite

Instituto de Psicologia da Universidade de São Paulo

Pinto, Julien Braga Calais Correia.

A expressão de genes relacionados à plasticidade sináptica durante o sono REM após exposição a um ambiente enriquecido / Julien Braga Calais Correia Pinto; orientador Koichi Sameshima. -São Paulo, 2009.

$102 \mathrm{p}$.

Dissertação (Mestrado - Programa de Pós-Graduação em Psicologia. Área de Concentração: Neurociências e Comportamento) Instituto de Psicologia da Universidade de São Paulo.

1. Memória 2. Aprendizagem 3. Sono 4. Expressão gênica 5. Plasticidade neuronal I. Título.

BF371 


\section{FOLHA DE APROVAÇÃO}

Julien Braga Calais Correia Pinto

A expressão de genes relacionados à plasticidade sináptica durante o sono REM após exposição a um ambiente enriquecido

Dissertação apresentada ao Instituto de Psicologia da Universidade de São Paulo para a obtenção de título de Mestre em Neurociências e Comportamento

Aprovada em:

Banca Examinadora

Prof. Dr. Instituição

Julgamento Assinatura

Prof. Dr. Instituição

Julgamento Assinatura

Prof. Dr. Instituição

Julgamento Assinatura 


\section{DEDICATÓRIA}

Dedico este trabalho

À minha noiva Elizabeth com amor e gratidão por sua compreensão, carinho, presença e ajuda indispensável durante a elaboração deste trabalho.

Ao meu pai Luiz André e à minha mãe Nélia Cristina pelo carinho e amor nutrido a mim, pelos ensinamentos e pelo incentivo emocional (e financeiro) que fizeram com que eu alcançasse os meus objetivos.

Aos meus avôs Constantino (in memoriam) e Francisco (in memoriam) e às minhas avós Nadir e Maria (Minininha) por sempre terem me incentivado e pela sabedoria e alegria que me passaram ao longo de todos esses anos.

Aos meus irmãos Lander, Wyller e André Luiz pela amizade, carinho e apoio em todos os momentos.

Aos meus tios e tias pelos conselhos e lições que ajudaram a moldar a minha personalidade.

Aos meus primos e primas pela amizade e companheirismo desde a infância que induziram algumas de minhas melhores memórias.

Ao meu sogro Chen e à minha sogra Margarida por terem me aceitado em sua família e pelo apoio durante a confecção desse trabalho.

Ao Luiz Fernando pela sua alegria e carinho.

Aos amigos do CEB e da Bio 37 pela companhia agradabilíssima. 


\section{AGRADECIMENTOS}

Agradeço

Ao prof. Dr. Koichi Sameshima pelo incentivo, apoio, confiança e ensinamentos que foram fundamentais para o desenvolvimento do meu raciocínio científico e construção de habilidades profissionais essenciais para o meu crescimento acadêmico.

À Dra . Elida Paula Benquique Ojopi pelo apoio, atenção, estímulo e orientação valorosos que certamente foram cruciais para que eu ganhasse maturidade pessoal e profissional e tornaram os momentos dedicados a esse trabalho muito mais agradáveis.

Ao prof. Dr. Sidarta Ribeiro pelo ensino, supervisão e, principalmente, incentivo em momentos decisivos para o sucesso dessa empreitada.

Ao Sérgio Arthuro Rolim pela ajuda nos experimentos durante e após o horário comercial.

Ao grupo de eletrofisiologia do Laboratório "Cesar Timo-Iaria" Dr. Edgard Morya, Eduardo Schenberg, Luiz Lana, Dr. Daniel Takahashi, Ana Carolina Bione Kunicki, Rafael Proença, Carlos Stein, Taísa Miranda, Marina Faveri e Birajara Machado pelas discussões instigantes, pela ajuda no desenvolvimento do trabalho (e no preenchimento dos milhares de formulários da FINEP) e por terem tornado o tempo que passei no laboratório muito mais agradável.

Ao grupo de genética do Laboratório de Neurociências (LIM 27) Maria Carolina Athié, Giselle Izzo, Carolina do Prado, Dr. Fabio Mury, Bárbara Nogueira, Dra. Camila Teixeira, Heloisa Müller e Carolina Almeida pela excelente convivência, companheirismo e pelo auxílio (e ensino) das técnicas empregadas nesse projeto.

À prof ${ }^{a}$. Dr ${ }^{a}$. Sara Joyce Shammah Lagnado e à Carolina Jaqueta pela ajuda na definição das regiões a serem analisadas e pelo ensino das técnicas de dissecação.

À Dra . Ângela Cristina do Valle e sua aluna Gabriela Matos pela ajuda no aperfeiçoamento dos eletrodos e da cirurgia de implante.

Ao Bruno Brito e à Gabriela Fujisaka pela ajuda no processamento dos encéfalos para histologia.

Ao Hindiael Belchior e ao Hao Zhang pela ajuda no estagiamento do sono. 
Ao prof. Dr. Luiz Roberto Britto e à prof ${ }^{\mathrm{a}}$. Dra ${ }^{\mathrm{a}}$. Débora Hipólide pelas valorosas discussões que melhoram o trabalho.

A todos os membros das bancas de qualificação e defesa.

A todos os membros da AASDAP e do laboratório "Cesar Timo-Iaria".

A todos os membros do Laboratório de Neurociências (Lim-27).

Ao Instituto de Psicologia da Universidade de São Paulo pela oportunidade de realização do curso de mestrado.

Ao Instituto de Psiquiatria da Faculdade de Medicina da Universidade de São Paulo ao pela disponibilização da infra-estrutura necessária ao desenvolvimento desse trabalho.

Ao Instituto de Ensino e Pesquisa do Hospital Sírio Libanês pela disponibilização da infraestrutura necessária ao desenvolvimento desse projeto.

À Associação Alberto Santos Dummont para Apoio à Pesquisa (AASDAP) pela disponibilização da infra-estrutura necessária ao desenvolvimento desse projeto.

À Fundação de Amparo à Pesquisa do Estado de São Paulo (FAPESP), pela concessão da bolsa de estudos (processo 2006/05436-8) e auxílio financeiro (processo 2007/07366-0) para o desenvolvimento desse projeto

À Financiadora de Estudos e Projetos (FINEP), pela concessão de auxílio financeiro (convênio referência FINEP $n^{0} .2629 / 06$, contrato $n^{\circ}$. 01.06.1092.00) que possibilitou o desenvolvimento desse trabalho.

A todos aqueles que contribuíram direta ou indiretamente para o desenvolvimento desse trabalho. 
To doubt everything or to believe everything are two equally convenient truths; both dispense with the necessity of reflection. 


\section{RESUMO}

Pinto, J.B.C.C. A expressão de genes relacionados à plasticidade sináptica durante o sono REM após exposição a um ambiente enriquecido. 2009. 103 f. Dissertação (Mestrado) - Instituto de Psicologia - Neurociências e Comportamento, Universidade de São Paulo, São Paulo, 2009.

Diversas evidências demonstram que as diferentes fases do sono agem de maneira complementar e diferencial na consolidação de memórias. No entanto os mecanismos celulares e moleculares dessa relação não estão estabelecidos. Foi postulado que a melhor maneira para se entender como o sono facilita o aprendizado é contrastando evidências experimentais obtidas em presença ou ausência de informação adquirida recentemente; e que a plasticidade sináptica dependente de atividade é o melhor correlato celular para o aprendizado e memória. Portanto, analisamos a expressão dos genes relacionados à plasticidade sináptica Arc, Bdnf, Camk4, Creb1, Egrl, Egr2, Fos, Nr4al, Ppp2ca e Ppp2r2d durante o sono de ratos adultos expostos ou não a um ambiente enriquecido. Nove dos 10 genes avaliados (Arc, Bdnf, Creb1, Egrl, Egr2, Fos, Nr4al, Ppp2ca e Ppp2r2d) mostraram aumento da expressão após a exposição. A expressão de $B d n f$ no hipocampo estava aumentada durante os estágios marcados pela dessincronização da atividade elétrica do cérebro (vigília e sono REM) sugerindo que $B d n f$ poderia ser um marcador da homeostase do sono. Pela primeira vez demonstramos que exposição ao ambiente enriquecido promoveu aumento na expressão de genes (Ppp2r2d, Ppp2r2ca) que codificam para a proteína fosfatase 2A (PP2A). Dado o papel dessa proteína na plasticidade sináptica dependente de atividade sugerimos que esse evento seja importante para as modificações na morfologia e atividade neuronal observados após a exposição a um ambiente enriquecido. Por fim, o nosso trabalho mostra que ocorre a reindução de genes relacionados à potencialização sináptica durante SREM (Egrl, Fos). E, pela primeira vez, demonstrou-se que um gene que codifica para uma proteína relacionada à depressão da atividade sináptica também está reinduzido (Ppp2r2d) no hipocampo. Esses resultados reforçam a necessidade de uma reativação na atividade cerebral durante o sono e, pela primeira vez, mostramse evidências experimentais que a potencialização e depressão da plasticidade sináptica ocorrem concomitantemente durante o sono.

Palavras-chave: MEMÓRIA; APRENDIZAGEM; SONO; EXPRESSÃO GÊNICA; PLASTICIDADE NEURONAL. 


\section{ABSTRACT}

Pinto, J.B.C.C. Expression of synaptic plasticity-related genes during REM sleep following novelty exposure. 2009. 103 f. Dissertation (Master's degree) - Instituto de Psicologia - Neurociências e Comportamento, Universidade de São Paulo, São Paulo, 2009.

Independent lines of evidence show differential and complementary roles of slow wave sleep and REM sleep in memory consolidation. However molecular and cellular mechanisms governing this relation are not known. It was suggested that comparison of experimental evidences obtained in presence or absence of recently acquired information is necessary to investigate sleep-dependent memory consolidation. It is well known that the activity-dependent synaptic plasticity is the best cellular and molecular correlate of learning and memory. Therefore we carried out experiments analyzing expression of synaptic plasticity-related genes (Arc, Bdnf, Camk4, Creb1, Egrl, Egr2, Fos, Nr4al, Ppp2ca e Ppp2r2d) during sleep in adult rats exposed or not to a novel experience. Expression of nine out of 10 analyzed genes (Arc, Bdnf, Creb1, Egrl, Egr2, Fos, Nr4al, Ppp2ca e Ppp2r2d) was increased following novelty exposure. Bdnf expression was increased in hippocampus during vigilance states marked by desynchronized brain electrical activity (waking and REM sleep). Hence, suggesting that $B d n f$ has a role as a homeostatic marker of sleep need. Here, we showed for the first time that exposure to novelty induces expression of protein phosphatase 2A (PP2A) coding genes (Ppp2r2d, Ppp2r2ca) in the hippocampus. Given PP2A role in activity dependant synaptic activity and its association to cytoskeleton proteins this could account for changes in neural activity and morphology observed after exposure to novelty. Finally, we found reinduction of synaptic potentiation related genes during REM sleep (Egrl, Fos). Furthermore, we also found reinduction of $P p p 2 r 2 d$, which is related to synaptic depression. These results suggest the need for neural circuit reactivation during sleep and, for the first time, we provide experimental evidences that the synaptic potentiation and depression occur concurrently during sleep.

Keywords: MEMORY; LEARNING; SLEEP, GENE EXPRESSION; NEURONAL PLASTICITY. 


\section{LISTA DE FIGURAS}

Figura 1 - Mecanismos gerais para a indução e manutenção da Potencialização de Longa Duração (LTP) e Depressão de Longa Duração (LTD).

Figura 2 - Aparato para experimentação comportamental. 45

Figura 3 - Regiões do encéfalo do rato dissecadas para análise de expressão gênica por PCR em tempo real

Figura 4 - Eletrodos cortical e hipocampal fixados ao soquete.

Figura 5 - Sistema para registro do potencial de campo local (PCL) e do comportamento animal.

Figura 6 - Características comportamentais e padrão do PCL hipocampal e cortical em cada um dos estados do ciclo sono vigília.

Figura 7 - Desenho experimental utilizado para identificar as alterações na expressão de genes relacionados à plasticidade após a exposição ao ambiente enriquecido.

Figura 8 - Controle de qualidade do mRNA extraído.

Figura 9 - Estabilidade média de expressão (M) dos genes selecionados como controles endógenos restantes durante a exclusão gradual dos controles endógenos com expressão menos estável

Figura 10 - Seções frontais de $40 \mu \mathrm{m}$ coradas por cresil-violeta (coloração de Nissl) mostrando o hipocampo dorsal direito dos quatro animais utilizados para a localização dos eletrodos.

Figura 11 - Tempo dos animais (em segundos) em cada estágio do ciclo sono vigília durante a última hora de registro pré-exposição; e durante a separação dos estados (últimos 35 min de registro)

Figura 12 - Hipnogramas dos animais dos grupos sono REM controle; sono REM exposto; sono de ondas lentas controle; sono de ondas lentas exposto; vigília controle e vigília exposto durante os últimos $40 \mathrm{~min}$ antes do sacrifício. 
Figura 13 - Controle de qualidade do mRNA extraído.

Figura 14 - Expressão do gene Arc determinada por PCR em tempo real no hipocampo e córtex somestésico de ratos.

Figura 15 - Expressão do gene $B d n f$ determinada por PCR em tempo real no hipocampo e córtex somestésico de ratos.

Figura 16 - Expressão do gene Camk4 determinada por PCR em tempo real no hipocampo e córtex somestésico de ratos

Figura 17 - Expressão do gene Creb1 determinada por PCR em tempo real no hipocampo e córtex somestésico de ratos

Figura 18 - Expressão do gene Egrl determinada por PCR em tempo real no hipocampo e córtex somestésico de ratos.

Figura 19 - Expressão do gene Egr2 determinada por PCR em tempo real no hipocampo e córtex somestésico de ratos.

Figura 20 - Expressão do gene Fos determinada por PCR em tempo real no hipocampo e córtex somestésico de ratos.

Figura 21 - Expressão do gene Nr4al determinada por PCR em tempo real no hipocampo e córtex somestésico de ratos

Figura 22 - Expressão do gene Ppp2ca determinada por PCR em tempo real no hipocampo e córtex somestésico de ratos

Figura 23 - Expressão do gene $\operatorname{Ppp} 2 r 2 d$ determinada por PCR em tempo real no hipocampo e córtex somestésico de ratos 


\section{LISTA DE TABELAS}

Tabela 1 - Descrição dos genes e respectivos ensaios TaqMan utilizados para análise de expressão gênica.

Tabela 2 - Estabilidade média de expressão dos controles endógenos 64

Tabela 3 - Modulação na expressão de genes relacionados à plasticidade neural pelo fator experiência relevante no córtex somestésico e hipocampo de ratos.

Tabela 4 - Modulação na expressão de genes relacionados à plasticidade neural pelo fator estágio de sono no hipocampo de ratos.

Tabela 5 - Modulação na expressão de genes relacionados à plasticidade neural pelo fator estágio de sono no córtex somestésico de ratos. 


\section{LISTA DE ABREVIATURAS E SÍGLAS ${ }^{1}$}

\begin{tabular}{|c|c|}
\hline $5-\mathrm{HT}_{3 \mathrm{C}}$ & receptor de serotonina $3 \mathrm{C}$ \\
\hline $\mathrm{A}_{1}$ & receptor de adenosina $A_{1}$ \\
\hline $\mathrm{A}_{2 \mathrm{a}}$ & receptor de adenosina $A_{2 a}$ \\
\hline$A c t b$ & actina, beta \\
\hline AF-1 & função ativadora 1 \\
\hline AMPA & $\alpha$-amino-3-hidroxil-5-metil-4-isoxazol-propionato \\
\hline Amphl & anfifisina II \\
\hline ANOVA & análise de variância \\
\hline AP-1 & proteína ativadora 1 \\
\hline $\operatorname{Arc}$ & proteína associada ao citoesqueleto regulada por atividade \\
\hline ATF-1 & fator de transcrição ativador 1 \\
\hline$B 2 m$ & Microglobulina, beta 2 \\
\hline$B d n f$ & fator neurotrófico derivado do encéfalo \\
\hline CAMK2 & proteína quinase dependente de $\mathrm{Ca}^{2+} /$ calmodulina II \\
\hline CAMK4 & proteína quinase dependente de $\mathrm{Ca}^{2+} /$ calmodulina IV \\
\hline cAMP & adenosina monofosfato cíclica \\
\hline CB1 & receptor de canabinóide $\mathrm{CB} 1$ \\
\hline $\mathrm{CBP}$ & proteína ligada ao CREB \\
\hline cDNA & DNA complementar \\
\hline$C l k$ & Clock \\
\hline CREB & proteína ligante ao elemento responsivo do cAMP \\
\hline Crebl & proteína ligante ao elemento responsivo do cAMP 1 \\
\hline Cttn & cortactina \\
\hline $\mathrm{CX}$ & córtex somestésico \\
\hline $\mathrm{dCREB} 2 \mathrm{~b}$ & proteína de ligação ao elemento de resposta ao cAMP em 17A \\
\hline DNA & ácido desoxirribonucleico \\
\hline dNTP & desoxirribonucleotídeos fosfatados \\
\hline $\mathrm{DP}$ & potência na banda delta (delta power) \\
\hline EA & exploração ativa (estágio do ciclo sono-vigília) \\
\hline
\end{tabular}

\footnotetext{
${ }^{1}$ As nomenclaturas e abreviações de genes e proteínas nesse trabalho seguem o proposto pelos International Committee on Standardized Genetic Nomenclature for Mice e Rat Genome and Nomenclature Committee (2009).
} 


\begin{tabular}{|c|c|}
\hline EEG & eletroencefalograma \\
\hline Egrl & resposta de crescimento inicial 1 \\
\hline Egr2 & resposta de crescimento inicial 2 \\
\hline ELK1 & ELK1, membro da família de oncogenes ETS \\
\hline EPM & erro padrão da média \\
\hline EPSPs & potenciais excitatórios pós-sinápticos \\
\hline ERK & quinase regulada por sinal extracelular \\
\hline $\mathrm{F}$ & fusos (estágio do ciclo sono-vigília) \\
\hline Fos & oncogene osteosarcoma FBJ \\
\hline Frapl & proteína de ligação ao FK506 12 \\
\hline FRP & formação reticular pontina \\
\hline gDNA & DNA genômico \\
\hline Gusb & Glucuronidase, beta \\
\hline Homerl & gene homólogo ao Homer1 da Drosófila \\
\hline HP & Hipocampo \\
\hline Itprl & receptor de inositol 1,4,5-trifosfato tipo I \\
\hline LED & light emission diode \\
\hline LTD & depressão de longa duração \\
\hline LTP & potencialização de longa duração \\
\hline M & estabilidade média de expressão \\
\hline MAPK & proteína quinase ativada por mitógeno \\
\hline MEF2D & fator de crescimento do miócito $2 \mathrm{D}$ \\
\hline mGLU & receptores metabotrópicos de glutamato \\
\hline MOPr & receptor opióide Um \\
\hline $\mathrm{Mp}$ & marcador de peso molecular \\
\hline mRNA & RNA mensageiro \\
\hline MV & $\begin{array}{l}\text { movimentação estereotipada das vibrissas (estágio do ciclo sono- } \\
\text { vigília) }\end{array}$ \\
\hline NBRE & elemento responsivo ao fator de crescimento neural - clone B \\
\hline NMDA & N-metil D-aspartato \\
\hline$N r 4 a 1$ & receptor nuclear subfamília 4, grupo A, membro 1 \\
\hline NSQ & núcleo supraquiasmático \\
\hline NTC & controle sem amostra (non template control) \\
\hline
\end{tabular}




\begin{tabular}{|c|c|}
\hline $\mathrm{OC}$ & grupo sono de ondas lentas controle \\
\hline $\mathrm{OE}$ & grupo sono de ondas lentas exposto \\
\hline p. ex. & por exemplo \\
\hline PCL & potencial de campo local \\
\hline $\mathrm{pCREB}$ & forma fosforilada de CREB \\
\hline Perl & Period 1 \\
\hline Per2 & Period 2 \\
\hline pERK2 & forma fosforilada da quinase regulada por sinal extracelular \\
\hline $\mathrm{PGD}_{2}$ & prostaglandina $\mathrm{D}_{2}$ \\
\hline PGO & ondas ponto-genículo-occipitais \\
\hline PI3 quinase & fosfatidil inositol 3 quinase \\
\hline PKA & proteína quinase $\mathrm{A}$ \\
\hline $\mathrm{PKC}$ & proteína quinase $\mathrm{C}$ \\
\hline PP1 & proteína fosfatase 1 \\
\hline PP2A & proteína fosfatase $2 \mathrm{~A}$ \\
\hline PP2B & calcineurina \\
\hline Ppp2ca & proteína fosfatase $2(2 \mathrm{~A})$, subunidade catalítica, isoforma alfa \\
\hline Ppp2r2d & proteína fosfatase $2(2 \mathrm{~A})$, subunidade regulatória $\mathrm{B}$, isoforma delta \\
\hline Ppp3r1 & $\begin{array}{l}\text { proteína fosfatase } 3 \text {, subunidade regulatória } \mathrm{B} \text {, isoforma alfa } \\
\text { (calcineurina } \mathrm{B} \text {, tipo } \mathrm{I} \text { ) }\end{array}$ \\
\hline $\mathrm{RC}$ & grupo sono REM controle \\
\hline $\mathrm{RE}$ & grupo sono REM exposto \\
\hline RNA & ácido ribonucleico \\
\hline Rpl19 & proteína ribossomal L19 \\
\hline rRNA & RNA ribossômico \\
\hline RTK & receptor de tirosina quinase \\
\hline SI & sono intermediário (estágio do ciclo sono-vigília) \\
\hline SOL & sono de ondas lentas (estágio do ciclo sono-vigília) \\
\hline SREM & sono REM (estágio do ciclo sono-vigília) \\
\hline SRF & fator de resposta ao soro \\
\hline STMN1 & statmina 1 \\
\hline SYN1 & sinapsina 1 \\
\hline TCF & fator complexo ternário \\
\hline
\end{tabular}


tws

UNG

$\mathrm{VC}$

VE

VG

VP

$w d b$
Twins

uracil-N-glicosilase

grupo vigília controle

grupo vigília controle

vigília (estágio do ciclo sono-vigília)

vigília passiva (estágio do ciclo sono-vigília)

widerborst 


\section{LISTA DE SÍMBOLOS}

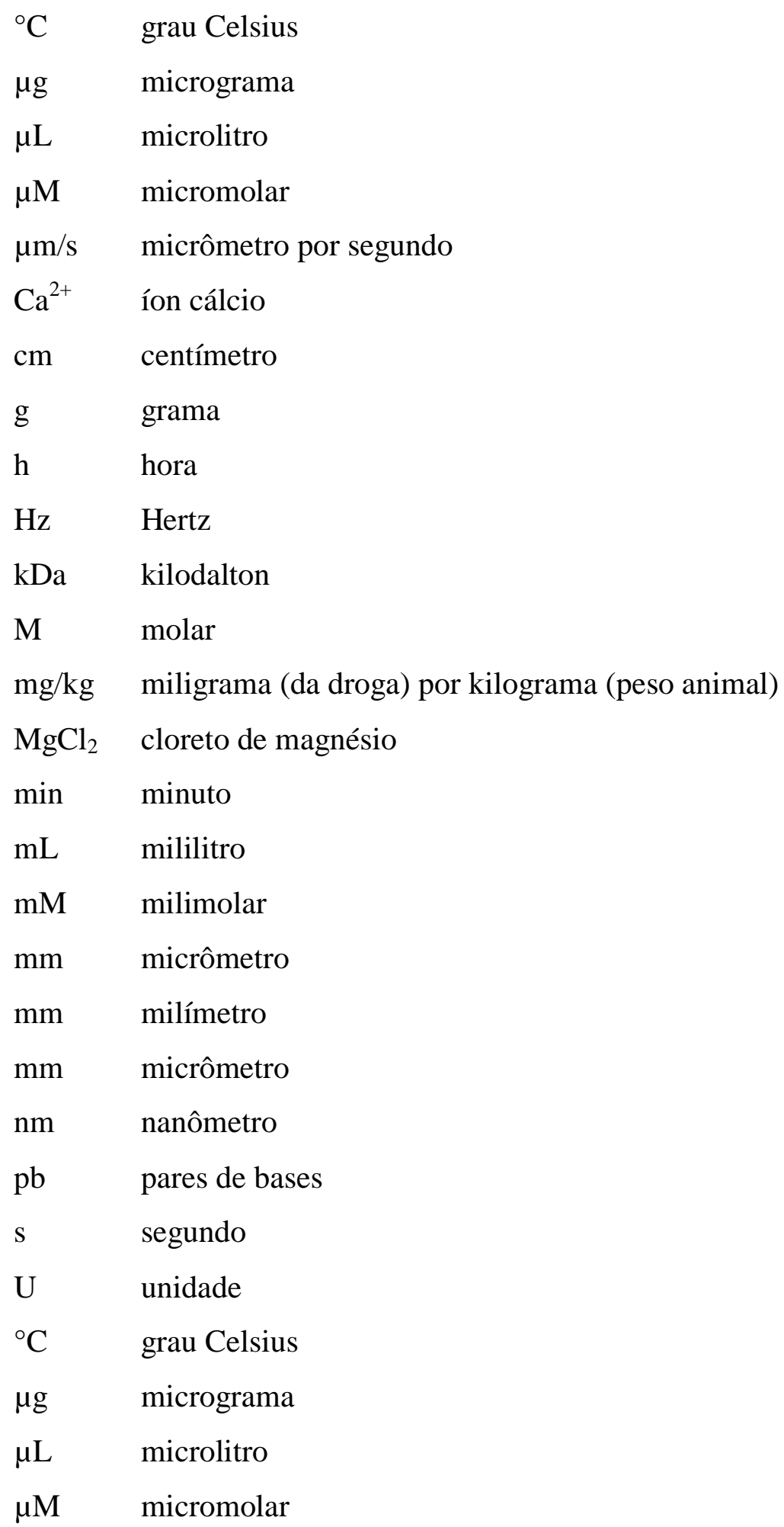




\section{SUMÁRIO}

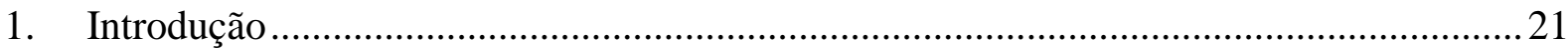

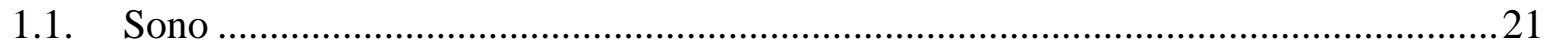

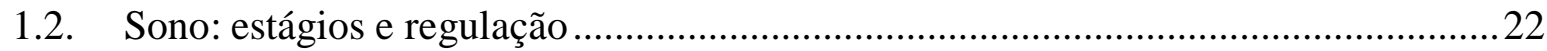

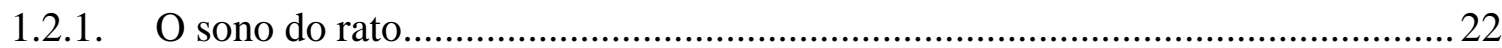

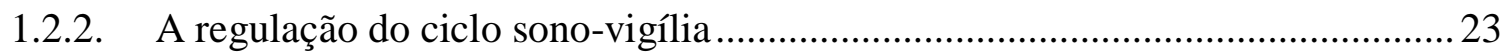

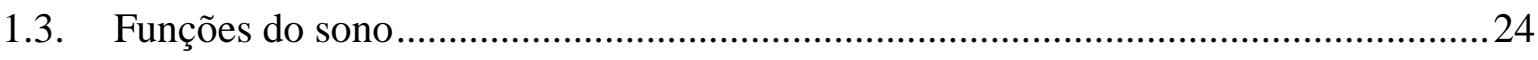

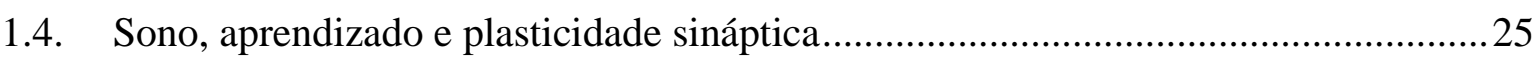

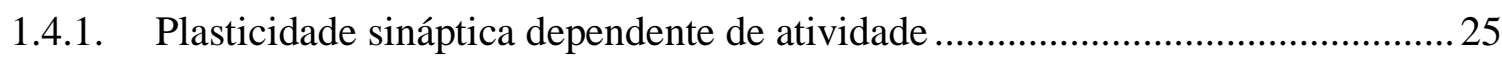

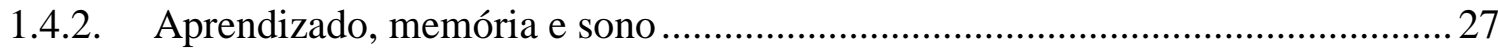

1.4.3. Alterações na transcrição e tradução durante o sono........................................... 30

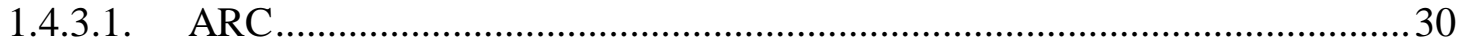

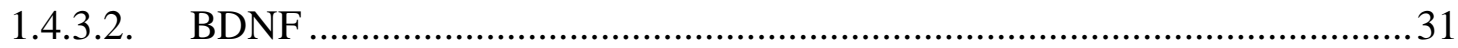

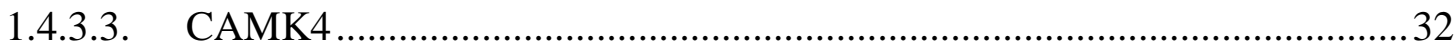

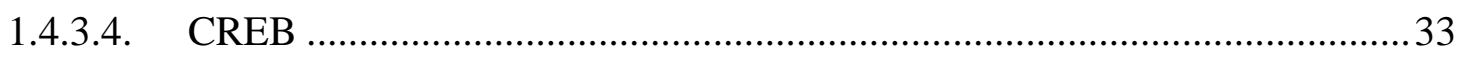

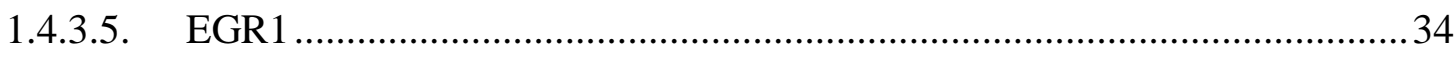

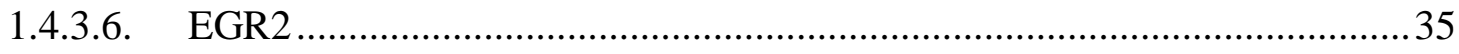

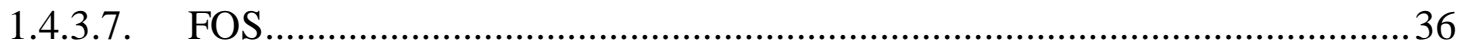

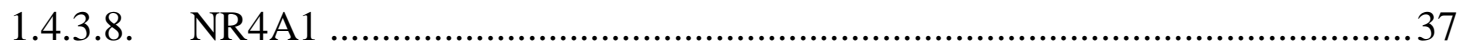

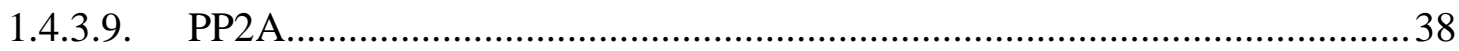

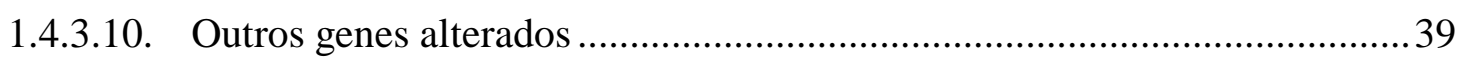

1.5. Duas teorias para a plasticidade sináptica durante o sono .......................................40

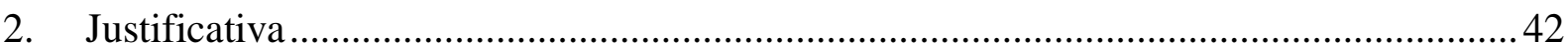

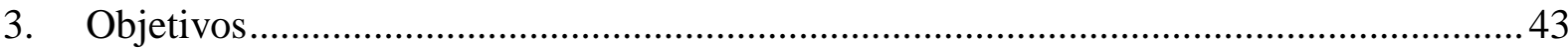

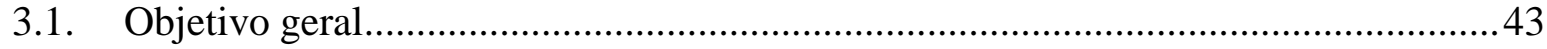

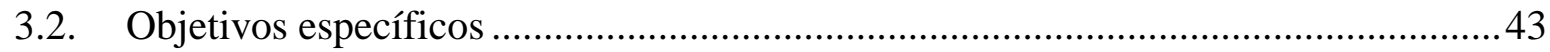

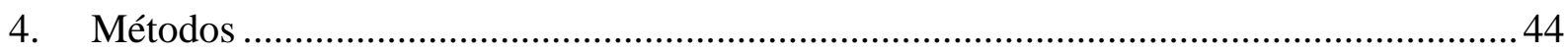

4.1. Determinação dos controles endógenos ...........................................................44

4.1.1. Análise do comportamento e coleta das regiões encefálicas ............................. 44

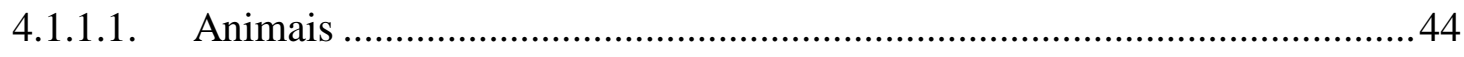

4.1.1.2. Aparato de experimentação comportamental ..............................................44

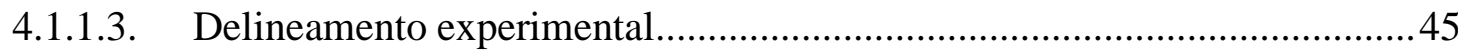




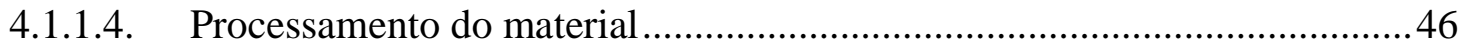

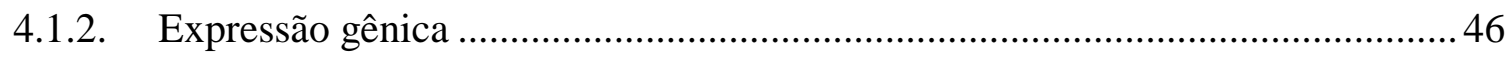

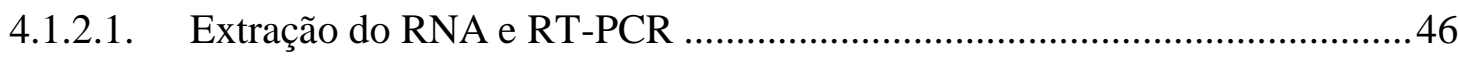

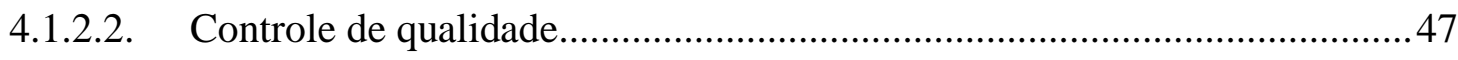

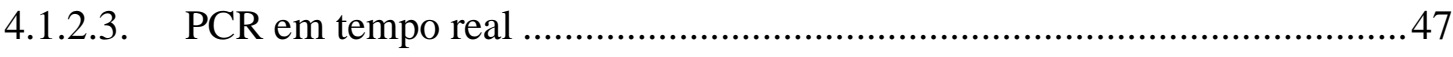

4.2. Expressão gênica modulada por sono e ambiente enriquecido.................................48

4.2.1. Comportamento, cirurgia e coleta ................................................................. 48

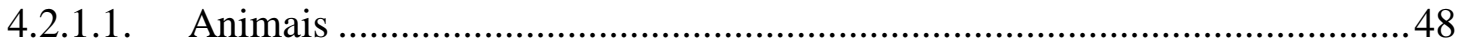

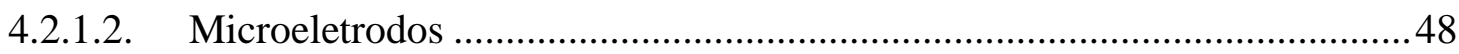

4.2.1.3. Cirurgia para implante de microeletrodos ................................................49

4.2.1.4. Aparato de experimentação comportamental .............................................50

4.2.1.5. Identificação dos estados de sono-vigília.....................................................51

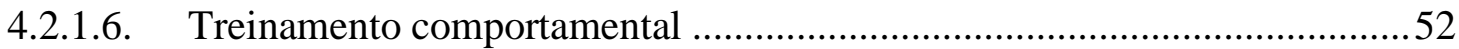

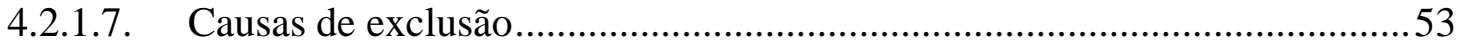

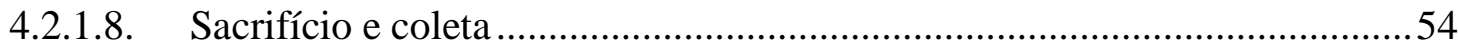

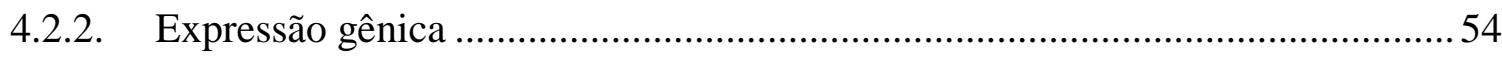

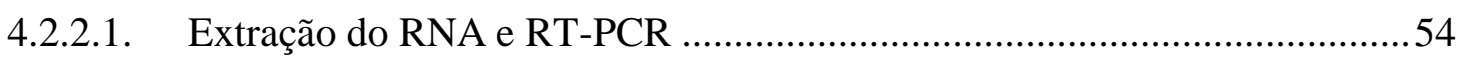

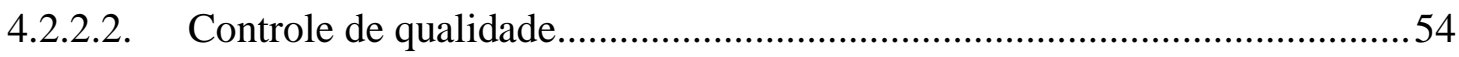

4.2.2.3. Seleção dos genes alvo ........................................................................5

4.2.2.4. Curvas de eficiência dos ensaios de PCR em tempo real - .........................55

4.2.2.5. Avaliação da expressão gênica por PCR em tempo real ..............................56

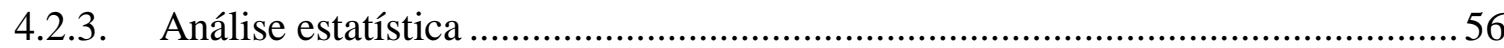

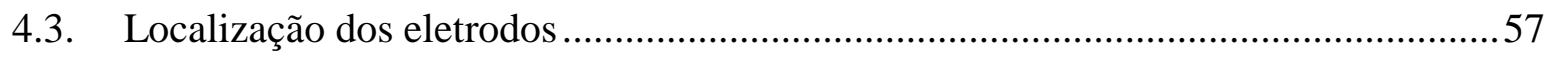

4.3.1. Animais, cirurgia e perfusão................................................................... 57

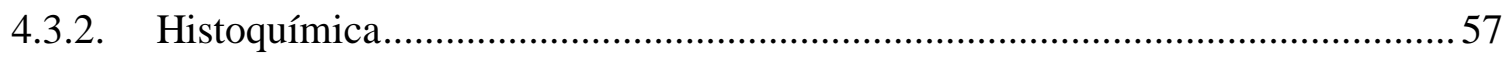

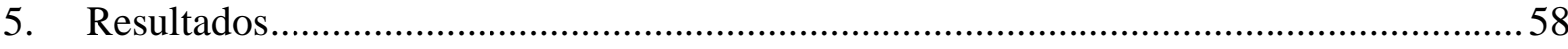

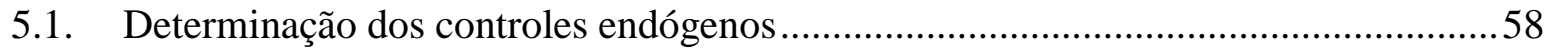

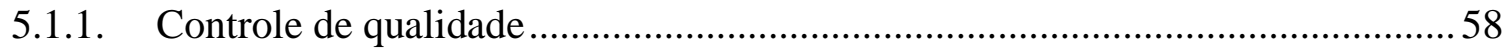

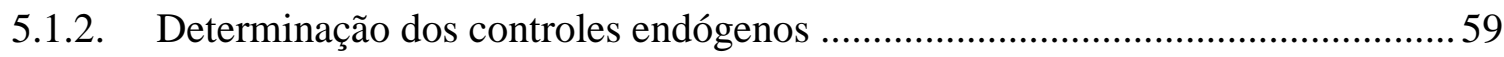

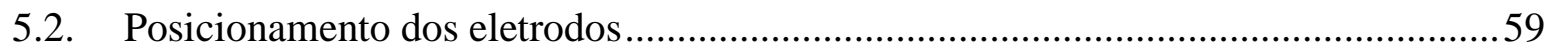

5.3. Expressão gênica modulada por sono e ambiente enriquecido................................60

5.3.1. Identificação e separação dos estágios do ciclo sono-vigília .............................. 60

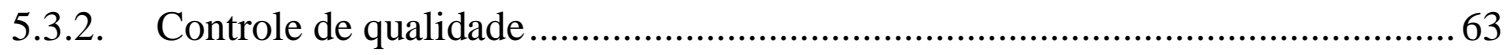

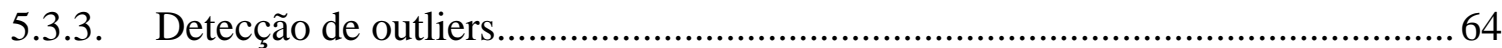




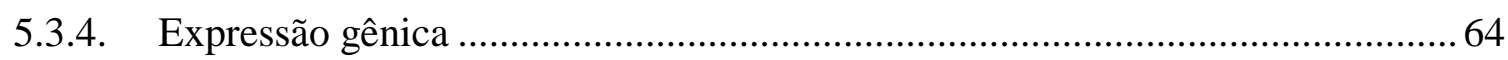

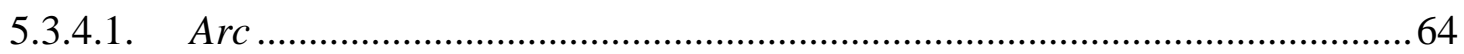

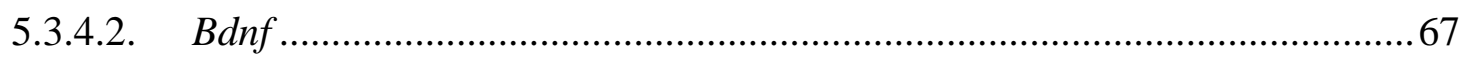

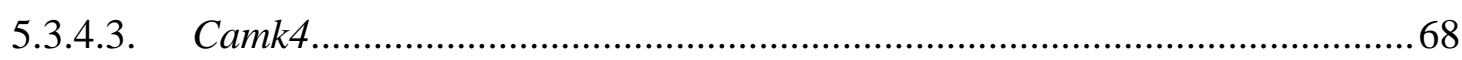

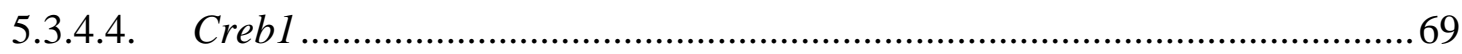

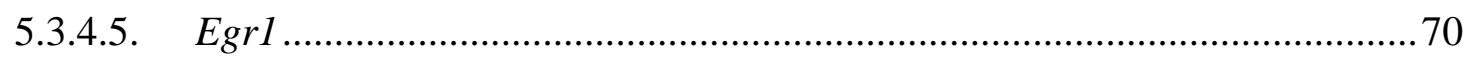

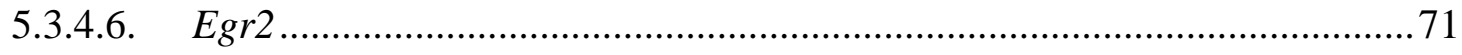

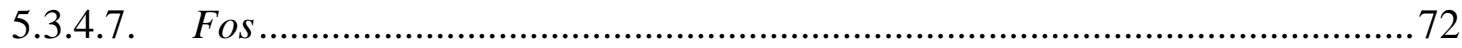

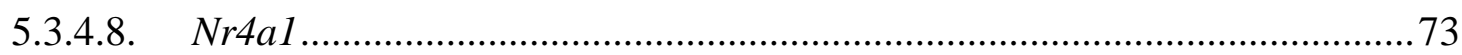

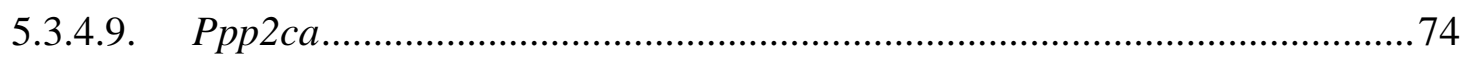

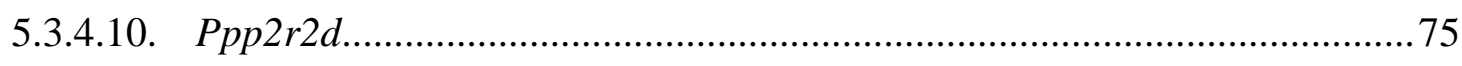

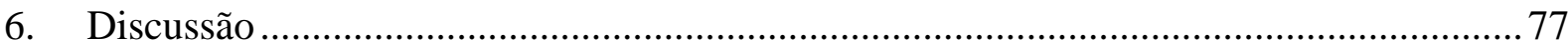

6.1. Exposição ao ambiente enriquecido e a expressão de genes relacionados à

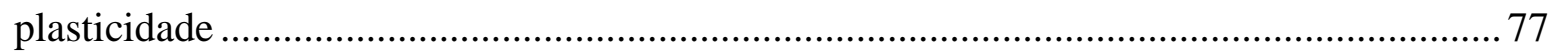

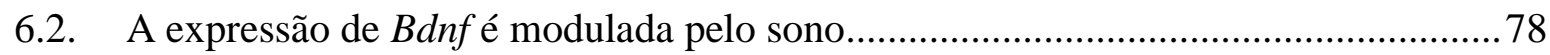

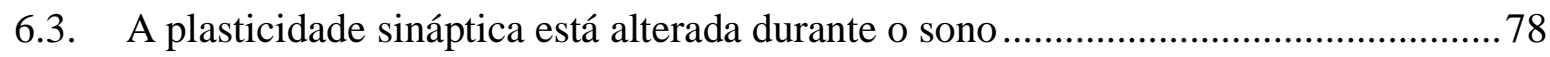

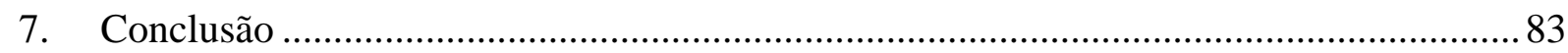

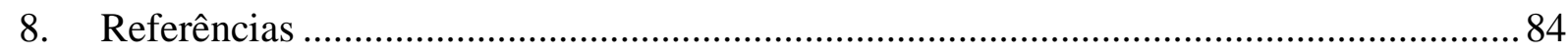

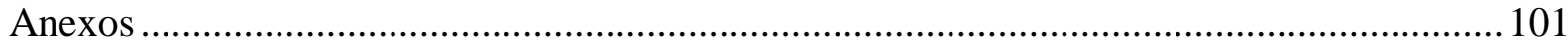




\section{Introdução}

\subsection{Sono}

Atualmente, acredita-se que todos os vertebrados terrestres exibam algum comportamento semelhante ao sono, como diminuição ou cessação dos movimentos, postura característica, diminuição da reatividade a estímulos externos, organização circadiana, fácil e imediata reversão ao estado de vigília (VG) e capacidade auto-regulatória (TOBLER, 1995; LESKU et al., 2006; ROTH et al., 2006; VASSALLI; DIJK, 2009). Similarmente, comportamentos semelhantes ao sono foram descritos em cetáceos e invertebrados (RAMON et al., 2004; GANGULY-FITZGERALD; DONLEA; SHAW, 2006; SIEGEL, 2008; VASSALLI; DIJK, 2009). Além disso, existem evidências de que alguns protistas, dinoflagelados, cianobactérias e euglenozoa apresentem ciclo circadiano (SIEGEL, 2008). Por fim, de uma maneira ainda controversa, Rector et al.(2009) sugerem que comportamentos semelhantes ao sono emergem de qualquer rede neural viável. Essas evidências indicam que o sono e o ciclo circadiano devem ter um componente ancestral conservado. Como a necessidade de sono varia de maneira espécie-específica, é possível que alterações na fisiologia dos animais ao longo do curso evolutivo tenham adicionado funções ao sono (SIEGEL, 2008; VASSALLI; DIJK, 2009).

Além da presença ubíqua de estados semelhantes ao sono ao longo da escala evolutiva (TOBLER, 1995; SIEGEL et al., 1999; SIEGEL, 2005; LESKU et al., 2006; ROTH et al., 2006), sua importância também é demonstrada pelo rebote de sono ocorrido após a privação total de sono, ou o rebote de sono de ondas lentas (SOL) ou sono REM (SREM) após a privação seletiva desses estágios. Sabe-se que ratos morrem após 2-3 semanas de privação completa de sono e que ratos privados somente de SREM sobrevivem duas a três vezes mais que aqueles com privação total (RECHTSCHAFFEN, 1998). A contribuição do sono para a saúde mental humana também foi estabelecida em estudos epidemiológicos de grande escala a respeito do sono normal e estudos clínicos documentando os efeitos adversos das doenças relacionadas ao sono (VASSALLI; DIJK, 2009). Por outro lado, a privação de sono foi utilizada com sucesso como tratamento para a Depressão Maior e Transtorno Bipolar (BUNNEY; POTKIN, 2008). 


\subsection{Sono: estágios e regulação}

Até meados do século XX, pensava-se que o sono fosse um processo passivo no qual atividade cerebral estava muito reduzida ou ausente e que ocorria devido à diminuição das informações provenientes dos diversos sistemas sensoriais (HOBSON, 2005). Esta hipótese a respeito do sono como um evento passivo, começou a ser alterado pelos trabalhos de von Ecomono em pacientes com encefalite letárgica. Von Ecomono (1930) evidenciou que regiões do mesencéfalo e diencéfalo eram responsáveis pela regulação do sono e da vigília. Esses dados foram confirmados posteriormente por Moruzzi e Magun (1949) ao demonstrarem que a dessincronização cortical em gatos era mediada por uma via ascendente que se iniciava na ponte e ia até a formação reticular mesencefálica ${ }^{2}$.

A caracterização dos diferentes estágios de sono só foi possível com o advento da eletroencefalografia. Berger (1929) registrou pela primeira vez a presença do ritmo delta e de fusos durante o estado caracterizado posteriormente como SOL. No entanto, foi o trabalho de Loomis, Harvey e Hobart (1937) que pioneiramente descreveu os padrões eletroencefalográficos durante o sono em humanos. Em 1953, a dessincronização cortical foi relatada como um fenômeno natural e cíclico durante o sono, sendo estabelecida como uma fase específica em que era também comum a ocorrência de movimentos oculares rápidos caracterizando assim o SREM (ASERINSKY; KLEITMAN, 1953).

\subsubsection{O sono do rato}

Apesar de os estágios do sono estarem bem descritos para diversos animais, nos ateremos ao rato, o nosso modelo de experimentação. Os ratos apresentam um sono polifásico predominantemente diurno, ou seja, com vários ciclos distribuídos entre o dia e a noite. O ciclo sono-vigília do rato pode ser divido em sete estágios: exploração ativa (EA), vigília passiva (VP), movimentação estereotipada das vibrissas (MV), fusos (F), sono de ondas lentas (SOL), sono intermediário (SI) e sono REM (SREM) (TIMO-IARIA et al., 1970; GOTTESMANN, 1996; FANSELOW; NICOLELIS, 1999; RIBEIRO et al., 2002).

No estado EA, o animal apresenta um comportamento exploratório, por meio de locomoção e/ou farejamento, com um potencial de campo local (PCL) cortical de baixa amplitude e ondas teta (5-9

\footnotetext{
${ }^{2}$ Para revisão, veja SAPER, SCAMMELL e LU (2005).
} 
Hz) e gama (30-55 Hz) proeminentes (TIMO-IARIA et al., 1970), além da presença de ondas teta no PCL hipocampal (RIBEIRO et al., 2002). Em VP, o animal fica imóvel ou engajado em comportamentos automáticos e estereotipados (alimentação, ingestão hídrica e movimentos de limpeza corporal). Apresenta PCL cortical e hipocampal de baixa amplitude e atividades gama e teta relativamente altas, porém menores do que durante EA (TIMO-IARIA et al., 1970; RIBEIRO et al., 2002). No estado de MV, o animal fica desperto e imóvel, com os olhos semi-abertos e as vibrissas apresentam movimentos rítmicos e estereotipados nas mesmas frequências das oscilações corticotalâmicas (7-12 Hz) (FANSELOW; NICOLELIS, 1999). As oscilações hipocampais se tornam variáveis sem a presença de ritmo teta (RIBEIRO et al., 2002).

Em F e SOL, o animal permanece imóvel, com os olhos fechados, e com movimentos respiratórios lentos e regulares. $\mathrm{O}$ estágio $\mathrm{F}$ se caracteriza pela presença de fusos do sono $(10-14 \mathrm{~Hz})$ com ausência ou baixa presença de ondas delta (1-4 Hz) no PCL cortical. Com o passar do tempo as ondas deltas tornam-se predominantes no córtex, apesar de fusos isolados ainda serem observados, sendo esse estado caracterizado como SOL (TIMO-IARIA et al., 1970). Nesses estágios, verifica-se um aumento na amplitude do PCL hipocampal e aumento progressivo das ondas lentas à medida que se aproxima do SOL (RIBEIRO et al., 2002). O sono intermediário (SI) é caracterizado pela presença concomitante de fusos corticais e ondas teta hipocampais e usualmente tem duração ente 1-5s (GOTTESMANN, 1996).

No estágio SREM, o rato apresenta atonia axial, mas podem ser observados movimentos intermitentes das orelhas, vibrissas e membros, com PCL cortical e hipocampal de baixa amplitude e ondas gama e teta intensas. O PCL observado no SREM é mais sincronizado e apresenta maior amplitude que durante a VG (TIMO-IARIA et al., 1970; FANSELOW; NICOLELIS, 1999; RIBEIRO et al., 2002).

Neste trabalho agruparemos os estágios descritos acima em três fases: vigília (VG) correspondente aos estados EA, VP e MV; sono de ondas lentas (SOL) correspondente aos estados F, SOL e SI; e sono REM (SREM).

\subsubsection{A regulação do ciclo sono-vigília}

Os modelos de regulação do sono sugerem a presença de dois mecanismos: um circadiano e outro de controle homeostático (BORBELY, 1982). Dessa maneira, a distribuição do sono ao longo de 24 
horas seria fortemente regulada pelo ritmo circadiano enquanto o processo homeostático controlaria a necessidade de sono.

Acredita-se que a regulação homeostática se dê por alguma substância ou estrutura que acumule a "necessidade de sono" durante a VG prolongada e que descarregue essa necessidade durante o sono (SAPER; SCAMMELL; LU, 2005). Foi proposto que a adenosina fosse o acumulador da necessidade de sono. Essa hipótese é sustentada pela observação de que a injeção de adenosina ou agonistas dos receptores $A_{1}$ no prosencéfalo basal de gatos promove a necessidade de sono e os níveis de adenosina aumentam em algumas regiões do encéfalo, incluindo o prosencéfalo basal, durante VG prolongada (BARRIGA-IBARS et al., 2005). Entretanto, existem evidências que os níveis de adenosina também sejam regulados pelo ciclo circadiano (BEERSMA; GORDIJN, 2007). O ritmo circadiano tem como 'relógio principal' o núcleo supraquiasmático (NSQ) (SAPER et al., 2005). Os neurônios no NSQ disparam em um ciclo de 24 horas governado por uma alça trancricional-traducional, que persiste mesmo que os neurônios estejam dissociados em cultura (REPPERT; WEAVER, 2002). A perda do NSQ resulta na perda dos ritmos circadianos de um grande número de comportamentos e processos fisiológicos, caso os animais não tenham acesso a outros estímulos de temporização (SAPER et al., 2005). A luz é o principal zeitgeber para a sincronização do oscilador circadiano principal. No entanto, sabe-se hoje que existem outros processos que são autonomamente rítmicos. Esses osciladores periféricos não apenas respondem ao NSQ, mas também a outros zeitgeibers, específicos para a função do órgão em consideração (BEERSMA; GORDIJN, 2007).

Os dois processos são gerados independentemente, porém sua interação determina o tempo, duração e a qualidade tanto do sono quanto da VG (FRANKEN; DIJK, 2009). Contudo, foi demonstrado que proteínas como Period 1 (Per1) e Period 2 (Per2) ${ }^{3}$, que estão no núcleo da regulação circadiana, têm papel na regulação homeostática do sono, sugerindo que esses processos estão relacionados (FRANKEN; DIJK, 2009).

\subsection{Funções do sono}

A função primordial do sono nos seres vivos ainda não está estabelecida. Porém, suas funções putativas têm sido extensivamente pesquisadas e muitas das definições sobre o sono estão

\footnotetext{
${ }^{3}$ As nomenclaturas e abreviações de genes e proteínas nesse trabalho seguem o proposto pelos International Committee on Standardized Genetic Nomenclature for Mice e Rat Genome and Nomenclature Committee (2009).
} 
relacionadas a funções atribuídas a ele (VASSALLI; DIJK, 2009). Dentre as funções que já foram atribuídas ao sono, encontram-se a modulação do sistema imune (BARRIGA-IBARS et al., 2005; LESKU et al., 2006), conservação da energia metabólica e termorregulação (BEUCKMANN; YANAGISAWA, 2002), maturação neural, saúde mental (GREENE; SIEGEL, 2004) e, principalmente, atuação em processos cognitivos e plasticidade sináptica (CARTWRIGHT, 2004; RIBEIRO; NICOLELIS, 2004; BORN; RASCH; GAIS, 2006; TONONI; CIRELLI, 2006).

\subsection{Sono, aprendizado e plasticidade sináptica}

\subsubsection{Plasticidade sináptica dependente de atividade}

O mecanismo celular mais aceito para o armazenamento de memórias é a plasticidade sináptica dependente de atividade. Essa conjectura foi postulada por Hebb (1949) ao afirmar que a rede neural teria propriedades relacionadas ao aprendizado apenas se as entradas que contribuíssem mais significativamente para o aumento da ativação dos neurônios pós-sinápticos fossem "reforçadas", enquanto as outras "enfraquecidas". Em preparações experimentais, as sinapses podem ser tanto potencializadas quanto deprimidas, dependendo do padrão de estimulação da atividade neuronal ou de tratamentos químicos (BENINGTON; FRANK, 2003).

Em um modelo prototípico, a potencialização de longa duração (LTP) é induzida no hipocampo por protocolos de estimulação tetânica de alta frequência (até $100 \mathrm{~Hz}$ ) ou por um protocolo de pareamento (uma estimulação de baixa frequência aferente é pareada com despolarização póssináptica) (BENINGTON; FRANK, 2003; LYNCH, 2004; MALENKA; BEAR, 2004). A indução da LTP (Figura 1A) ocorre pela liberação de glutamato pelo neurônio pré-sináptico e, simultaneamente, despolarização do neurônio pós-sináptico ativando o receptor $\mathrm{N}$-metil D-aspartato (NMDA), que acarreta em influxo de $\mathrm{Ca}^{2+}$. $\mathrm{O}$ aumento de $\mathrm{Ca}^{2+}$ intracelular ativa a proteína quinase II dependente de $\mathrm{Ca}^{2+} /$ Calmodulina (CAMK2, também conhecida como CaMKII) por autofosforilação. A ativação da CAMK2 fosforila o receptor $\alpha$-amino-3-hidroxil-5-metil-4-isoxazolpropionato (AMPA) de glutamato e, via alterações no citoesqueleto, leva a um aumento na reciclagem do receptor. Conjuntamente, esses eventos promovem a expressão da LTP por um aumento da condutância dos receptores AMPA (LYNCH, 2004; MALENKA; BEAR, 2004). Outras proteínas quinases também foram implicadas nas cascatas de fosforilação associadas à LTP, incluindo a proteína quinase ativada por mitógeno (MAPK), fosfatidil inositol 3 quinase (PI3 quinase), tirosinas quinases, proteína quinase $\mathrm{C}(\mathrm{PKC})$, proteína quinase $\mathrm{A}$ (PKA) e proteína 
quinase IV dependente de $\mathrm{Ca}^{2+} /$ calmodulina (CAMK4, também conhecida como CaMKIV) (DAVIS, S. et al., 2000; BENINGTON; FRANK, 2003; LYNCH, 2004; MALENKA; BEAR, 2004). A manutenção da LTP (LYNCH, 2004) depende de síntese protéica e de transcrição gênica (MALENKA; BEAR, 2004). O aumento na transcrição se dá pela fosforilação de fatores de transcrição como a proteína ligante ao elemento responsivo ao cAMP (CREB) que ativam a maquinaria de transcrição. O RNA mensageiro (mRNA) é traduzido gerando novos fatores de transcrição (p. ex. FOS ${ }^{4}, \mathrm{EGR}^{5}{ }^{5}, \mathrm{NR} 4 \mathrm{~A} 1^{6}$ ) ou proteínas efetoras (p. ex. subunidades de receptores AMPA, proteínas ligadas ao citoesqueleto). Isso torna possível a promoção de mudanças de longa duração no tamanho, forma e número de sinapses (BENINGTON; FRANK, 2003; MALENKA; BEAR, 2004).

A depressão de longa duração (LTD) é comumente induzida experimentalmente por protocolos de estimulação por baixa frequência $(0,5-5 \mathrm{~Hz})$ com maior número de estímulos (p. ex. 900). A condição necessária para induzir LTD é a ativação de uma dada sinapse sem a geração de potenciais de ação (BENINGTON; FRANK, 2003). Duas classes principais de LTD foram identificadas, uma dependente da ativação de receptores NMDA (Figura 1) e outra dependente de receptores metabotrópicos de glutamato (mGLU) (WINDER; SWEATT, 2001). Ambas as formas são dependentes de aumento de $\mathrm{Ca}^{2+}$ intracelular; entretanto a magnitude desse aumento é menor que o necessário para a geração da LTP (PI; LISMAN, 2008). Níveis menores de $\mathrm{Ca}^{2+}$ intracelular ativam as proteínas fosfatases 1 (PP1) e 2A (PP2A) ao invés de proteínas quinases (WINDER; SWEATT, 2001; PI; LISMAN, 2008). Como resultado, ocorre uma inibição de proteínas quinases (PKA, PKC) (THIELS et al., 2000), produzindo uma resposta molecular equivalentemente complexa à LTP, porém na direção oposta. As alterações incluem a diminuição da condutância dos receptores AMPA por desfosforilação e internalização do receptor (BENINGTON; FRANK, 2003). É consenso que é necessária a síntese protéica para a manutenção da LTD. Por outro lado, o papel da transcrição nesse processo ainda é controverso (MALENKA; BEAR, 2004; LINDECKE et al., 2006). Os mecanismos de plasticidade sináptica estão descritos mais detalhadamente em sinapses glutamatérgicas no hipocampo (MALENKA; BEAR, 2004). Contudo, esses processos podem ser encontrados em outras regiões, como neocórtex e cerebelo, e mediados por outros tipos de receptores como receptor de canabinóide 1 (CB1), receptor de serotonina 3C (5-HT $3 \mathrm{C})$, receptor

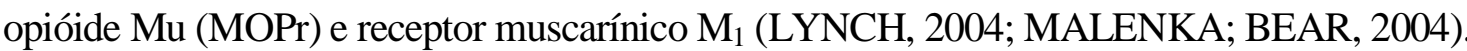

\footnotetext{
${ }^{4}$ Veja a sessão 1.4.3.7.

${ }^{5}$ Veja a sessão 1.4.3.5.

${ }^{6}$ Veja a sessão 1.4.3.8.
} 


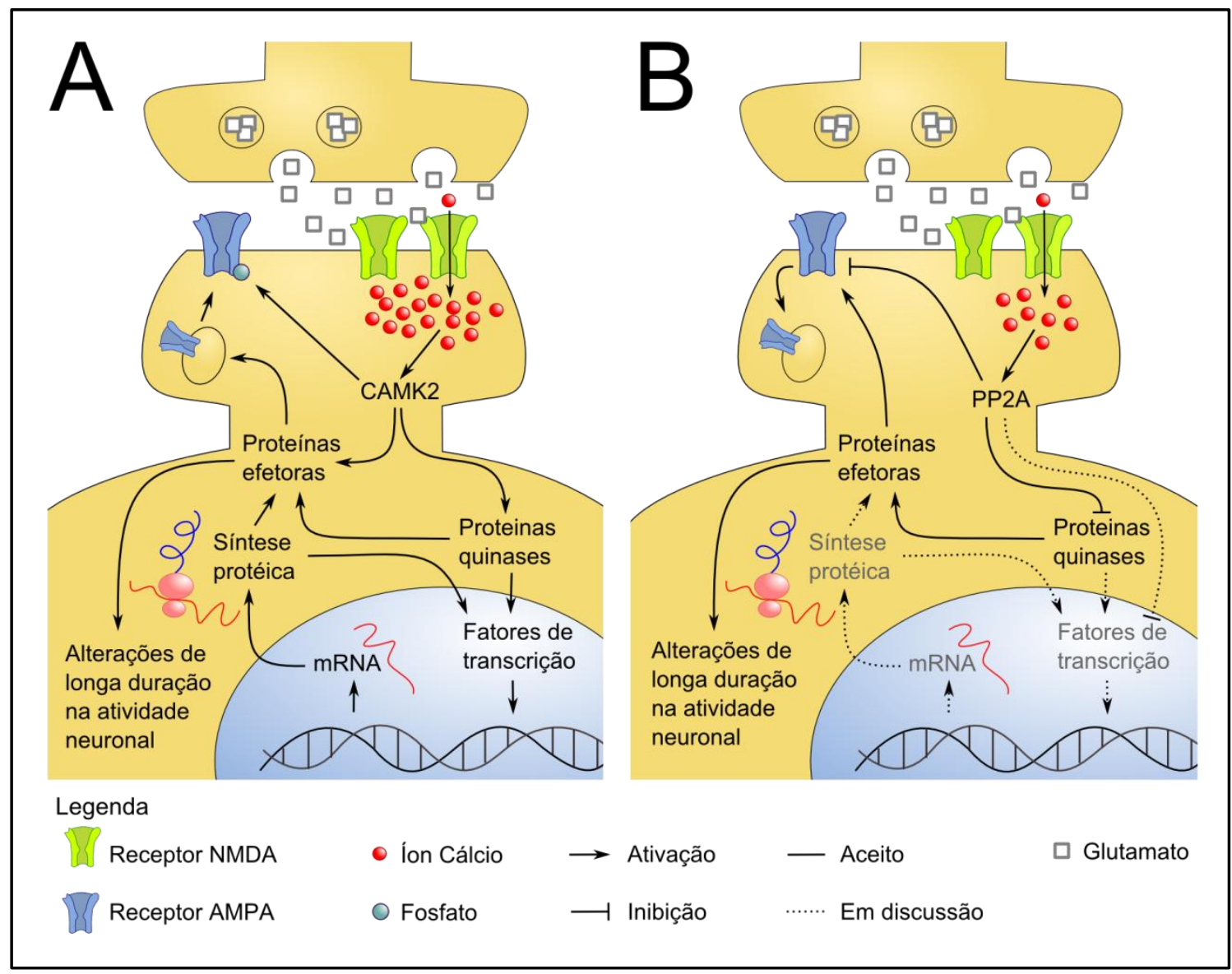

Figura 1 - Mecanismos gerais para a indução e manutenção da $(A)$ Potencialização de Longa Duração (LTP) e (B) Depressão de Longa Duração (LTD). (A) O mecanismo prototípico para indução da LTP ocorre via ativação de receptores NMDA, que promovem um aumento nos níveis de íons cálcio $\left(\mathrm{Ca}^{2+}\right)$ intracelular. $O$ aumento nos níveis de $\mathrm{Ca}^{2+}$ leva à ativação da proteína quinase dependente de $\mathrm{Ca}^{2+} /$ calmodulina II (CAMK2). A CAMK2 fosforila os receptores AMPA e recruta novos receptores para sinapse via alterações no citoesqueleto. Essas alterações geram um aumento na condutância dos receptores AMPA e, consequentemente, um aumento nos potenciais excitatórios pós-sinápticos (EPSPs). A ativação de CAMK2 também promove a ativação de outras quinases e sistemas de segundos mensageiros. Estes, por sua vez, ativam fatores de transcrição que elevam o nível da transcrição e tradução de novas proteínas efetoras e fatores de transcrição. A indução da transcrição e tradução de novas proteínas causa alterações de longa duração na atividade neuronal e é responsável pela manutenção da LTP. (B) A LTD também é induzida por um aumento nos níveis de $\mathrm{Ca}^{2+}$ intracelular, entretanto esses níveis são menores que os observados na LTP. Os níveis menores de $\mathrm{Ca}^{2+}$ causam a ativação de proteínas fosfatases, em especial, da proteína fosfatase 2A (PP2A). A ativação da fosfatase promove a internalização e desfosforilação dos receptores AMPA diminuindo a condutância da membrana e os EPSPs. É consenso que a manutenção da LTD necessita de tradução de novas proteínas; no entanto ainda existem divergências sobre o papel da transcrição nova nesse processo.

\subsubsection{Aprendizado, memória e sono}

A primeira evidência científica de que o sono exercia influência sobre o aprendizado foi observada em 1924, quando se verificou o efeito positivo do sono na retenção de informação verbal em comparação ao igual tempo de VG (JENKINS; DALLENBACH, 1924). No entanto, apenas na década de 70, a ciência começou a reconhecer o papel do sono na consolidação das memórias. Os 
efeitos deletérios da privação de sono no aprendizado tanto antes (YOO et al., 2007) quanto após a tarefa (KARNI et al., 1994; SMITH; ROSE, 1996; STICKGOLD et al., 2000b; WALKER et al., 2002) estão entre as principais observações que sustentam essa visão. A diminuição do desempenho cognitivo não é observada apenas após a restrição total de sono, mas em situações nas quais os indivíduos limitam o total de sono diário para até 4 horas por duas semanas (VAN DONGEN et al., 2003).

Os efeitos deletérios de um período prolongado de VG na cognição são cumulativos e diretamente proporcionais ao período de privação. Esses efeitos diminuem durante um período de sono, mas não durante o mesmo período de descanso acordado. Portanto, a fadiga muscular causada por exercício extenuante, assim como a sensação subjetiva de sonolência podem ser revertidos após um descanso de poucas horas; entretanto, o desempenho cognitivo retorna para o nível basal apenas após um cochilo ou uma noite completa de sono (ROGERS; DORRIAN; DINGES, 2003; CIRELLI, 2005). Os efeitos cognitivos do sono são encontrados nos diversos domínios modais, incluindo os sistemas visual (KARNI et al., 1994; SMITH; ROSE, 1996; STICKGOLD et al., 2001; YOO et al., 2007), auditivo (GAAB et al., 2004) e motor (KURIYAMA; STICKGOLD; WALKER, 2004).

A privação seletiva de um dos estágios de sono, ou até específica a uma janela temporal dentro de um estágio, pode inibir a consolidação de memórias (SMITH; BUTLER, 1982; SMITH; ROSE, 1996), indicando que exista mais de uma única fase para a consolidação de memórias durante o sono (STICKGOLD et al., 2000b; FOGEL; SMITH; COTE, 2007). Nessa direção, o SOL tem sido relatado como importante para a consolidação de tarefas motoras (WALKER et al., 2002; HUBER et al., 2004; NISHIDA; WALKER, 2007), verbais e dependentes do hipocampo (MARSHALL et al., 2006); o SREM é implicado em tarefas de procedimento que envolvam regras e estratégia (FOGEL et al., 2007), episódicas de conteúdo emocional (HU; STYLOS-ALLAN; WALKER, 2006) e independentes do hipocampo (FU et al., 2007); e tanto o SOL quanto o SREM têm sido associados com a consolidação de tarefas visuais (KARNI et al., 1994; STICKGOLD; JAMES; HOBSON, 2000a; WAGNER et al., 2007). Em linha com essa visão, a indução de ondas lentas via aplicação de potenciais oscilatórios transcranianos durante o SOL na primeira parte da noite seletivamente melhora a desempenho em uma tarefa declarativa verbal dependente do hipocampo, mas não em uma tarefa de procedimento ou tarefa declarativa não-verbal (MARSHALL et al., 2006). No entanto, existem evidências indicando que essa divisão é muito simplificada (SCHABUS, 2009). Fogel et al. (2007) observaram que uma tarefa de reconhecimento de palavras (declarativa verbal) promove aumento da potência na banda teta durante SREM, sugerindo o papel do SREM na aquisição dessa tarefa. Uma teoria paralela sugere que a complexidade da tarefa 
motora define se SOL ou SREM seriam necessários para a consolidação de memórias (SCHABUS, 2009).

Foi demonstrado que mediante a apresentação de um odor durante o aprendizado de uma tarefa dependente do hipocampo ocorre um aumento na retenção da tarefa após re-exposição ao odor durante o SOL (RASCH et al., 2007). Conjuntamente, a re-exposição ao odor promove um aumento na atividade hipocampal durante o SOL (RASCH et al., 2007). Esse fenômeno sugere que informação nova pode ser associada durante o SOL, auxiliando no processamento de informações.

Outro aspecto que sugere o efeito do sono na plasticidade é a predominância do SOL e, em particular, do SREM observada logo após o nascimento e nos primeiros anos de vida. Assim, o tempo de sono é máximo, ao mesmo tempo em que a plasticidade é máxima no sistema nervoso (VASSALLI; DIJK, 2009). Nesse sentido, a plasticidade na dominância ocular durante o período crítico em gatos é aumentada pelo sono e esse efeito depende da potencialização sináptica (FRANK; ISSA; STRYKER, 2001; ATON et al., 2009).

Hennevin et al. (1995) investigaram a capacidade de o cérebro codificar e consolidar memórias durante o SREM, por meio de estimulação direta. Seus resultados indicam que tanto a consolidação do aprendizado quanto a formação de novas associações podem ser mediadas pela formação reticular pontina (FRP) durante o sono. Além disso, uma correlação positiva significativa entre o aumento na densidade de ondas ponto-genículo-occipitais (PGO) geradas pela FRP durante o SREM pós-treino e a melhora subsequente no desempenho da tarefa foi demonstrada (DATTA, 2000).

Uma hipótese central no trabalho de diversos pesquisadores é que a consolidação de memórias durante o sono se baseia na reativação de redes neuronais implicadas na codificação de informação durante a VG (BORN et al., 2006). Nessa linha, Pavlides e Wilson (1989) mostraram que atividade de place cells no hipocampo durante a VG pode influenciar a atividade durante o sono subsequente. Sendo assim, um aumento na atividade de uma célula após a exposição do animal ao place field correspondente àquela célula aumenta a sua atividade durante o SOL e o SREM, mas não durante as VG subsequentes. Posteriormente, foi demonstrado que essa reativação não se restringia a redes neuronais no hipocampo, mas também ocorria na circuitaria do córtex cerebral, estriado, putamen e tálamo (PAVLIDES; WINSON, 1989; MCNAUGHTON et al., 1994; QIN et al., 1997; RIBEIRO et al., 1999; MAQUET et al., 2000; LOUIE; WILSON, 2001; RIBEIRO et al., 2004b). Similarmente, experiências relevantes durante o período de VG resultam em ativação 
cerebral em humanos durante o sono subsequente, tanto durante o SOL (RASCH et al., 2007) quanto SREM (MAQUET et al., 2000). Acredita-se que essa reativação que ocorre entre regiões corticais e hipocampais poderia proporcionar um meio de transferência das representações de memória das redes hipocampais para as redes corticais, o que eventualmente levaria ao armazenamento permanente no córtex (BORN et al., 2006).

\subsubsection{Alterações na transcrição e tradução durante o sono}

Estudos em coelhos mostraram uma correlação positiva entre a síntese de RNA em frações nucleares purificadas de neurônios neocorticais e a sincronização do eletroencefalograma (EEG) durante o sono (GIUDITTA; RUTIGLIANO; VITALE-NEUGEBAUER, 1980). De maneira semelhante, a síntese de DNA estava negativamente correlacionada à quantidade de SREM em ratos que não aprenderam uma tarefa de esquiva (GIUDITTA et al., 1985). No entanto, esse resultado não foi replicado em trabalhos posteriores do mesmo grupo, apesar da associação entre alguns parâmetros de sono e o metabolismo do DNA ter sido demonstrada (AMBROSINI et al., 1988).

Um aumento na taxa de síntese protéica foi observado em cérebros de ratos, correlacionado à ocorrência de SOL, mas não ao estado desperto ou SREM. Essa correlação ocorria no cérebro como um todo e em algumas regiões discretas (RAMM; SMITH, 1990). Esses dados também foram demonstrados na maioria das regiões cerebrais de macacos Rhesus (NAKANISHI et al., 1997). Em relação ao SREM, Bobillier et al. (1971) relataram que a privação de SREM não provocou alteração na síntese de proteínas in vitro. Por outro lado, Shapiro e Girdwood (SHAPIRO; GIRDWOOD, 1981) mostraram uma pequena queda na síntese de proteínas in vivo, principalmente no cerebelo.

Trabalhos mais recentes utilizaram técnicas modernas de biologia molecular para descrever o papel do sono na síntese de substâncias envolvidas com a plasticidade sináptica. A seguir, as informações referentes à expressão de alguns genes e proteínas relacionados à plasticidade e a sua regulação ao longo do sono serão detalhadas.

\subsubsection{ARC}

A proteína associada ao citoesqueleto regulada por atividade (ARC) é expressa em neurônios que passaram por modificações na estrutura e função (STEWARD et al., 1998; TZINGOUNIS; NICOLL, 2006). ARC tem um papel importante na modificação das sinapses ativadas, por meio de 
interações com receptores AMPA, com a CAMK2 e com a actina (TZINGOUNIS; NICOLL, 2006; BRAMHAM et al., 2008). O mRNA de Arc acumula-se seletivamente próximo às sinapses ativadas, onde é traduzido localmente (STEWARD et al., 1998; TZINGOUNIS; NICOLL, 2006; BRAMHAM et al., 2008). Além disso, ARC se localiza na camada molecular do giro denteado (STEWARD et al., 1998; TZINGOUNIS; NICOLL, 2006; BRAMHAM et al., 2008) e sua expressão é modulada por exposição a um ambiente enriquecido (RIBEIRO et al., 2007), tarefa comportamental (DATTA; LI; AUERBACH, 2008) e por indução de LTP na via perforante do giro denteado in vivo (RIBEIRO et al., 2002). Por isso, o gene Arc é utilizado como marcador de atividade neuronal (GUZOWSKI, 2002).

Trabalhos utilizando privação de sono sugerem que a expressão de mRNA e proteína ARC é maior durante a VG em relação ao mesmo período de sono (CIRELLI; TONONI, 2000a; b; TAISHI et al., 2001; CIRELLI; GUTIERREZ; TONONI, 2004; TERAO et al., 2006; TERAO et al., 2008). Estes trabalhos também sugerem um efeito circadiano na expressão de $A r c$, pois os níveis do gene são maiores quando a privação de sono é realizada à noite (HUBER; TONONI; CIRELLI, 2007). Na mesma direção, a expressão de Arc está reduzida após indução de SOL e SREM pelo tratamento com prostaglandina $\mathrm{D}_{2}\left(\mathrm{PGD}_{2}\right)$ ou CGS21680, um agonista do receptor de adenosina $\mathrm{A}_{2 \mathrm{a}}$ (TERAO et al., 2008).

Por outro lado, evidências indicam que a expressão de $A r c$ durante o sono depende das experiências vividas pelo animal durante a VG precedente. Datta et al. (ULLOOR; DATTA, 2005; DATTA et al., 2008) demonstraram que o treinamento em esquiva ativa de duas vias durante a VG aumenta a expressão de ARC (mRNA e proteína) no hipocampo e amígdala durante o SREM. Esse efeito é mediado pelo centro gerador de ondas PGO (DATTA et al., 2008). Na mesma direção, a expressão de Arc é reinduzida no córtex durante o SREM após a exposição a um ambiente enriquecido (RIBEIRO et al., 2004a; RIBEIRO et al., 2007), e após a indução de LTP na via perforante medial do hipocampo de ratos (RIBEIRO et al., 2002).

\subsubsection{BDNF}

O fator neurotrófico derivado do encéfalo (BDNF) é amplamente expresso no cérebro, em particular abundância no hipocampo, amígdala e cerebelo, sendo expresso primariamente em neurônios glutamatérgicos (KUCZEWSKI et al., 2009). A secreção de BDNF é dependente do aumento na concentração intracelular de $\mathrm{Ca}^{2+}$ via canais NMDA, canais de $\mathrm{Ca}^{2+}$ dependentes de voltagem ou depósitos intracelulares de $\mathrm{Ca}^{2+}$ (KUCZEWSKI et al., 2009). O papel do BDNF na plasticidade 
sináptica dependente de atividade já foi amplamente descrito (KUCZEWSKI et al., 2009). Nessa direção, padrões de estimulação elétrica que geram LTP em sinapses glutamatérgicas induzem a expressão de BDNF (AICARDI et al., 2004). Neurônios com aumento na expressão de $B d n f$ apresentam maior complexidade na árvore dendrítica em slices de hipocampo de ratos (WIRTH et al., 2003).

Diversos grupos estudaram os efeitos da privação de sono na expressão de $B d n f$. A expressão de Bdnf está aumentada no hipocampo e córtex de ratos neonatos (HAIRSTON et al., 2004) e adultos (CIRELLI; TONONI, 2000a; b; TAISHI et al., 2001; FUJIHARA et al., 2003; CIRELLI et al., 2004; TERAO et al., 2006; HUBER et al., 2007) após a privação de sono. O aumento de $B d n f$ também foi observado durante o sono rebote no hipocampo de ratos neonatos (HAIRSTON et al., 2004). No entanto, existem registros de redução de BDNF (proteína e mRNA) após privação de sono de 8h e 48h (GUZMAN-MARIN et al., 2006).

O BDNF foi implicado na regulação da homeostase do sono (FARAGUNA et al., 2008). A favor dessa hipótese, a administração intraventricular de BDNF aumenta a duração de SOL em ratos e coelhos (KUSHIKATA; FANG; KRUEGER, 1999) e potência na banda delta (DP - delta power) durante o SOL. Além disso, a injeção de anticorpos anti-BDNF acarreta no efeito oposto (FARAGUNA et al., 2008). Por outro lado, um avanço de 8 h no ciclo claro-escuro aumenta agudamente a expressão da proteína BDNF no hipocampo (SEI et al., 2003), indicando que expressão desse gene pode ser regulada também por um mecanismo circadiano.

Os efeitos do SREM na expressão de BDNF (mRNA e proteína) são menos consistentes. A administração intraventricular de BDNF aumenta a duração de SREM em coelhos, mas não em ratos (KUSHIKATA et al., 1999). Por outro lado, a expressão de $B d n f$ foi correlacionada à expressão de ondas PGO no SREM de ratos (ULLOOR; DATTA, 2005; DATTA et al., 2008) e a expressão de BDNF foi positivamente correlacionada à duração do SREM no hipocampo, mas não no córtex de ratos (GUZMAN-MARIN et al., 2006).

\subsubsection{CAMK4}

A CAMK4 é expressa tanto no núcleo quanto no citoplasma de neurônios de diversas regiões cerebrais, incluindo córtex, cerebelo e hipocampo (HO et al., 2000; FUKUSHIMA et al., 2008; LEE et al., 2009). A CAMK4 ativa diversos fatores de transcrição, incluindo CREB (BITO; DEISSEROTH; TSIEN, 1996; FUKUSHIMA et al., 2008), o fator de transcrição ativador 1 (ATF- 
1), os membros fator de resposta ao soro (SRF) e fator de crescimento do miócito 2D (MEF2D) da família MADS-box e a proteína ligada ao CREB (CBP) (HO et al., 2000). A CAMK4 também fosforila e regula a função de proteínas sinápticas, como a sinapsina 1 (SYN1) (OHMSTEDE; JENSEN; SAHYOUN, 1989) e statmina 1 (STMN1) (MELANDER GRADIN et al., 1997). Essa proteína foi implicada em vários aspectos da sinalização neuronal por $\mathrm{Ca}^{2+}$, entre eles na fosforilação de CREB em resposta à neurotransmissão excitatória (BITO et al., 1996), na produção de resposta a fatores neurotróficos (FINKBEINER et al., 1997), e na plasticidade sináptica (HO et al., 2000). Ratos nocaute para Camk4 apresentaram déficits na manutenção da LTP no hipocampo (HO et al., 2000; KANG et al., 2001), assim como da LTD no cerebelo (HO et al., 2000). Além disso, os animais também apresentavam déficits em memórias dependentes do hipocampo (KANG et al., 2001). Similarmente, o aumento na Camk4 promove a formação de memórias de longa duração dependentes do hipocampo e a LTP (FUKUSHIMA et al., 2008).

Em relação à possível modulação durante o sono, Cirelli et al. (2004; 2005) observaram um aumento na expressão de Camk4 durante o sono em comparação à VG.

\subsubsection{CREB}

As proteínas da família CREB são fatores críticos em muitas funções no sistema nervoso, incluindo neurogênese, sobrevida, desenvolvimento, diferenciação neuronal, assim como neuroproteção, crescimento e regeneração axonais, ritmos circadianos, plasticidade sináptica e formação de memórias (ALBERINI, 2009).

CREB é, geralmente, expresso de maneira constitutiva e ativado via modificações pós-traducionais, como fosforilação. A fosforilação de CREB pode ser causada por uma grande variedade de processos de sinalização, incluindo aumento de $\mathrm{Ca}^{2+}$, via ativação de canais dependentes de ligantes ou voltagem (p. ex. receptores NMDA), por aumento de adenosina monofosfato cíclica (cAMP) via ativação de receptores acoplados a proteínas $\mathrm{G}$, ou ativação do receptor de tirosina quinase (RTK) por fatores de crescimento (ALBERINI, 2009). O camundongo nocaute para as isoformas $\alpha$ e $\Delta$ apresentaram déficits na formação de memórias dependentes do hipocampo e amígdala e da LTP (BOURTCHULADZE et al., 1994). A expressão do repressor transcricional de CREB (dCREB2b) ou da forma dominante negativa de CREB bloqueia a formação de memórias de longa duração em drosófilas (XIA et al., 2009). 
Alguns trabalhos demonstraram que o sono pode influenciar a expressão de CREB. No entanto, alguns trabalhos relataram aumento da expressão desse gene e/ou proteína durante o sono enquanto outros relataram a diminuição. De um lado, foi observado que (1) a imunomarcação para a forma fosforilada de CREB (pCREB) se apresentava elevada no córtex cerebral de ratos privados de sono (CIRELLI; TONONI, 2000a); (2) Crebl estava reduzido no hipotálamo e no córtex cerebral após a indução de SREM e SOL via tratamento com agonista do receptor $\mathrm{A}_{2 \mathrm{a}}$ (TERAO et al., 2008); e (3) camundongos nocaute para as isoformas $\alpha$ e $\Delta$ de CREB diminuíam o tempo em VG durante o início da fase ativa do animal (escuro) em comparação a camundongos selvagens (GRAVES et al., 2003).

Por outro lado, (1) a expressão de Crebl estava reduzida no hipocampo após privação de sono (GUZMAN-MARIN et al., 2006); (2) a expressão pCREB estava aumentada no hipocampo e na amígdala, e correlacionada ao aumento na atividade das ondas PGO durante o SREM (ULLOOR; DATTA, 2005; DATTA et al., 2008); e (3) a presença da forma dominante negativa de CREB em drosófila impedia o aumento no tempo de sono por estimulação durante a VG (GANGULYFITZGERALD et al., 2006).

\subsubsection{EGR1}

Duas espécies de proteínas de pesos moleculares de 82 e 88 kDa são codificadas pelo gene resposta de crescimento inicial 1 (Egrl). Essas proteínas contêm um domínio de ligação ao DNA altamente conservado composto de três motivos em dedos de zinco que reconhece o segmento de DNA 5'-GCGC/GGGGCG-30' nos promotores dos genes alvo (KNAPSKA; KACZMAREK, 2004; ALBERINI, 2009).

A elevação de $\mathrm{Ca}^{2+}$ citosólico via receptores glutamatérgicos (kainato, AMPA, NMDA) medeia a indução de Egrl (CONDORELLI et al., 1994; GHOSH et al., 1994). Sgambato et al. (1998) observaram que a ativação transiente da MAPK e da quinase regulada por sinal extracelular (ERK) era responsável pela indução de Egrl. Ademais, os fatores de transcrição ELK1 e CREB estavam fosforilados simultaneamente com a indução de Egrl (DAVIS, S. et al., 2000). A indução de Egrl também depende da ativação da PKA e PKC (SIMPSON; MORRIS, 1995).

Egrl foi o primeiro gene descrito cuja expressão estava consistentemente aumentada após a indução de LTP em ratos acordados (COLE et al., 1989). Camundongos nocautes para Egrl apresentam déficits na formação de memórias de longa duração (JONES et al., 2001) e na manutenção da LTP 
(BAUMGARTEL et al., 2008). Entretanto, camundongos com expressão elevada de Egrl no prosencéfalo apresentavam aumento na força sináptica (BAUMGARTEL et al., 2008). A expressão de Egrl está aumentada durante a consolidação de diversas tarefas comportamentais, como esquiva ativa de duas vias (DATTA et al., 2008), condicionamento de medo ao contexto (MALKANI; ROSEN, 2000b), aversão condicionada ao sabor (JONES et al., 2001), tarefas de discriminação visual (TOKUYAMA et al., 2002) e exposição a um ambiente enriquecido (PINAUD, 2004).

A expressão de Egrl é modulada pelo ritmo circadiano. Especificamente, a expressão é aumentada no hipocampo durante a fase clara e reduzida durante a fase escura em ratos (RONNBACK et al., 2005). Além disso, o aumento da expressão de Egrl por exposição a um ambiente enriquecido é mais intenso durante a fase escura (RONNBACK et al., 2005; HUBER et al., 2007).

Após a privação de sono, foi observado um aumento na expressão de Egrl no córtex, tálamo, hipotálamo e cerebelo de ratos e camundongos (O'HARA et al., 1993; CIRELLI; TONONI, 2000a; b; CIRELLI et al., 2004; TERAO et al., 2006). No entanto, assim como sugerido para Arc, a expressão de Egrl durante o sono é modulada pelas experiências prévias do animal durante a VG. Corroborando essa afirmação, Ribeiro et al. (1999; 2002; 2004a; 2007) demonstraram que a expressão de Egrl é reinduzida durante o SREM após a exposição a um ambiente enriquecido no hipocampo e córtex e após a indução de LTP gerada por estimulação de alta frequiência na via perforante medial do hipocampo de ratos. Na mesma direção, foi demonstrado que a atividade das ondas PGO durante o SREM são diretamente correlacionadas ao nível de expressão de Egrl no hipocampo e amígdala (ULLOOR; DATTA, 2005; DATTA et al., 2008).

\subsubsection{EGR2}

A proteína resposta de crescimento inicial 2 (EGR2) murina apresenta 445 aminoácidos com três domínios em dedo de zinco e um peso molecular de $48 \mathrm{kDa}$. O sítio de ligação ao DNA específico para o EGR2 é o motivo 5'-GCGGGGGCGG-3'. A expressão de Egr2 é induzida pelo agonista muscarínico pilocarpina no córtex, núcleo accumbens e hipocampo (HUGHES; DRAGUNOW, 1994), pelo antagonista gabaérgico bicuculina no córtex e amígdala, pela inibição de calcinerina (PP2B) (LAM et al., 2009) e pela inativação do receptor $A_{2 a}$ no estriado (YU et al., 2005). Em contraste, antagonistas mGluR5 reduzem a expressão de Egr2 no córtex de ratos (GASS; OLIVE, 2008) 
Protocolos de estimulação que promovem aumento da expressão de $E g r 2$ no hipocampo também melhoram a memória espacial e induzem a LTP. Essa indução de Egr2 é inibida por antagonistas do receptor NMDA (WORLEY et al., 1993). Sendo assim, Egr2 é considerado importante para a manutenção da LTP. Recentemente, DeSteno e Schmauss (2008) mostraram que a indução de Egr2 ocorre em áreas do córtex pré-frontal medial de camundongos expostos a uma tarefa de mudança de atenção (attention-set-shifting task), porém não em tarefa de memória espacial. No entanto, a indução de Egr2 não foi claramente observada em uma tarefa de condicionamento de medo ao contexto (MALKANI; ROSEN, 2000b). Similarmente, camundongos nocaute para Egr2 em neurônios do prosencéfalo apresentavam melhora na aprendizagem de habilidades motoras no rotarod e melhora no reconhecimento de objetos (POIRIER et al., 2007; POIRIER et al., 2008).

A expressão de Egr2 é controlada pelo ritmo circadiano sendo, especificamente, reduzida durante a fase escura e aumentada durante a fase clara no hipocampo em ratos (RONNBACK et al., 2005). Cirelli et al. (2004) observaram que a expressão de Egr2 estava aumentada após 8h de privação de sono por gentle handling.

\subsubsection{FOS}

FOS (oncogene osteosarcoma FBJ) é uma fosfoproteína nuclear, que se liga, principalmente, com membros da família de fatores de transcrição JUN formando um heterodímero denominado proteína ativadora 1 (AP-1). Esta, por sua vez, estimula a expressão de genes contendo a sequência consenso para a AP-1 (5'-TGAG/CTCA-3') e com menor afinidade a CRE. A proteína FOS contém 380 aminoácidos e pesa entre 55 e 62 kDa (HERDEGEN; LEAH, 1998; ALBERINI, 2009).

A expressão de Fos encontra-se aumentada no hipocampo de ratos e camundongos após tarefas de condicionamento apetitivo ${ }^{7}$ em camundongos (HEURTEAUX et al., 1993; BERTAINA; DESTRADE, 1995), esquiva ativa de duas vias (NIKOLAEV et al., 1992), discriminação de odores (HESS; LYNCH; GALL, 1995), labirinto radial (AMIN et al., 2006), labirinto aquático (GUZOWSKI et al., 2001) e após exposição a um ambiente enriquecido (HERDEGEN; LEAH, 1998). Ratos colocados em um campo aberto apresentam níveis elevados de Fos no córtex, hipocampo e núcleos talâmicos (HANDA; NUNLEY; BOLLNOW, 1993). Além disso, a repetição de estímulos visuais ou auditivos não é efetiva para nova indução de FOS (HERDEGEN; LEAH, 1998).

\footnotetext{
${ }^{7}$ Food-reward conditioning.
} 
Protocolos de estimulação que promovem aumento da expressão de Fos no hipocampo também melhoram a memória espacial e induzem a LTP (WORLEY et al., 1993). Nesse sentido, o camundongo nocaute para Fos no sistema nervoso central apresenta déficits seletivos para aprendizado dependente do hipocampo (espacial e medo ao contexto) e redução da magnitude da LTP no hipocampo. Estudos farmacológicos nesse animal apontaram o envolvimento de Fos na via do receptor NMDA (FLEISCHMANN et al., 2003). A injeção de NMDA aumenta a expressão de Fos no hipocampo e córtex in vivo e em neurônios hipocampais e corticais em cultura (LEREA; MCNAMARA, 1993), e evoca a atividade de ligação ao DNA de AP-1 em extratos nucleares (OGITA; YONEDA, 1994). A indução de Fos também é mediada por receptores AMPA, kainato e mGLU de glutamato, receptores adrenérgicos alfa e beta, dopaminérgicos D1 e colinérgicos nicotínicos e muscarínicos (HERDEGEN; LEAH, 1998).

A privação de sono aumenta a expressão de Fos no hipocampo e córtex de camundongos neonatos e também é aumentada durante o sono rebote (HAIRSTON et al., 2004). Similarmente, a privação de sono induz a expressão de Fos no córtex e hipocampo de ratos e camundongos adultos (O'HARA et al., 1993; CIRELLI et al., 2004; TERAO et al., 2006). Em contrapartida, o camundongo nocaute para Fos apresenta um aumento no tempo de VG e redução no tempo de SOL durante a fase clara do dia. Paradoxalmente, foi observado um aumento da amplitude de baixas frequências $(0,3-4 \mathrm{~Hz})$ no EEG desse animal (SHIROMANI et al., 2000).

\subsubsection{NR4A1}

NR4A1 (receptor nuclear subfamília 4, grupo A, membro 1) é membro da subfamília Nr4a de receptores nucleares e consiste de um domínio N-terminal de função ativadora 1 (AF-1), dois domínios centrais ligantes de DNA em dedos de zinco e um domínio de ligação a ligante na porção C-terminal. A proteína se liga ao DNA como um monômero ao motivo NBRE (5'-AAAGGTCA-3') e funciona como ativador transcricional (POLS; BONTA; DE VRIES, 2007).

A expressão de Nr4al é induzida pelo aumento de $\mathrm{Ca}^{2+}$ no soma (PINATO et al., 2009) e, em cultura de neurônios hipocampais, é dependente do receptor NMDA, mas não dos receptores AMPA e kainato (BADING et al., 1995), da autofosforilação de CAMK2 (PI; LISMAN, 2008) e da ativação da calcineurina (PP2B) e de CREB (LAM et al., 2009). A expressão de Nr4al é mediada pelo fator complexo ternário (TCF) e por SRF após a indução de LTP por meio de agonista mGLUR (LINDECKE et al., 2006). A inibição de histona deacetilases promove um aumento na expressão de Nr4al no hipocampo, melhora na LTP e na memória de medo ao contexto (VECSEY 
et al., 2007). Estimulação de alta frequência promove aumento na expressão de $N r 4 a 1$, melhora na memória espacial e indução de LTP (WORLEY et al., 1993). Pistas de contexto associadas à comida palatável elicitavam uma ativação motora condicionada e estavam associadas ao aumento de expressão de Nr4al em áreas corticolímbicas, talâmicas e hipotalâmicas (SCHILTZ et al., 2007). Durante a consolidação e evocação de uma tarefa de condicionamento aversivo ao contexto, foi relatado um aumento na expressão de Nr4al no hipocampo, amígdala e córtex (MALKANI; ROSEN, 2000a; VON HERTZEN; GIESE, 2005). Após a exposição a um ambiente enriquecido por $31 \mathrm{~h}$ é observado um aumento na expressão de $N r 4 a l$ no hipocampo (RONNBACK et al., 2005).

No NSQ de hamsters, foi observado que Nr4al é expresso de maneira circadiana, com maior intensidade durante a noite subjetiva (LIN et al., 1997), sendo sua expressão induzida pela luz apenas durante a noite subjetiva (LIN et al., 1997; MORRIS et al., 1998). Nr4al é expresso na glândula pineal de ratos em uma base circadiana, com expressão elevada à noite (HUMPHRIES et al., 2004). Por outro lado, a privação de sono por exposição a um ambiente enriquecido e/ou gentle handling aumenta a expressão de Nr4al no córtex e hipocampo de ratos e camundongos (O'HARA et al., 1993; CIRELLI; TONONI, 2000b; CIRELLI et al., 2004; TERAO et al., 2006).

\subsubsection{PP2A}

A PP2A existe como um complexo constituído pela subunidade catalítica (subunidade C) de 36 $\mathrm{kDa}$, subunidade estrutural (subunidade A) de $65 \mathrm{kDa}$ e a possibilidade de presença de subunidades reguladoras (subunidades B). As subunidades A e C são expressas por uma ampla gama de tecidos e tipos celulares, no entanto as subunidades B estão expressas primariamente no encéfalo. Nesse sentido, foi mostrada a presença das subunidades $B \alpha$ e $B \beta$ nas células piramidais da camada $C A 1$ do hipocampo (WINDER; SWEATT, 2001; NICHOLLS et al., 2008).

Após aplicação de inibidores das PP1/PP2A, como caliculina ou microssistina, há um rápido aumento da transmissão sináptica em slices de hipocampo (FIGUROV; BODDEKE; MULLER, 1993). A inibição de PP2A é detectada imediatamente após a indução da LTP, persistindo por 60 minutos após a indução. Essa inibição é dependente do receptor NMDA e bloqueada pela inibição da calmodulina (FUKUNAGA et al., 2000). Bloqueio do receptor NMDA e inibição de PP2A impedem a despotencialização e inibição da LTP causada por estimulação de baixa frequência no hipocampo de porcos-da-índia (O'DELL; KANDEL, 1994) e ratos (KLANN, 2002; WOO; NGUYEN, 2002). Em conjunto, esses resultados sugerem que a supressão da atividade da PP2A 
pode ter um papel chave nos processos necessários para a manutenção de LTP. Essas observações apontam para uma inibição da fosfatase, como mecanismo de melhora da força sináptica, e levam à hipótese de que uma inibição persistente da PP2A pode contribuir para a facilitação e manutenção da LTP (BELMEGUENAI; HANSEL, 2005).

Em contraste, diversos estudos demonstraram que PP2A está envolvida na regulação da LTD (BELMEGUENAI; HANSEL, 2005). A pré-incubação com inibidores de PP1/PP2A impede a indução da LTD dependente de receptores NMDA em CA1 (THIELS et al., 2000; KANG-PARK et al., 2003). Similarmente, a indução de LTD aumenta a atividade enzimática de PP2A. Por fim, o bloqueio da LTD após estimulação impede o aumento na atividade da PP2A (THIELS et al., 1998). O camundongo transgênico com inibição de PP2A apresenta déficits na formação de LTD, mas não na transmissão sináptica basal e na LTP (NICHOLLS et al., 2008). Esses camundongos apresentam déficits na adaptação a novas situações (NICHOLLS et al., 2008) e piora a formação de memória espacial (CHAO; MA; LEE, 2007). Sumarizando os dados acima, Pi e Lisman (2008) propuseram um modelo no qual a PP2A, em conjunto com a CAMK2, forma uma switch triestável, que determina a indução de LTP ou LTD, em resposta a um estímulo de $\mathrm{Ca}^{2+}$ variável.

Genes que codificam para a subunidade regulatória de PP2A em drosófilas (twins - tws e widerborst $-w d b)$ apresentam atividade circadiana e estabilizam o complexo Period-Time em células S2. Além disso, manipulações nos níveis de expressão de $t w s$ e $w d b$ promovem alterações na expressão e fosforilação de Per em neurônios clock e nos ritmos biológicos (SATHYANARAYANAN et al., 2004). Similarmente, RNAs de interferência para twins e $w d b$ diminuem a expressão de clock (Clk) em células S2 de drosófila (KIM; EDERY, 2006). Por fim, Ganguly-Fitzgerald et al. (2006) mostraram que drosófilas com mutações em subunidades regulatórias da PP2A não apresentavam o aumento de sono induzido por experiência prévia durante a VG observada em moscas selvagens.

\subsubsection{Outros genes alterados}

A expressão de outros genes relacionados à plasticidade sináptica dependente de atividade também é modulada pelo sono. Nessa direção, a privação de sono modifica a expressão dos genes relacionados à LTP Syn1 e da Camk2 no hipocampo (GUZMAN-MARIN et al., 2006). Existem relatos de alterações na expressão do gene homólogo ao Homer1 da drosófila (Homer1), dependendo do período do dia no qual o animal foi privado de sono (NELSON et al., 2004; MARET et al., 2007). A privação de sono reduz número de receptores NMDA (CHEN et al., 2006; MCDERMOTT et al., 2006), o nível da forma fosforilada da quinase regulada por sinal extracelular 
(pERK2) (GUAN; PENG; FANG, 2004) e a expressão de cortactina (Cttn) induzida por experiência nova no hipocampo (DAVIS, C. J. et al., 2006). Por fim, Cirelli, Gutierrez e Tononi (2004) demonstraram que durante o sono ocorre um aumento na expressão de genes que codificam para a calcineurina (Ppp3r1), proteína de ligação ao FK506 12 (Frapl), receptor de inositol 1,4,5trifosfato tipo I (Itprl) e anfifisina II (Amphl), cujas proteínas estão relacionadas à depressão e despotencialização sináptica.

\subsection{Duas teorias para a plasticidade sináptica durante o sono}

Atualmente, duas teorias estão sendo discutidas em relação a como o sono promove a consolidação de memórias dependentes do hipocampo. Um assume que a consolidação de memórias envolve a reativação das memórias recém-codificadas durante o SOL, promovendo um diálogo entre as circuitarias talâmica, cortical e hipocampal que eventualmente levaria a uma transferência das representações para a circuitaria neocortical. Seguido por alterações estruturais durante o SREM levando a um aumento na conectividade nas sinapses ativas e reduzindo a conectividade nas sinapses inativas para que ocorra o armazenamento de memórias de longa duração (RIBEIRO; NICOLELIS, 2004; BORN et al., 2006).

Em favor dessa teoria, está a observação da repetição de padrões de ativação durante o sono de circuitos que foram implicados na codificação das memórias durante a VG (PAVLIDES; WINSON, 1989; RIBEIRO et al., 1999; MAQUET et al., 2000; RIBEIRO et al., 2004b; BORN et al., 2006; RASCH et al., 2007). Nessa direção, a reativação foi encontrada tanto em registros de um único neurônio quanto em registros de diversas unidades neuronais (BORN et al., 2006) assim como na atividade de regiões cerebrais em humanos por ressonância magnética funcional (MAQUET et al., 2000; RASCH et al., 2007). A hipótese também é sustentada por experimentos que associam a expressão de $E g r l, A r c, B d n f$ e pCREB ao SREM após a exposição a um ambiente enriquecido, treinamento em tarefa comportamental ou indução de LTP no hipocampo (RIBEIRO et al., 1999; RIBEIRO et al., 2002; RIBEIRO et al., 2004a; SAHA; DATTA, 2005; ULLOOR; DATTA, 2005; RIBEIRO et al., 2007; DATTA et al., 2008).

A outra teoria assume que a melhora na memória é uma consequência indireta de uma redução global na conectividade sináptica induzida pela atividade oscilatória lenta durante o SOL e um aumento seletivo na força das sinapses mais ativas durante a VG. Essas duas condições ocorreriam em ciclo aumentando a razão sinal ruído para informação recém-codificada (TONONI; CIRELLI, 2003; 2006). 
Essa teoria foi derivada das observações que genes relacionados à LTP como Arc, Egrl e Bdnf e a forma fosforilada da proteína CREB estão aumentados após a privação de sono (CIRELLI; TONONI, 2000a); que o aumento na densidade sináptica induzido por aprendizado é evidente por apenas algumas horas e, em seguida, retorna aos níveis basais (EYRE et al., 2003); e que as atividades cognitivas, motoras e sensórias estão frequentemente associadas a um aumento na taxa de disparo neuronais (SJOSTROM; TURRIGIANO; NELSON, 2001). Por outro lado, eles observaram que moléculas relacionadas à depressão e despotencialização sinápticas estão mais expressas durante o sono (CIRELLI et al., 2004). Similarmente, foi observada a redução nos níveis de neurotransmissores (acetilcolina, noradrenalina, serotonina e histamina) (TONONI; CIRELLI, 2006) e que o sono favorece a desfosforilação no encéfalo (CIRELLI; TONONI, 1998). No entanto, deve ser salientado que a expressão de genes relacionados à plasticidade não é totalmente perdida durante o sono (NEUNER-JEHLE; RHYNER; BORBELY, 1995) e que a diferentes fases do sono agem de maneira complementar e diferencial na consolidação de memórias (STICKGOLD et al., 2000b; FOGEL et al., 2007; SCHABUS, 2009). Por fim, a melhor abordagem experimental para a avaliação dos mecanismos pelos quais o sono facilita o aprendizado se dá pela comparação de variáveis neurais (p. ex. expressão gênica ou padrão de disparos neuronal) obtidas na presença ou ausência de informação adquirida recentemente (GIUDITTA et al., 1995; RIBEIRO; NICOLELIS, 2004). 


\section{Justificativa}

A relação entre sono e aprendizado é comprovada por experimentos usando eletrofisiologia, observação do comportamento e técnicas de imageamento cerebral (PAVLIDES; WINSON, 1989; SMITH; ROSE, 1996; RASCH et al., 2007). Similarmente, a plasticidade sináptica dependente de atividade é o melhor correlato celular e molecular para o aprendizado e memória (BENINGTON; FRANK, 2003). A fim de elucidar os mecanismos pelos quais o sono interfere na consolidação de memórias alguns grupos analisaram a expressão de genes relacionados à plasticidade sináptica. No entanto, a maioria desses trabalhos não distinguiu as fases do sono e/ou não comparou situações ricas em informação a outras empobrecidas (CIRELLI; TONONI, 2000b; a; TAISHI et al., 2001; CIRELLI et al., 2004; TERAO et al., 2006; TERAO et al., 2008). Esses experimentos acabaram por levar a teorias contraditórias a respeito da função do sono na memória (TONONI; CIRELLI, 2006), e até mesmo à ressurreição de teorias sugerindo que sono e memória não estão relacionados (VERTES; EASTMAN, 2000; SIEGEL, 2001). Portanto, é de grande importância estudar a alteração na expressão de genes relacionados à plasticidade sináptica ao longo dos diferentes estágios de sono e em condições que favoreçam a aquisição de informação. 


\section{Objetivos}

\subsection{Objetivo geral}

O presente trabalho tem como objetivo principal analisar a expressão de genes relacionados à plasticidade sináptica ao longo do ciclo sono-vigília de ratos expostos ou não a um ambiente enriquecido.

\subsection{Objetivos específicos}

Mensurar a expressão dos genes Arc, Bdnf, Camk4, Crebl, Egrl, Egr2, Fos, Nr4al, Ppp2ca, Ppp2r2d em regiões circunscritas do córtex somestésico e hipocampo de ratos durante a vigília, sono de ondas lentas e sono REM.

Analisar os efeitos da exposição ao ambiente enriquecido, do estágio de sono e a interação entre os dois fatores na expressão dos genes medidos.

Avaliar a implicação dos achados no contexto das duas teorias sobre o eixo de formação de memória hipocampo-cortical 


\section{Métodos}

\subsection{Determinação dos controles endógenos}

\subsubsection{Análise do comportamento e coleta das regiões encefálicas}

\subsubsection{Animais}

Em um primeiro momento 14 ratos Wistar (Rattus norvegicus) adultos machos pesando entre $180 \mathrm{e}$ $260 \mathrm{~g}$, foram alocados em gaiolas individuais sob um ciclo de luz de 12/12 h - luzes acesas às 7h00min Comida e água foram fornecidas ad libitum. Os animais foram divididos igualmente entre o grupo experimental e controle.

\subsubsection{Aparato de experimentação comportamental}

A gaiola de experimentação é uma caixa de madeira revestida internamente com fórmica preta medindo $40 \mathrm{~cm}$ de largura, $40 \mathrm{~cm}$ de comprimento e $50 \mathrm{~cm}$ de altura com teto aberto. $\mathrm{O}$ piso é feito com uma grade metálica e, abaixo do piso existe um compartimento contendo maravalha para facilitar a higienização. Em uma das paredes há uma abertura para o suprimento de água. A ração foi colocada sobre a grade durante o procedimento de habituação (Figura 2A, B)

O enriquecimento do ambiente é feito pela introdução de quatro objetos na gaiola de experimentação (Figura 2C). O primeiro objeto é uma bola de plástico afixada a uma mola; o segundo objeto é uma escova torcida para que os pelos tenham maior contato com o animal; o terceiro objeto é um cano recoberto de tachinhas para gerar uma superfície pontiaguda; o último objeto é um cano de PVC com uma abertura do tamanho do focinho do animal e que possui cereais açucarados no interior, que servem de recompensa ao animal. Todos os objetos são novos para os sujeitos experimentais e desenhados de maneira a maximizar as diferenças de forma, textura e significado comportamental. A Figura 2D mostra a disposição dos objetos que compõem o ambiente enriquecido dentro da gaiola de experimentação no momento da exposição. 


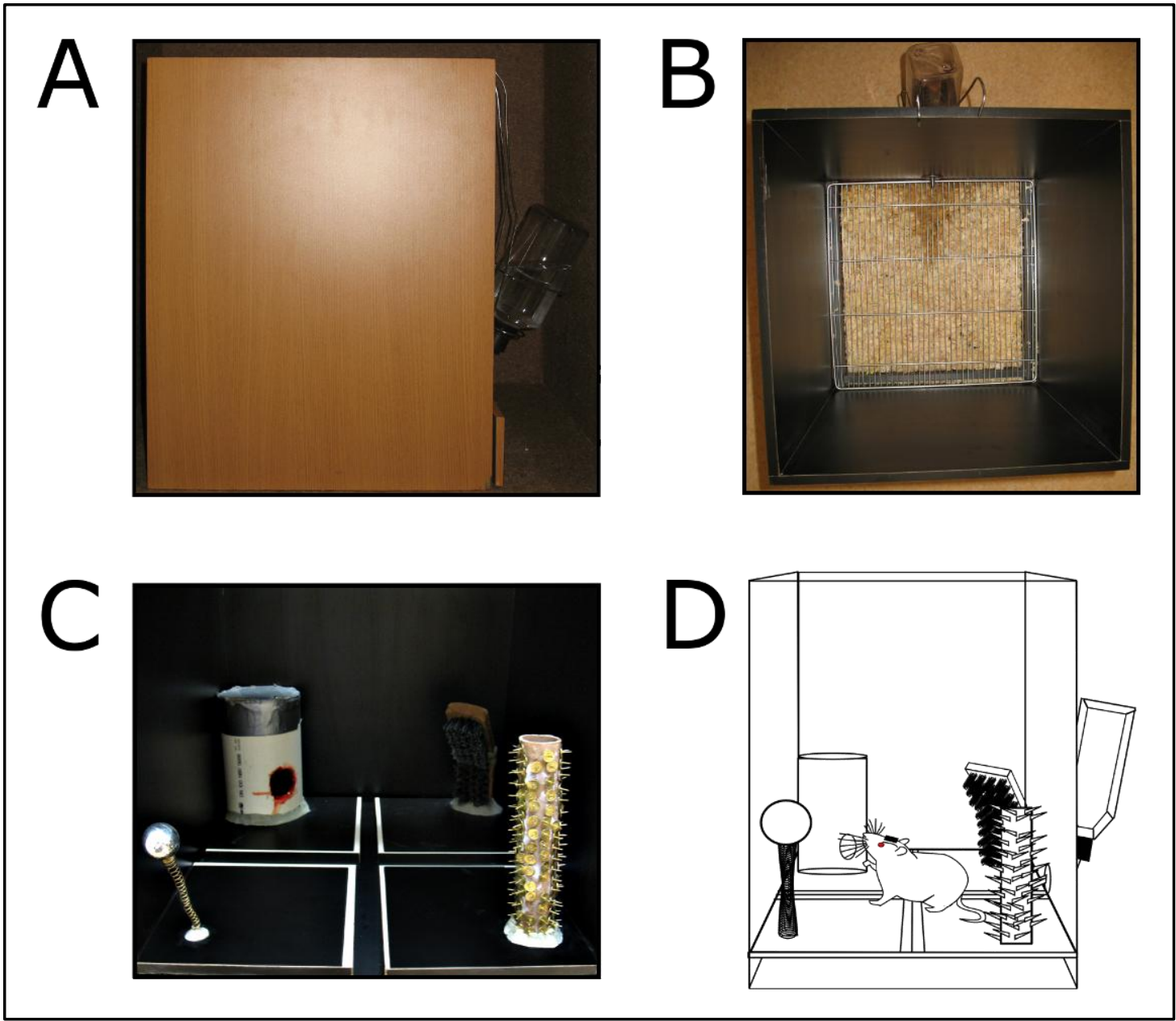

Figura 2 - Aparato para experimentação comportamental. (A) Vista lateral e (B) vista superior da gaiola de experimentação. (C) Quatro objetos que compõem o ambiente enriquecido. (D) Desenho esquemático demonstrando a disposição dos objetos dentro da gaiola de experimentação durante a exposição ao ambiente enriquecido.

\subsubsection{Delineamento experimental}

Os animais foram distribuídos igualmente entre os grupos controle e exposto. Os animais foram habituados à caixa de atividade $(3 \mathrm{~h})$, seguido por uma exposição ao ambiente enriquecido por $20 \mathrm{~min}$, e finalizado por $30 \mathrm{~min}$ sem interferência no ambiente experimental (grupo exposto). O grupo controle foi mantido no ambiente experimental durante $3 \mathrm{~h} 50 \mathrm{~min}$ sem interferência. Todos os experimentos se realizaram entre 19h30min e 0h00min em ambiente com ausência de estímulos luminosos e atenuação dos estímulos auditivos. Finda a sessão experimental os animais foram anestesiados com halotano e sacrificados por decapitação em guilhotina. 


\subsubsection{Processamento do material}

Os encéfalos foram retirados rapidamente do crânio e colocados em uma placa de Petri resfriada e coberta com papel filtro umedecido com salina gelada. Áreas circunscritas aos córtices somestésico primário, visual primário e frontal foram coletadas (Figura 3A). Posteriormente, o restante do córtex foi retirado e o hipocampo foi exposto (Figura 3B). O hipocampo dorsal foi dissecado e coletado, deixando exposto o tálamo que foi coletado em seguida. Por fim, as porções laterais do cerebelo foram coletadas. As porções coletadas foram armazenadas em tubos cônicos e congeladas imediatamente em uma mistura de gelo seco pulverizado e etanol absoluto, e estocados a $-80^{\circ} \mathrm{C}$.

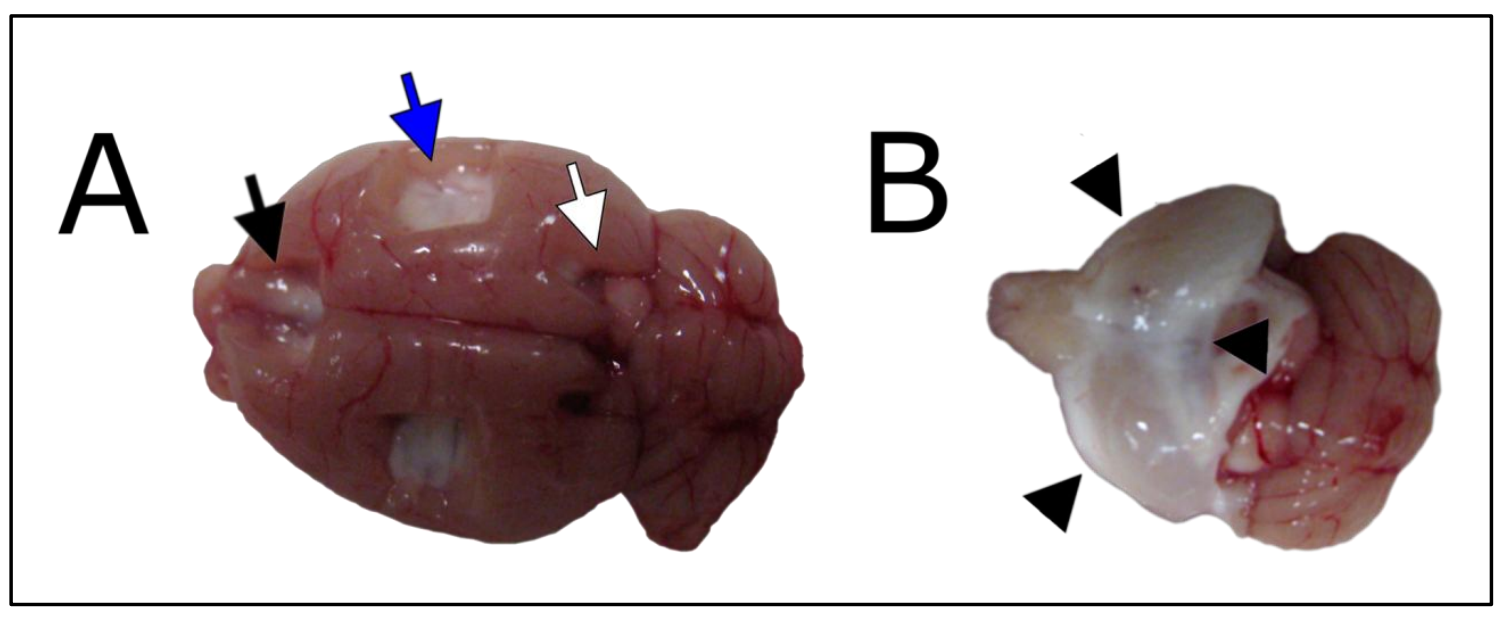

Figura 3 - Regiões do encéfalo do rato dissecadas para análise de expressão gênica por PCR em tempo real. (A) Visão superior do encéfalo; as setas indicam as regiões corticais dissecadas: branca córtex visual; azul - córtex somestésico; preta - córtex frontal. (B) Visão superior do encéfalo após a retirada do córtex cerebral; as cabeças de seta evidenciam o hipocampo.

\subsubsection{Expressão gênica}

\subsubsection{Extração do RNA e RT-PCR}

Amostras de tecido pesando entre 8,4 e 24,2 g foram utilizadas para extração de RNA pelo método do TRIzol ${ }^{\circledR}$ (Invitrogen), segundo as instruções do fabricante.

A solução contendo $1 \mu \mathrm{g}$ de RNA, $0,5 \mu \mathrm{g}$ de oligo(dT) 15 (Invitrogen) em volume final de $5 \mu \mathrm{L}$ foi aquecida a $70^{\circ} \mathrm{C}$ por $5 \mathrm{~min}$, resfriada a $4^{\circ} \mathrm{C}$ por 5 min e mantida em gelo. Na etapa subsequente, foram adicionados $3 \mathrm{mM}$ de $\mathrm{MgCl}_{2} ; 0,0625 \mathrm{mM}$ de dNTP Mix; $1 \mathrm{x}$ do ImProm-II reaction buffer (Promega); 1 U ImProm Reverse Transcriptase (Promega) em volume final de $20 \mu \mathrm{L}$. Em seguida, o oligo(dT) anelou-se ao RNA a $25^{\circ} \mathrm{C}$ por $5 \mathrm{~min}$. Posteriormente, a primeira fita foi estendida a 
$42{ }^{\circ} \mathrm{C}$ por $60 \mathrm{~min}$. Após incubação a $70^{\circ} \mathrm{C}$ por $15 \mathrm{~min}$, a transcriptase reversa foi inativada pelo calor. Finalmente o produto foi armazenado congelado a $-20^{\circ} \mathrm{C}$.

\subsubsection{Controle de qualidade}

A pureza do RNA foi medida usando o Nanodrop Spectrophotometer (Thermo Scientific). A integridade do RNA foi observada em gel de agarose $1 \%$ com $0,02 \mathrm{M}$ de tiocianato de guanidina, corado com brometo de etídio. Para excluir a possibilidade de contaminação por DNA genômico (gDNA) foi realizada uma PCR, utilizando oligonucleotídeos (Integrated DNA Tecnologies) que flanqueavam o íntron 2 do gene da $\beta$-actina (Actb). Dessa maneira, o produto amplificado teria $194 \mathrm{pb}$ em caso de gDNA e de 107 pb no caso de DNA complementar (cDNA). Os oligonucleotídeos utilizados foram senso 5'-GTCTTCCCCTCCATCGTG-3' e antissenso 5'-AGGATGCCTCTCTTGCTCTG-3'. Para a reação, foram aplicados 1 x de tampão para PCR; 0,125 $\mathrm{mM}$ de dNTP (Invitrogen), 1,25 $\mathrm{mM}$ de $\mathrm{MgCl}_{2}, 0,25 \mu \mathrm{M}$ de cada oligonucleotídeo, $1 \mathrm{U}$ de Taq DNA polimerase (LGC Biotecnologia) e 0,5 $\mu \mathrm{L}$ de cDNA diluído 1:10. O volume final da reação foi de $10 \mu \mathrm{L}$. As condições de termociclagem consistiram de um passo a $94{ }^{\circ} \mathrm{C}$ por 3 min seguido de 35 ciclos a $94{ }^{\circ} \mathrm{C}$ por $30 \mathrm{~s}, 56^{\circ} \mathrm{C}$ por $20 \mathrm{~s} \mathrm{e} 72{ }^{\circ} \mathrm{C}$ por $30 \mathrm{~s}$ e finalizados por um passo de extensão a $72{ }^{\circ} \mathrm{C}$ por 5 min. A PCR foi verificada em um gel de poliacrilamida $8 \%$ corado com nitrato de prata (amostras de córtex somestésico) e/ou agarose 1\% corado com brometo de etídio (amostras de córtex somestésico e hipocampo).

\subsubsection{PCR em tempo real}

A análise foi feita em pools de três ou quatro animais, segundo a região e a exposição ou não ao ambiente novo. As reações foram feitas em triplicata e foram testados quatro genes comumente utilizados como controles endógenos - microglobulina, beta $2(B 2 m)$, glucuronidase, beta $(G u s b)$, proteína ribossomal L19 (Rpl19) e Actb via ensaios TaqMan (Applied Biosystems). Em cada reação, foram adicionados $1,5 \mu \mathrm{L}$ de amostra diluída 5 ou 10 vezes; $0,75 \mu \mathrm{L}$ de TaqMan Assays 20 X (Applied Biosystems) e 7,5 $\mu \mathrm{L}$ de TaqMan Master Mix (Applied Biosystems) em um volume final de $15 \mu \mathrm{L}$. As reações foram realizadas no 7500 Real-Time PCR System (Applied Biosystems). No primeiro passo, a amostra foi aquecida a $50{ }^{\circ} \mathrm{C}$ por 2 minutos para ativação da uracil-Nglicosilase (UNG). Em seguida a Taq Polimerase foi ativada a $95^{\circ} \mathrm{C}$ por 10 minutos. $\mathrm{O}$ terceiro passo consistiu de 40 ciclos de desnaturação a $95{ }^{\circ} \mathrm{C}$ por $15 \mathrm{~s}$ e amplificação/extensão a $60{ }^{\circ} \mathrm{C}$ por 1 minuto. Os dados foram coletados durante o primeiro passo do estágio 3. 
A eficiência de cada reação foi determinada segundo o proposto por Ramarkers et al. (2003) utilizando o programa LineRegPCR. A análise dos resultados e seleção dos melhores controles endógenos foi o programa Genorm (PrimerDesign), segundo descrito por Vandesompele et al. (2002)

\subsection{Expressão gênica modulada por sono e ambiente enriquecido}

\subsubsection{Comportamento, cirurgia e coleta}

\subsubsection{Animais}

Quarenta e sete ratos Wistar (Rattus norvegicus) adultos machos, pesando entre 250 e $300 \mathrm{~g}$ no momento da cirurgia, foram alocados em jaulas individuais sob um ciclo de luz de 12/12 $\mathrm{h}$ - luzes acesas às 7h00min. Comida e água foram fornecidas ad libitum. Dos 47 animais submetidos ao treinamento comportamental 30 foram selecionados para análise da expressão gênica ${ }^{8}$. Os animais selecionados foram divididos em seis grupos ( $\mathrm{n}=5$ por grupo).

\subsubsection{Microeletrodos}

Os microeletrodos bipolares foram confeccionados com fios de níquel-cromo de $180 \mu \mathrm{m}$ de diâmetro isolados com teflon (hipocampal) ou $160 \mu \mathrm{m}$ de diâmetro isolados com verniz (cortical). Os eletrodos hipocampais foram justapostos com auxílio de uma cola de cianoacrilato e a ponta foi cortada em bisel (Figura 4). A ponta dos eletrodos corticais foi curvada em torno de um tubo plástico e o isolamento da superfície de contato foi retirado com auxílio de uma lâmina de bisturi (Figura 4). As superfícies nuas de cada pólo do eletrodo foram posicionadas a uma distância entre 0,5 e $1 \mathrm{~mm}$ (nos sentido dorsoventral para os hipocampais e anteroposterior e mediolateral para os corticais). Um fio de prata ou aço sem isolamento de $200 \mu \mathrm{m}$ foi utilizado como terra. O fio terra e os eletrodos foram previamente soldados aos pinos de um soquete fêmea (Figura 4) que, por sua vez, foi fixado ao crânio com cola de secagem rápida de cianoacrilato.

\footnotetext{
${ }^{8}$ Veja a seção 4.2.1.7.
} 


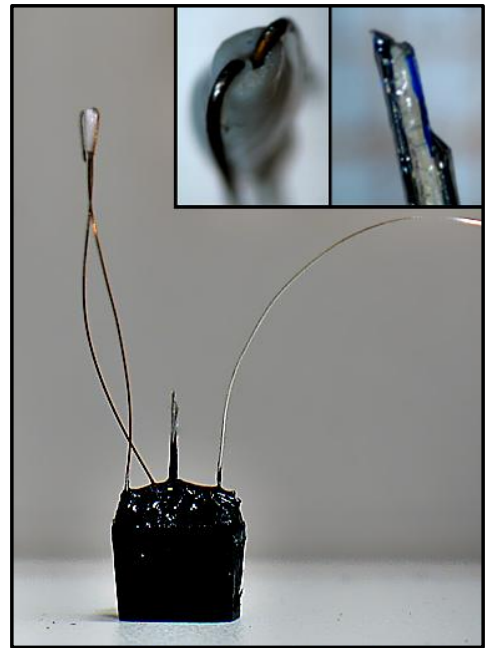

Figura 4 - Eletrodos cortical e hipocampal fixados ao soquete. No detalhe aumento de $5 \mathrm{x}$ das pontas dos eletrodos cortical (à esquerda) e hipocampal (à direita). $O$ fio terra também pode ser observado.

\subsubsection{Cirurgia para implante de microeletrodos}

Os animais foram pré-anestesiados com halotano e, posteriormente, com injeção intramuscular de cloridrato de cetamina $(100 \mathrm{mg} / \mathrm{kg})$, cloridrato de xilazina $(4 \mathrm{mg} / \mathrm{kg})$ e sulfato de atropina $(0,05 \mathrm{mg} / \mathrm{kg})$. O nível anestésico foi mantido com doses suplementares de $20 \%$ da dose inicial de cloridrato de cetamina quando necessário.

O animal foi fixado ao aparelho estereotáxico por meio de barras de fixação auricular rombas para evitar lesão dos tímpanos dos ratos. Foi realizada tricotomia, seguida de assepsia com álcool etílico $70 \%$ e Iodopolvidona (Rioquimica). Em seguida, uma incisão sagital foi feita e o crânio exposto. Os sangramentos foram estancados por compressão e limpos com solução salina. O bregma e lambda foram alinhados. Três parafusos soldados a fios de aço foram fixados ao crânio. Os parafusos davam suporte ao soquete contendo os microeletrodos e serviam de terra para os registros eletroscilográficos. Dois parafusos foram fixados ao osso interparietal e um ao osso frontal esquerdo. Os microeletrodos para registro do potencial de campo local foram implantados unilateralmente (hemisfério direito) segundo as coordenadas relativas ao bregma (em $\mathrm{mm})$ : anteroposterior $-3,0$; mediolateral 1,5 ; dorsoventral 3,3 para o giro denteado do hipocampo, e anteroposterior $-3,0$; mediolateral 5,8; dorsoventral 0,0 sobre o córtex somestésico primário (PAXINOS; WATSON, 1997).

O soquete contendo os eletrodos foi fixado ao aparelho estereotáxico e o eletrodo cortical foi posicionado sobre o córtex e fixado com cola de cianoacrilato de secagem rápida. Posteriormente, o eletrodo subcortical foi posicionado sobre a superfície cortical, e, em seguida, perfurou a dura- 
máter. $\mathrm{O}$ eletrodo foi inserido no cérebro a uma velocidade constante de $2,5 \mu \mathrm{m} / \mathrm{s}$ até atingir a posição esperada. O eletrodo foi fixado com cola de secagem rápida. O fio terra aos parafusos de fixação. O soquete foi fixado ao crânio com cola de secagem rápida de cianoacrilato. O animal foi colocado em observação após a cirurgia. Diclofenaco resinato $2 \mathrm{mg} / \mathrm{kg}$ foi administrado por gavagem após o despertar e diariamente (3-5 dias). Para auxiliar na cicatrização o animal foi préanestesiado com halotano e os ferimentos cirúrgicos foram limpos com solução salina e solução diluída de clorexidina (0,5\%). Em seguida, a pomada Fibrase (Laboratórios Pfizer) foi administrada no entorno da lesão.

\subsubsection{Aparato de experimentação comportamental}

A gaiola de experimentação e o ambiente enriquecido (Figura 2) são similares ao descrito no experimento anterior ${ }^{9}$. A gaiola de experimentação era colocada na caixa de registro durante a aquisição do PCL (Figura 5). A caixa de registro é uma caixa de madeira fechada, com revestimento interno para diminuir o nível de ruído e recoberta externamente com placas de cobre para isolamento eletromagnético. A caixa de registro possui iluminação independente, vermelha ou branca por meio de light emission diodes (LED) no teto.

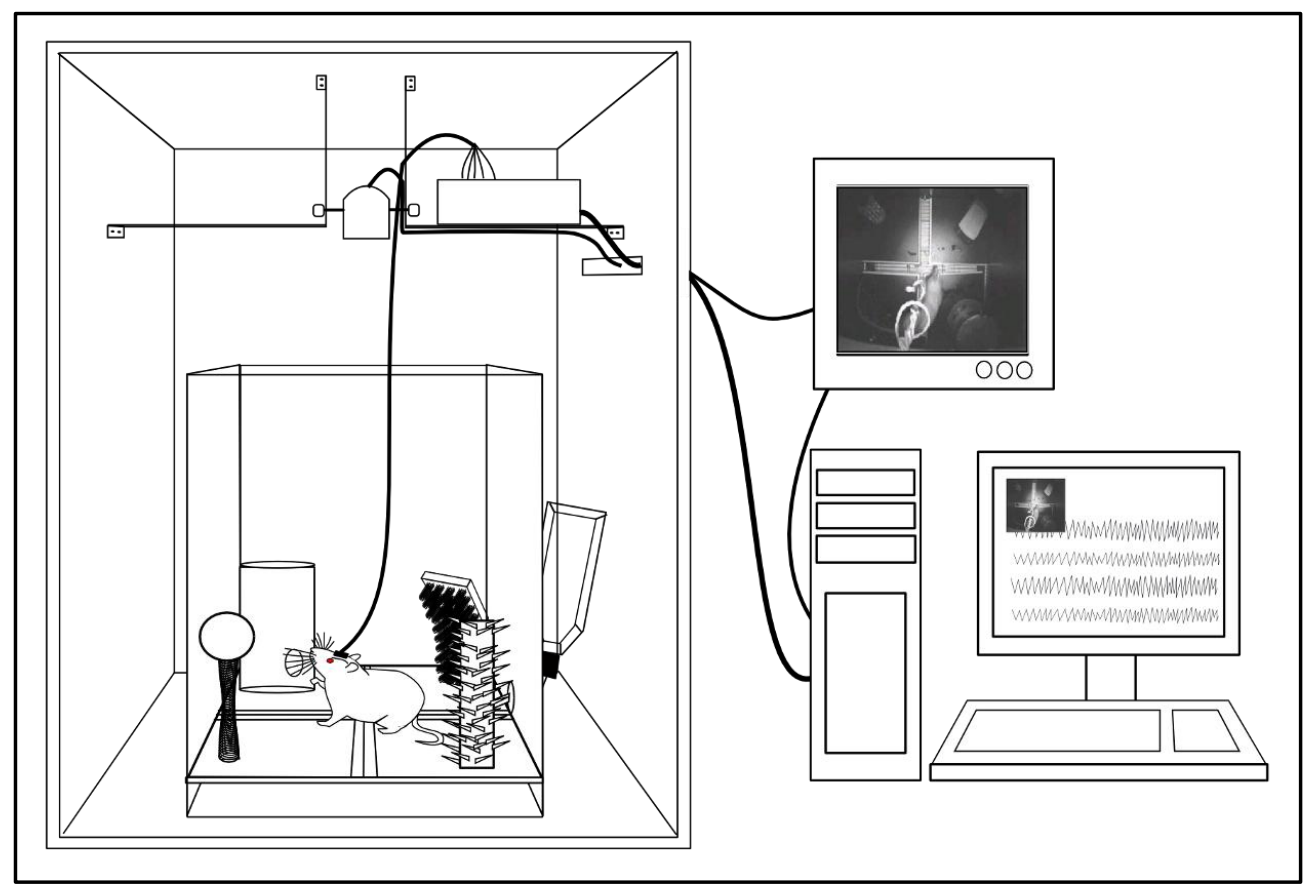

Figura 5 - Sistema para registro do potencial de campo local (PCL) e do comportamento do animal. A gaiola de experimentação era colocada dentro da caixa de registro. O PCL era amplificado e digitalizado e em seguida enviado para um computador para análise e armazenamento. Simultaneamente o comportamento do animal era registrado por meio de uma câmera $\mathrm{CCd}$ e sincronizado ao PCL.

\footnotetext{
${ }^{9}$ Veja a seção 4.1.1.2.
} 
O PCL foi adquirido e digitalizado a $300 \mathrm{~Hz}$ utilizando um Brain Net Bnt-36 (Lynx Tecnologia Eletrônica). O conversor analógico-digital foi colocado dentro da gaiola (Figura 5) e era alimentado por baterias para diminuir o ruído proveniente da rede elétrica. Filtros passa-baixa $(0,1 \mathrm{~Hz})$ e passaalta $(100 \mathrm{~Hz})$ analógicos foram usados no registro do PCL. Uma câmera CCD foi utilizada para monitorar o animal (Figura 5). Os registros neurais e de vídeo foram sincronizados e adquiridos pelo programa Vídeo Gravações (EMSA Equipamentos Médicos).

\subsubsection{Identificação dos estados de sono-vigília}

O animal era considerado em SREM, caso apresentasse postura característica e cessação dos movimentos, exceto por movimentos cíclicos das orelhas, vibrissas e membros. Os PCL cortical e hipocampal deveriam apresentar baixa amplitude e ritmos teta evidentes (Figura 6A). Os ratos foram considerados em SOL se permanecessem imóveis e com os olhos fechados. Em relação ao PCL cortical e hipocampal, era necessária a observação de um aumento na amplitude e a presença de ondas lentas (Figura 6B). Ratos que apresentavam as características dos estágios EA, VP e MV foram considerados em VG (Figura 6C).

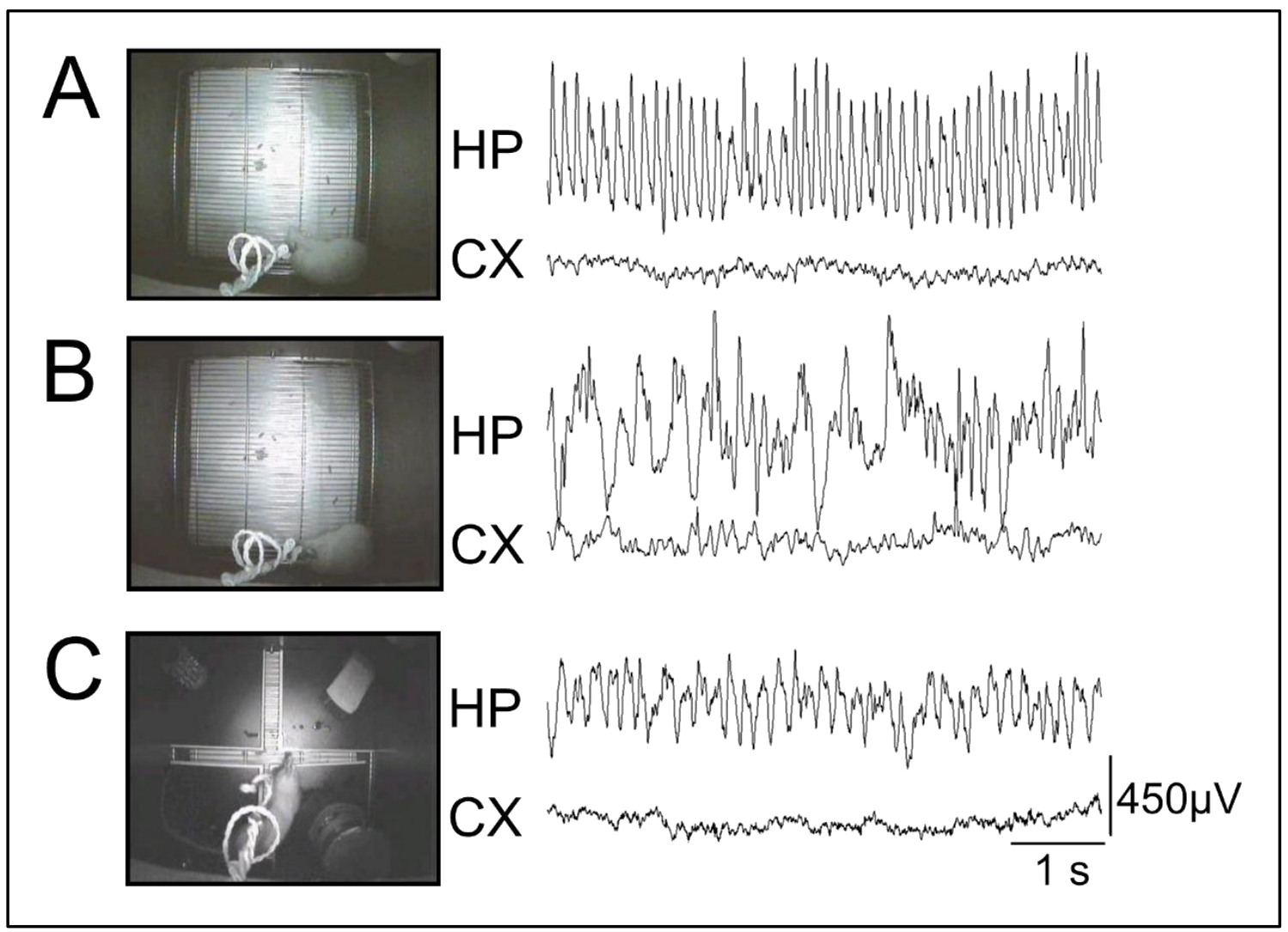

Figura 6 - Características comportamentais e padrão do PCL hipocampal e cortical em cada um dos estados do ciclo sono vigília. (A) Sono REM. (B) Sono de ondas lentas. (C) Vigília durante a exploração do ambiente enriquecido. HP: hipocampo, CX: córtex somestésico. 


\subsubsection{Treinamento comportamental}

Os animais foram manipulados por sete sessões de $20 \mathrm{~min}$ ao longo dos quatro dias que precederam a cirurgia (Figura 7A). Esse procedimento tinha o objetivo de diminuir a resposta de estresse ao experimentador e ao ambiente. Após 2-5 dias para recuperação pós-operatória, os animais foram transferidos para a gaiola de experimentação e mantidos no biotério por cinco dias. O PCL foi registrado por uma hora do segundo ao quarto dias após a alocação na gaiola de experimentação. Antes desse procedimento o animal foi manipulado por cinco minutos. Os registros foram feitos com a gaiola de experimentação dentro da caixa de registro. Após o último registro, o animal foi mantido ligado a um cabo de registro falso por $12 \mathrm{~h}$ (período noturno) a fim de reproduzir o longo tempo ligado ao sistema de registro no dia do teste. Após esse período, os animais foram mantidos sem interferência no biotério até o dia do teste. Esses procedimentos tinham como objetivo identificar os padrões de sono, reduzir o estresse do animal ao experimentador e habituar os animais às condições de registro minimizando a saliência dos estímulos provenientes do ambiente de registro. Os animais foram submetidos a treinamento comportamental em pares e os grupos experimentais foram aleatorizados.

Os grupos foram definidos por dois critérios: estágio de sono e exposição ao ambiente enriquecido. Com isso foram formados seis grupos: SREM controle (RC), SREM exposto (RE), SOL controle (OC), SOL exposto (OE), VG controle (VC) e VG exposto (VE).

No dia do teste, após 4 horas de habituação com registro (início entre 16 e 17 h), animais pertencentes aos grupos RE, OE e VE foram expostos ao ambiente enriquecido por 20 min (Figura 7B). Posteriormente, os animais foram privados de sono por $1 \mathrm{~h}$ por meio de toques na caixa de registro (gentle handling). Os grupos $\mathrm{RE}$ e $\mathrm{OE}$ foram sacrificados transcorridos $30 \mathrm{~min}$ desde o primeiro episódio de SREM e SOL, respectivamente. O rato era incluído no grupo RE, se permanecesse em SREM por um mínimo de $90 \mathrm{~s}$ após a privação de sono. Se o rato permanecesse por pelo menos 5 min pós-privação de sono em SOL e não entrasse em SREM ele era agrupado como OE. O grupo VE foi sacrificado imediatamente após a privação de sono. Os grupos RC, $\mathrm{OC}$ e VC seguem os protocolos descritos, respectivamente, para RE, OE e VE, sem a exposição ao ambiente enriquecido (Figura 7B). 


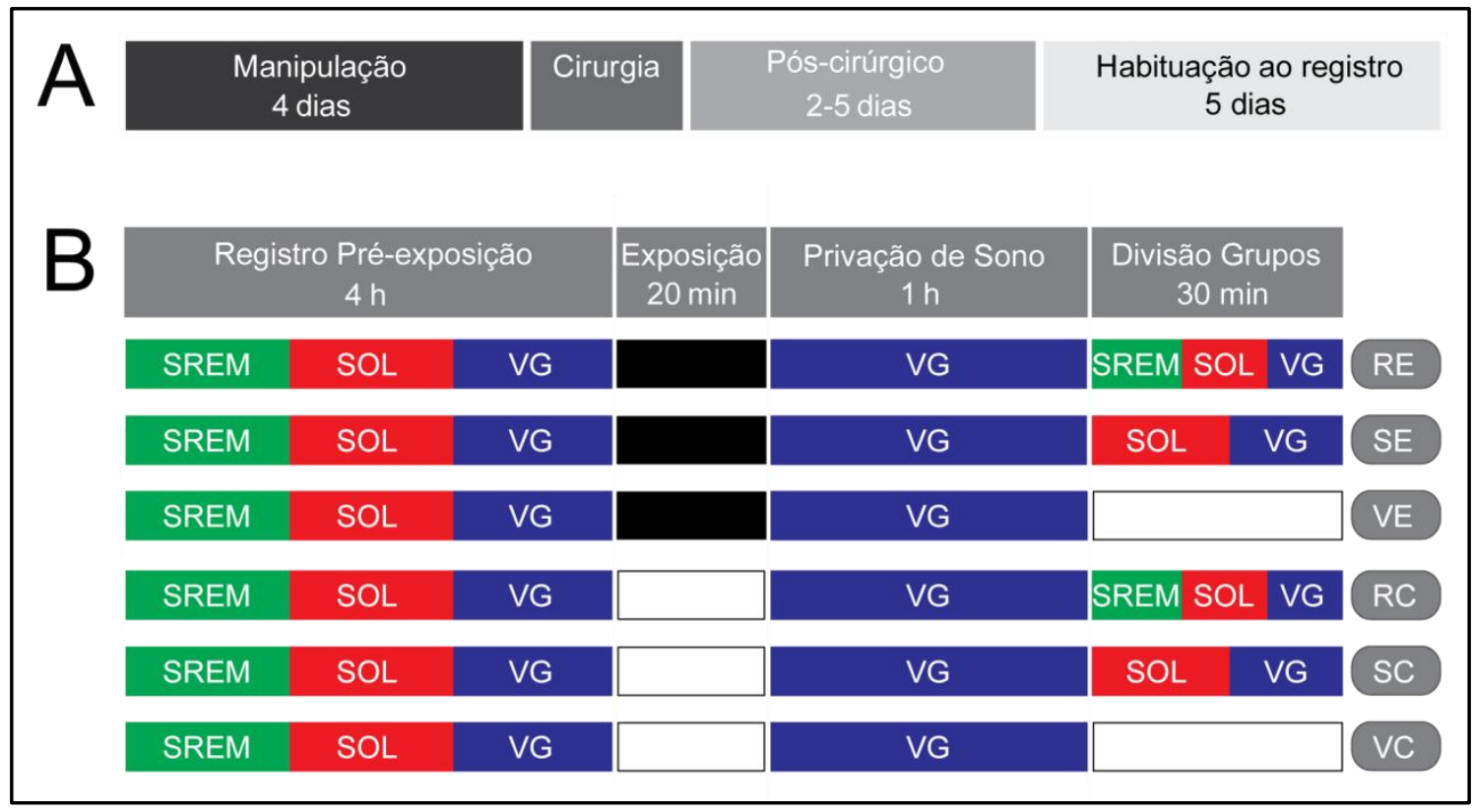

Figura 7 - Desenho experimental utilizado para identificar as alterações na expressão de genes relacionados à plasticidade após a exposição ao ambiente enriquecido. (A) Os animais foram manipulados por quatro dias antes da cirurgia e, após o período pós-cirúrgico habituados às condições de registro. (B) Foram formados 6 grupos. Todos os animais eram mantidos por $4 \mathrm{~h}$ no ambiente de registro antes da exposição. Em seguida eram expostos ao ambiente enriquecido por 20 minutos (grupos expostos) e, então, privados de sono por $1 \mathrm{~h}$. Os animais dos grupos de vigília (VG) eram sacrificados imediatamente após a privação de sono enquanto aqueles dos grupos de sono de ondas lentas (SOL) e sono REM (SREM) eram mantidos por 30 min após o atingirem o critério de sono. Note que apenas os animais dos grupos SREM apresentavam ciclos completos de sono, enquanto nos outros grupos o sono era interrompido após atingir o estágio de interesse. RE: grupo SREM exposto; SE: grupo SOL exposto; VE: grupo VG exposto; RC: grupo SREM controle; SC: grupo SOL controle; VC: grupo VG controle.

De acordo com o protocolo descrito acima, os animais dos grupos VE e VC se mantiveram principalmente em VG antes do sacrifício; os animais dos grupos OE e OC ficaram em SOL, mas apresentavam também momentos em VG; e os animais dos grupos RE e RC apresentavam os três estágios (Figura 7B). Esses critérios foram usados anteriormente com sucesso (RIBEIRO et al., 1999; RIBEIRO et al., 2002).

Os objetos foram introduzidos entre $20 \mathrm{~h} 00 \mathrm{~min}$ e $21 \mathrm{~h} 00 \mathrm{~min}$, de maneira a facilitar a exploração tátil do ambiente realizada pelas vibrissas e a privação de sono. Após as $18 \mathrm{~h}$ os animais foram mantidos sob iluminação infravermelha. Durante o encaminhamento dos ratos ao sacrifício e durante a colocação e retirada dos objetos o ambiente foi iluminado com luzes vermelhas, uma frequência invisível para o rato. Nesses momentos o monitor e outras fontes de luz na sala foram desligados.

\subsubsection{Causas de exclusão}

Foram excluídos ratos que faleceram durante a cirurgia $(n=1)$, aqueles com implante danificado $(n=1)$, registro interrompido durante o dia do teste $(n=2)$, registro com PCL de baixa qualidade 
$(n=2)$, alterações morfológicas visíveis após a cirurgia $(n=2)$, problemas durante a privação de sono $(n=4)$ ou que não atingiram os critérios para inclusão em quaisquer dos grupos (n=5).

\subsubsection{Sacrifício e coleta}

Atingido o tempo de referência após o evento de interesse (logo após a privação para VG ou 30 min após o SREM ou SOL os ratos foram anestesiados com halotano e sacrificados por decapitação em guilhotina. Os encéfalos foram dissecados segundo o procedimento definido no experimento anterior e foram armazenados a $-80{ }^{\circ} \mathrm{C}$.

\subsubsection{Expressão gênica}

\subsubsection{Extração do RNA e RT-PCR}

Amostras de tecido pesando de 18,0 e 23,5 g foram congeladas, maceradas em nitrogênio líquido e utilizadas para extração de RNA pelo método do TRIzol ${ }^{\circledR}$ (Invitrogen). $1 \mathrm{~mL}$ de TRIzol foi adicionado e o tecido foi homogeneizado. Em seguida a solução foi passada por uma seringa de diâmetro pequeno a fim de quebrar o gDNA. O RNA foi reprecipitado em $500 \mu \mathrm{L}$ de isopropanol. O sobrenadante foi lavado em etanol $75 \%$ duas vezes. O sobrenadante foi descartado e o precipitado foi diluído em $20 \mu \mathrm{L}$ de água livre de RNAse. A solução contendo RNA foi aquecida a $55^{\circ} \mathrm{C}$ por 10 min para facilitar a solubilização do RNA.

\subsubsection{Controle de qualidade}

O controle de qualidade foi realizado como descrito no experimento anterior ${ }^{10}$.

\subsubsection{Seleção dos genes alvo}

Foram selecionados genes relacionados à plasticidade sináptica e que haviam sido anteriormente correlacionados a alguma fase do ciclo sono-vigília e/ou sofrido alterações decorrentes de privação de sono em estudos de larga escala. Alterações no perfil de expressão ou de ativação dos genes Arc, Egrl, Bdnf, Crebl após a exposição a um ambiente enriquecido, treinamento em tarefa comportamental, e/ou indução de LTP no hipocampo in vivo (RIBEIRO et al., 1999; RIBEIRO et

\footnotetext{
${ }^{10}$ Veja a seção 4.1.2.2.
} 
al., 2002; ULLOOR; DATTA, 2005). O bloqueio da atividade de subunidades da PP2A e CREB impede a indução do sono por novidade na drosófila (GANGULY-FITZGERALD et al., 2006).

Por outro lado, trabalhos de expressão gênica em larga escala haviam mostrado aumento na expressão dos genes Arc, Bdnf, Egrl, Egr2, Fos e Nr4al após a privação de sono ou VG espontânea (CIRELLI; TONONI, 2000b; CIRELLI et al., 2004; TERAO et al., 2006) e de Camk4 no sono em comparação a igual tempo de VG (CIRELLI et al., 2004). No entanto, a expressão desses genes não foi avaliada entre SOL e SREM, além da modulação por experiência relevante.

\subsubsection{Curvas de eficiência dos ensaios de PCR em tempo real -}

Confeccionamos curvas de eficiência para ensaios TaqMan (Applied Biosystems) descritos na Tabela 1. O cálculo da eficiência foi feito pelo programa qBase v1.3.5 segundo descrito por Hellemans et al. (2007). A curva consiste de quatro pontos diluídos por um fator de 10 (1, 1:10, 1:100, 1:1000) a partir de um pool contendo cDNA extraídos de todos os ratos. Os três primeiros pontos da curva foram feitos em duplicata, enquanto o último ponto (1:1000) foi feito em quadruplicata, devido à maior variabilidade entre as replicatas. Em cada reação, foram adicionados

Tabela 1 - Descrição dos genes e respectivos ensaios TaqMan utilizados para análise de expressão gênica.

\begin{tabular}{|c|c|c|c|}
\hline Gene & Nome do Gene & ID do Ensaio & Éxon alvo \\
\hline Arc & $\begin{array}{l}\text { Proteína associada ao citoesqueleto regulada por } \\
\text { atividade }\end{array}$ & Rn00571208_g1 & 1 \\
\hline Bdnf & Fator neurotrófico derivado do encéfalo & Rn02531967_s1 & 2 \\
\hline Camk4 & Proteína quinase dependente de cálcio/calmodulina IV & Rn00562394_m1 & 2 \\
\hline Creb1 & Proteína 1 ligante ao elemento responsivo ao cAMP & Rn00578826_m1 & 3 \\
\hline Egr1 & Resposta de crescimento inicial 1 & Rn00561138_m1 & 1 \\
\hline Egr2 & Resposta de crescimento inicial 2 & Rn00586224_m1 & 1 \\
\hline Fos & Oncogene osteosarcoma FBJ & Rn02396759_m1 & 1 \\
\hline Gusb & Glucuronidase, beta & Rn00566655_m1 & 8 \\
\hline Nr4a1 & Receptor nuclear subfamília 4, grupo A, membro 1 & Rn00666995_m1 & 6 \\
\hline Ppp2ca & $\begin{array}{l}\text { Proteína fosfatase } 2(2 \mathrm{~A}) \text {, subunidade catalítica, } \\
\text { isoforma alfa }\end{array}$ & Rn00820754_g1 & 1 \\
\hline Ppp2r2d & $\begin{array}{l}\text { Proteína fosfatase } 2(2 \mathrm{~A}) \text {, subunidade regulatória } \mathrm{B} \text {, } \\
\text { isoforma delta }\end{array}$ & Rn00518189_m1 & 1 \\
\hline Rpl19 & Proteína ribossomal L19 & Rn00821265_g1 & 3 \\
\hline
\end{tabular}


1,5 $\mu \mathrm{L}$ de amostra; $0,75 \mu \mathrm{L}$ de TaqMan Assays $20 \mathrm{x}$ (Applied Biosystems) e 7,5 $\mu \mathrm{L}$ de TaqMan Master Mix (Applied Biosystems) em volume final de $15 \mu \mathrm{L}$. As reações foram realizadas no 7500 Real-Time PCR System (Applied Biosystems). No primeiro passo, a amostra foi aquecida a $50{ }^{\circ} \mathrm{C}$ por 2 min para ativação da UNG. No segundo passo, a Taq Polimerase foi ativada a $95{ }^{\circ} \mathrm{C}$ por 10 min. O terceiro passo consistiu de 45 ciclos com desnaturação a $95^{\circ} \mathrm{C}$ por $15 \mathrm{~s}$ e amplificação/extensão a $60^{\circ} \mathrm{C}$ por 1 min. Os dados foram coletados durante o primeiro passo do estágio 3.

\subsubsection{Avaliação da expressão gênica por PCR em tempo real}

Os genes Gusb e Rpl19 foram utilizados como controles endógenos segundo determinado no experimento anterior ${ }^{11}$. Os demais genes descritos na Tabela 1 foram analisados como alvo. Nesses experimentos foram utilizados cDNA diluídos 10 vezes. Para diminuir os erros na estimativa do valor da expressão, cada amostra foi analisada em triplicata e o valor médio foi usado. Além disso, todas as amostras de uma dada região cerebral foram analisadas na mesma placa e cada gene analisado em placas diferentes como proposto por Hellemans et al. (2007). A análise da expressão foi realizada pelo programa qBase v 1.3.5.

\subsubsection{Análise estatística}

Para determinar a presença de outliers na amostra, foi utilizado o teste de Grubbs ESD, como proposto por Motulsky (1997) para a interação entre exposição ao ambiente enriquecido e estágio de sono. Em seguida, foi feita uma análise de variância (ANOVA) de duas vias com exposição ao ambiente enriquecido e estágio de sono como fatores fixos. O teste de Tukey HSD foi usado como post hoc quando aplicável. Uma ANOVA de uma via foi utilizada para comparar o tempo em cada estágio do sono entre os grupos durante a última hora da habituação ao registro (registro préexposição) e nos últimos 35 minutos de antes do sacrifício. O nível de significância de 5\% foi adotado em todas as análises.

\footnotetext{
${ }^{11}$ Veja a sessão 5.1
} 


\subsection{Localização dos eletrodos}

\subsubsection{Animais, cirurgia e perfusão}

Quatro ratos Wistar (Rattus norvegicus) adultos machos, pesando entre 295 e 395 g no momento da cirurgia, tiveram eletrodos implantados no hipocampo e córtex somestésico primário para registro do PCL, como descrito acima ${ }^{12}$. Após 4-7 dias da cirurgia, os ratos foram registrados e expostos ao ambiente enriquecido. Para observar o padrão do PCL, os ratos (pesando 400 a $530 \mathrm{~g}$ ) foram registrados por 1-3 meses após cirurgia.

Os ratos receberam uma sobredose de cloridrato de cetamina e cloridrato de xilazina. Posteriormente, foram perfundidos transcardialmente com salina em tampão fosfato a $37{ }^{\circ} \mathrm{C}$ seguido por solução de paraformaldeído em tampão fosfato $4 \%$ a $4{ }^{\circ} \mathrm{C}$. A mandíbula e o palato foram quebrados com uma goiva e o encéfalo foi lentamente retirado do osso. Durante a remoção do encéfalo cuidados foram tomados para evitar movimentos laterais a fim de não danificar as áreas em torno do implante de eletrodos.

\subsubsection{Histoquímica}

Para o preparo histoquímico, os quatro encéfalos coletados foram lavados em solução salina tamponada, mergulhados em sacarose tamponada $20 \%$ para desidratar, congelados rapidamente e estocados em um freezer -80 C para assegurar preservação do tecido. Os encéfalos foram seccionados em um criostato e seções frontais seriais de $40 \mu \mathrm{m}$ foram montadas em lâminas gelatinizadas. Posteriormente, as seções foram coradas por cresil-violeta (coloração de Nissl) para observação da estrutura geral do tecido neural. A localização do eletrodo foi feita a partir da comparação das lâminas com figuras de referência (PAXINOS; WATSON, 1997).

\footnotetext{
${ }^{12}$ Veja a seção 4.2.1.3.
} 


\section{Resultados}

\subsection{Determinação dos controles endógenos}

\subsubsection{Controle de qualidade}

O RNA extraído a partir das regiões encefálicas alvo estava em boa quantidade e qualidade. A banda de RNA ribossômico (rRNA) 28S apresentava intensidade aproximadamente duas vezes maior que a banda $18 \mathrm{~S}$ (Figura 8A). A razão de absorbância $\mathrm{A}_{260 / 280 \mathrm{~nm}}$ encontrava-se entre

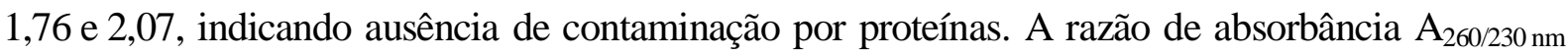
encontrava-se entre 0,51 e 2,22 indicando pequena a moderada contaminação por compostos aromáticos. A PCR desenhada para detectar a presença de gDNA mostra apenas a presença da banda de cDNA (107 pb), mas não de gDNA (194 pb). Esse resultado sugere ausência de contaminação por gDNA (Figura 8B).

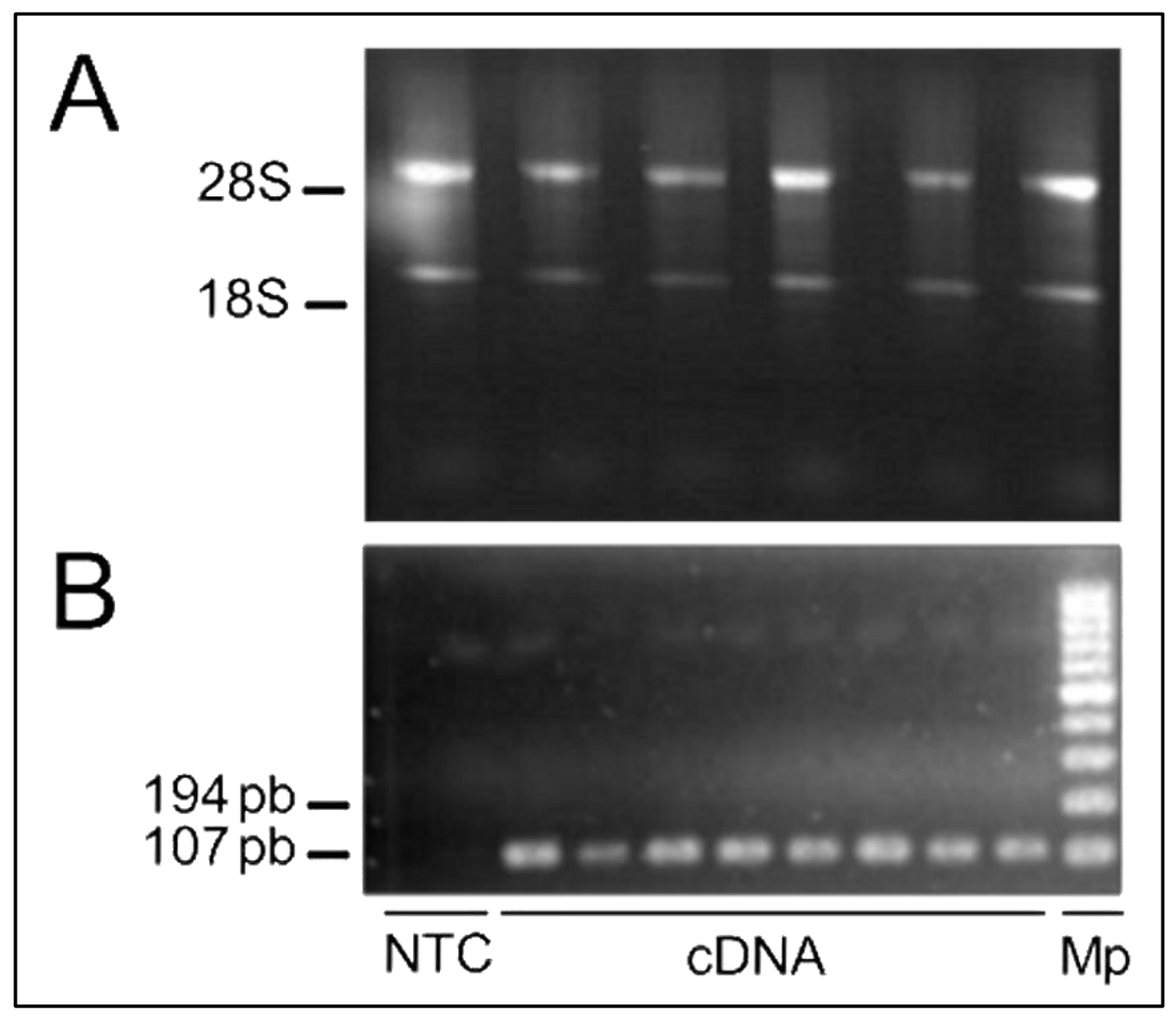

Figura 8 - Controle de qualidade do mRNA extraído. (A) Gel de agarose 1\% com isotiocianato corado com brometo de etídio, mostrando a presença das bandas correspondentes aos rRNA $18 \mathrm{~S}$ e 28S. (B) PCR diferencial para determinar contaminação de gDNA para o gene Actb em gel de agarose $1 \%$ corado com brometo de etídio. cDNA: DNA complementar; gDNA: DNA genômico; NTC: Controle sem amostra; Mp: Marcador de peso molecular de 100 pb. 


\subsubsection{Determinação dos controles endógenos}

As amostras apresentavam boa amplificação diluídas tanto 5 quanto 10 vezes. A eficiência média da amplificação era de 1,98;2,14; 2,04; e 2,07, respectivamente, para os genes Actb, B2m, Gusb, Rpl19. Dentre os genes testados, Actb apresentou menor estabilidade média de expressão (M) ( $\mathrm{M}=0,78$ diluição 1:5; $\mathrm{M}=0,86$ diluição $1: 10)$, seguido pelo $B 2 m(\mathrm{M}=0,57$ diluição 1:5; $\mathrm{M}=0,59$ diluição 1:10). Os dois genes mais estáveis foram os Gusb e Rpl19, cujos valores de M para o par foram 0,41 (diluição 1:5) e M=0,49 (diluição 1:10) (Figura 9).

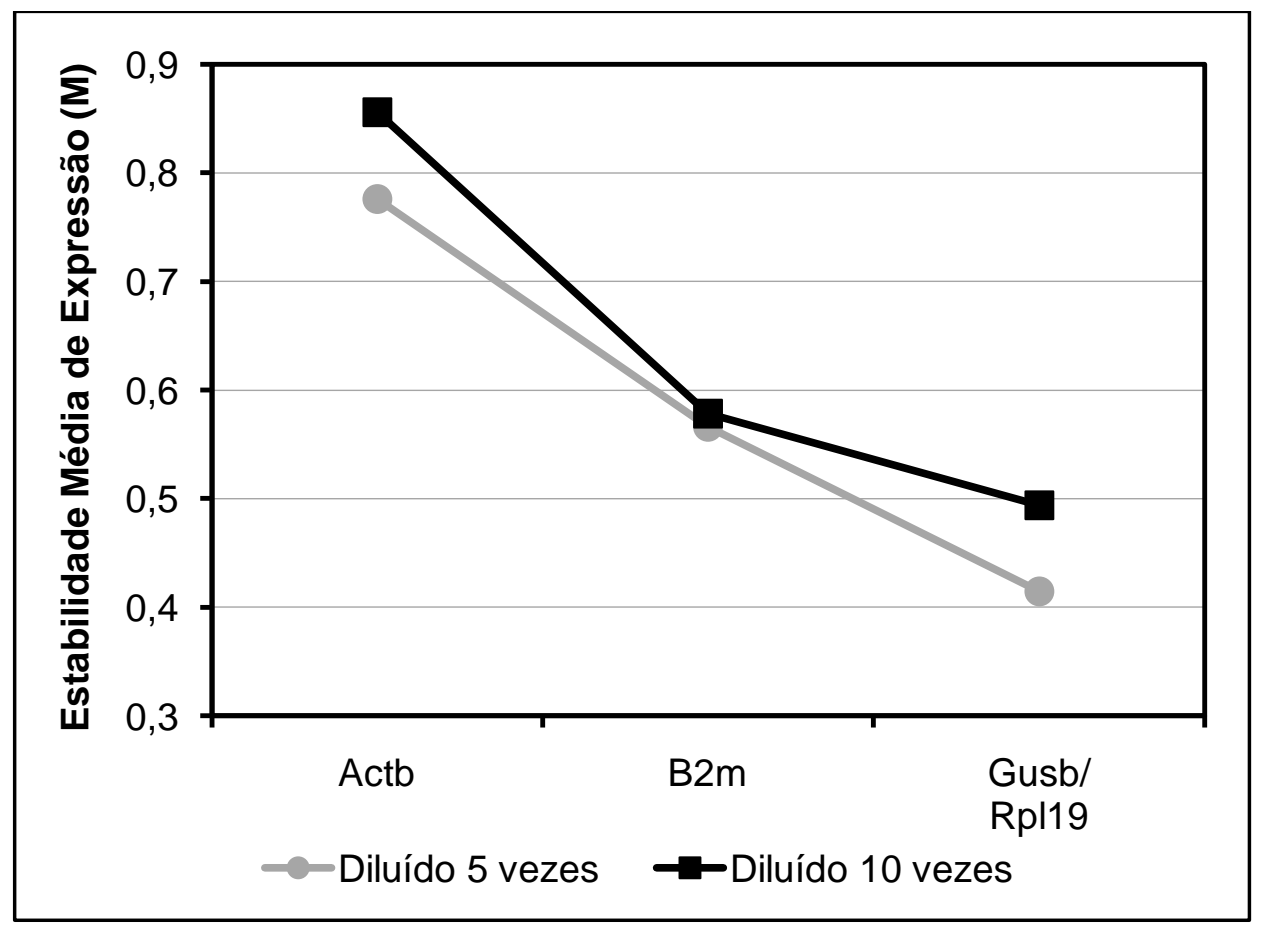

Figura 9 - Estabilidade média de expressão (M) dos genes selecionados como controles endógenos restantes durante a exclusão gradual dos controles endógenos com expressão menos estável. O procedimento foi realizado no mesmo pool amostras diluído 5 ou 10 vezes.

\subsection{Posicionamento dos eletrodos}

Pela análise histológica é possível observar o rastro dos eletrodos subcorticais, atingindo a camada polimórfica do giro denteado em todos os ratos analisados $(n=4)$ (Figura 10). Esse dado indica que os implantes foram direcionados ao lugar correto. Os eletrodos corticais eram superficiais e, portanto, não deixavam marcas no encéfalo. Por isso não foi possível localizá-los utilizando cortes histológicos. No entanto, o posicionamento dos eletrodos corticais foi realizado seguindo os mesmos procedimentos dos eletrodos subcorticais. 


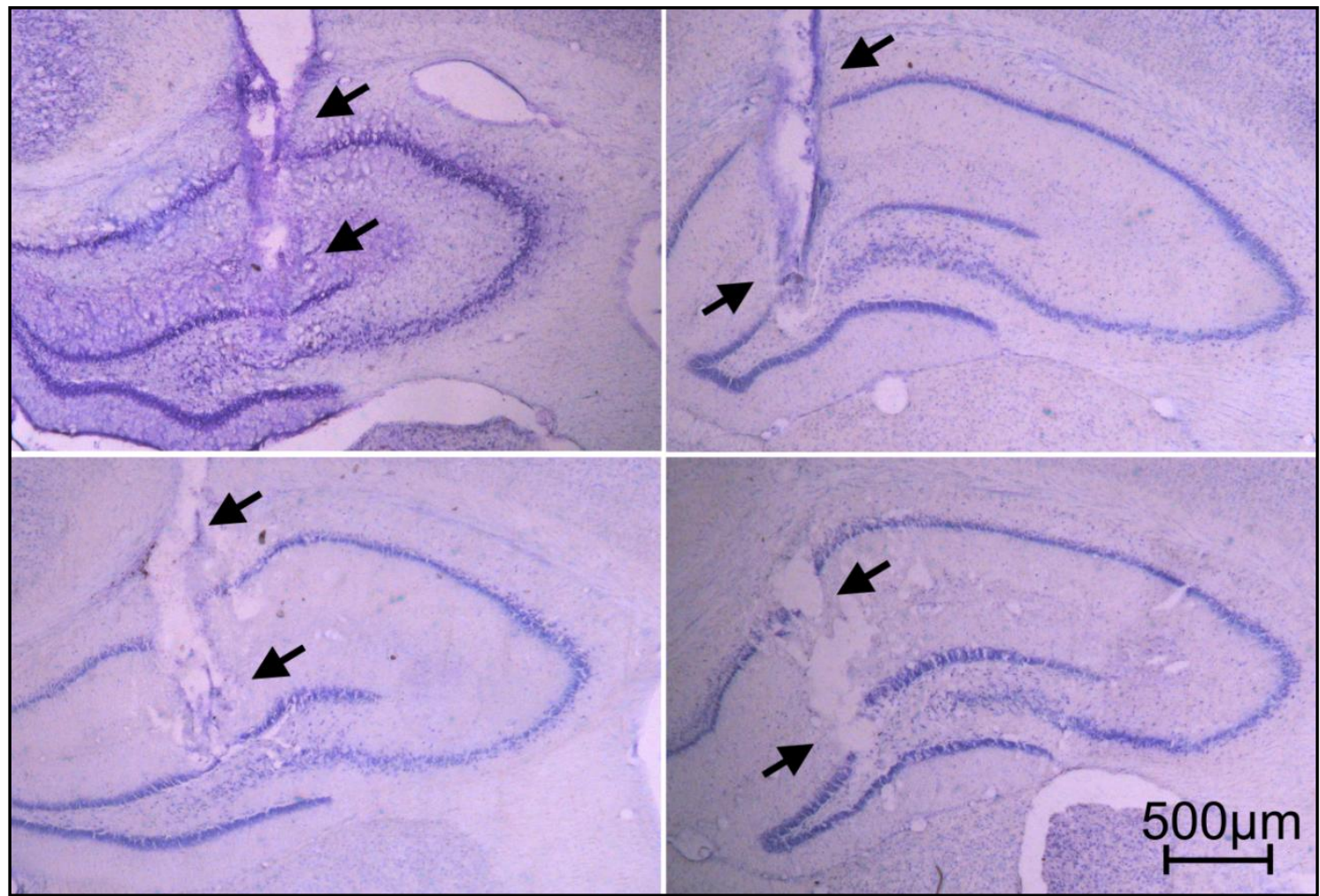

Figura 10 - Seções frontais de $40 \mu \mathrm{m}$ coradas por cresil-violeta (coloração de Nissl) mostrando o hipocampo dorsal direito dos quatro animais utilizados para a localização dos eletrodos. As setas mostram os rastros dos eletrodos.

\subsection{Expressão gênica modulada por sono e ambiente enriquecido}

\subsubsection{Identificação e separação dos estágios do ciclo sono-vigília}

A arquitetura do sono se manteve inalterada durante o registro pré-exposição. Assim, o tempo que os animais permaneceram em VG $(F=0,464 ; d f=5 ; p=0,799)$, SOL $(F=0,907 ; d f=5 ; p=0,493)$ e SREM $(F=0,138 ; d f=5 ; p=0,981)$ foi semelhante em todos os grupos durante o registro préexposição (Figura 11A). Por outro lado o tempo que os animais permaneceram em VG $(F=6,827$; $d f=5 ; p<0,001)$, SOL $(F=6,589 ; d f=5 ; p<0,001)$ e SREM $(F=20,805 ; d f=5 ; p<0,001)$ foi significativamente diferente no momento da separação dos grupos (nos últimos 35 min antes do sacrifício) (Figura 11B). A Figura 12 mostra um enriquecimento no tempo que os animais permaneceram nos estágios-alvo antes do sacrifício. Como o esperado, esse enriquecimento é maior em torno de 30 min antes do sacrifício. 


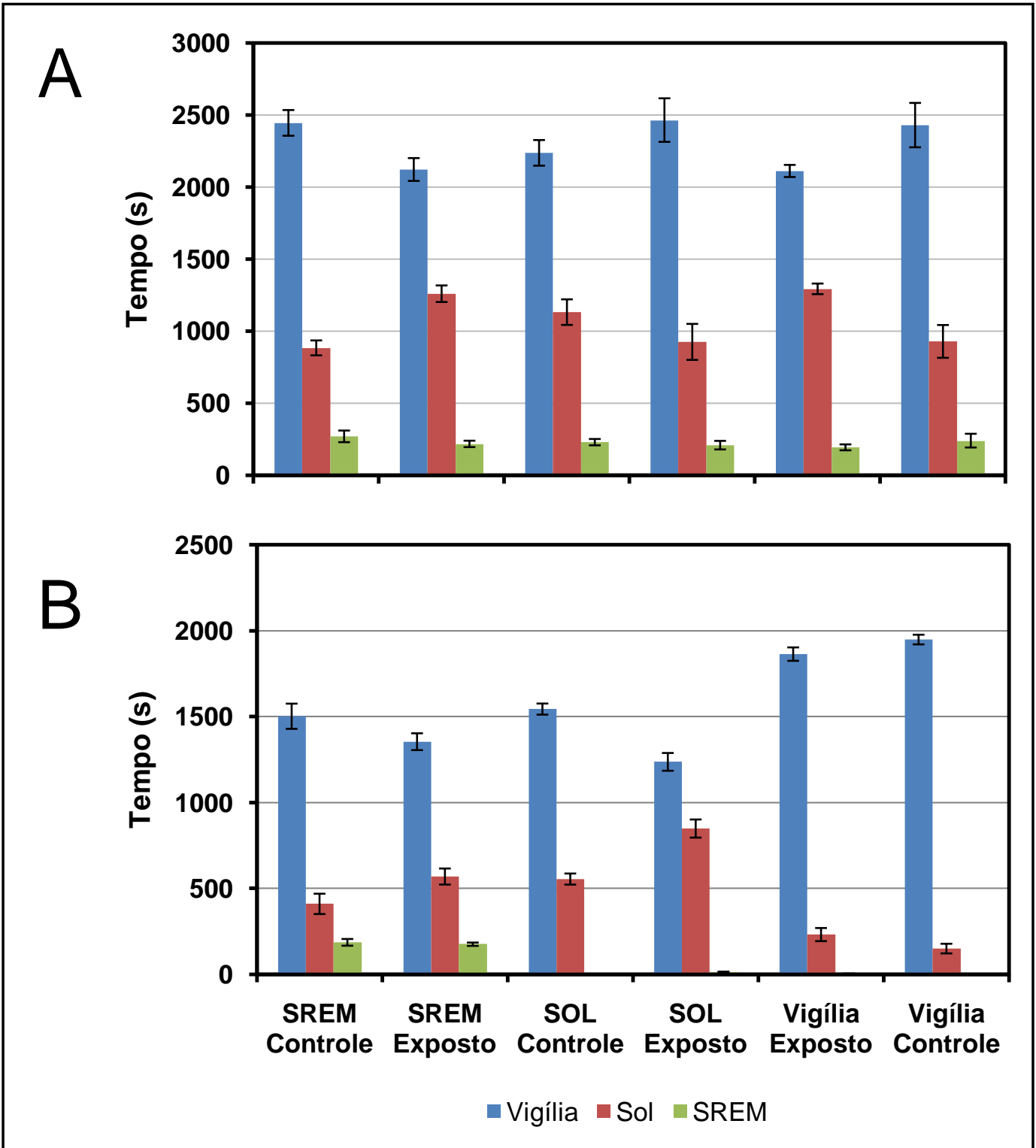

Figura 11 - Tempo dos animais (em segundos) em cada estágio do ciclo sono vigília (A) durante a última hora de registro pré-exposição; e (B) durante a separação dos estados (últimos 35 min de registro). Os resultados são apresentados como média \pm erro padrão da média. SREM: sono REM; SOL: sono de ondas lentas. 


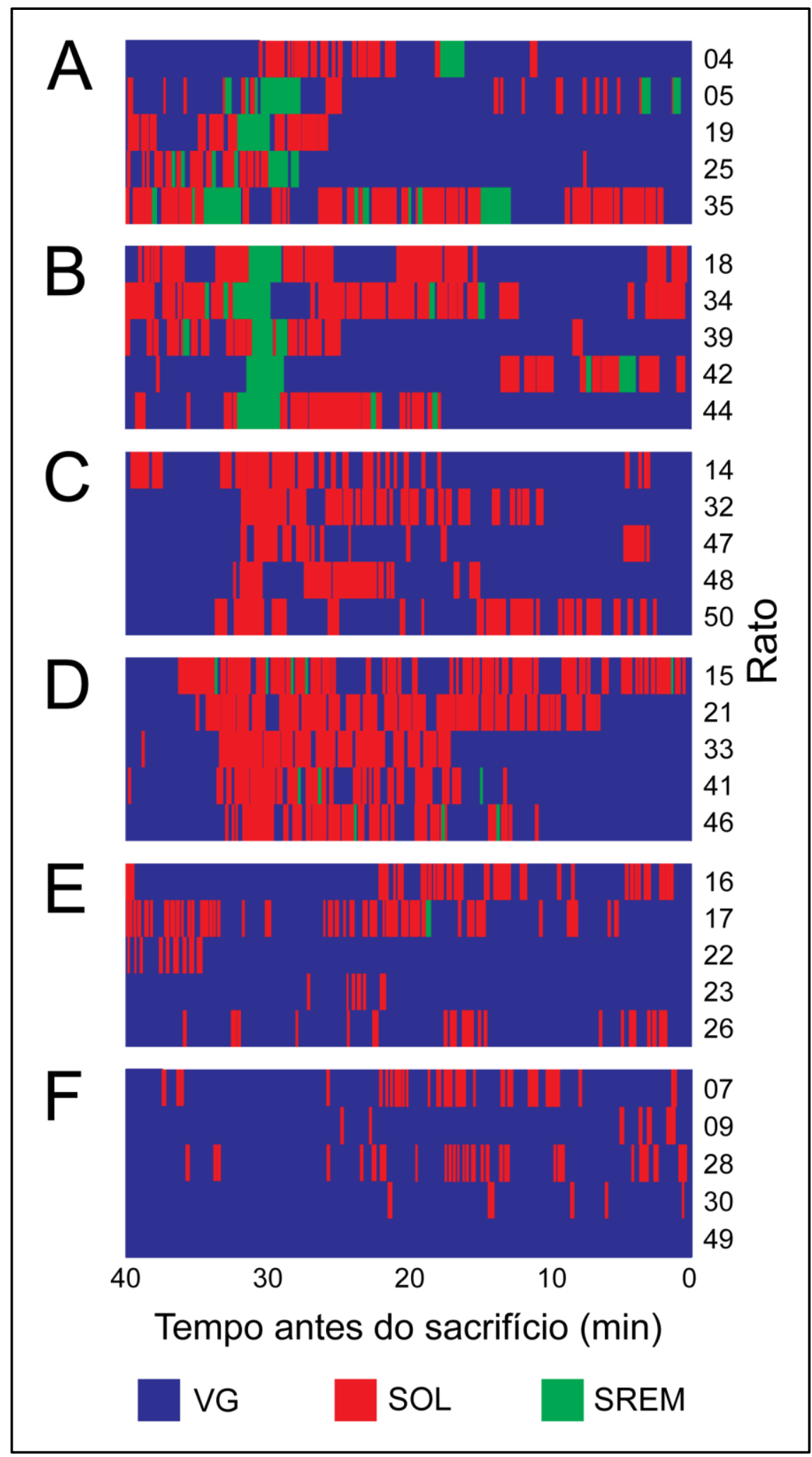

Figura 12 - Hipnogramas dos animais dos grupos (A) sono REM controle; (B) sono REM exposto; (C) sono de ondas lentas controle; (D) sono de ondas lentas exposto; (E) vigília controle; e (F) vigília exposto durante os últimos 40 min antes do sacrifício. VG: vigília; SOL: sono de ondas lentas; SREM: sono REM. 


\subsubsection{Controle de qualidade}

O RNA extraído a partir das regiões alvo estava em boa quantidade e qualidade. A banda de rRNA 28S apresentava intensidade aproximadamente duas vezes maior que a banda 18S (Figura 13A). A

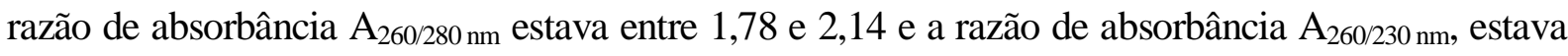
entre 1,77 e 2,37. A PCR desenhada para detectar a presença de gDNA só mostra a presença da banda de cDNA (107 pb), mas não de gDNA (194 pb), sugerindo ausência de contaminação por gDNA (Figura 13B).

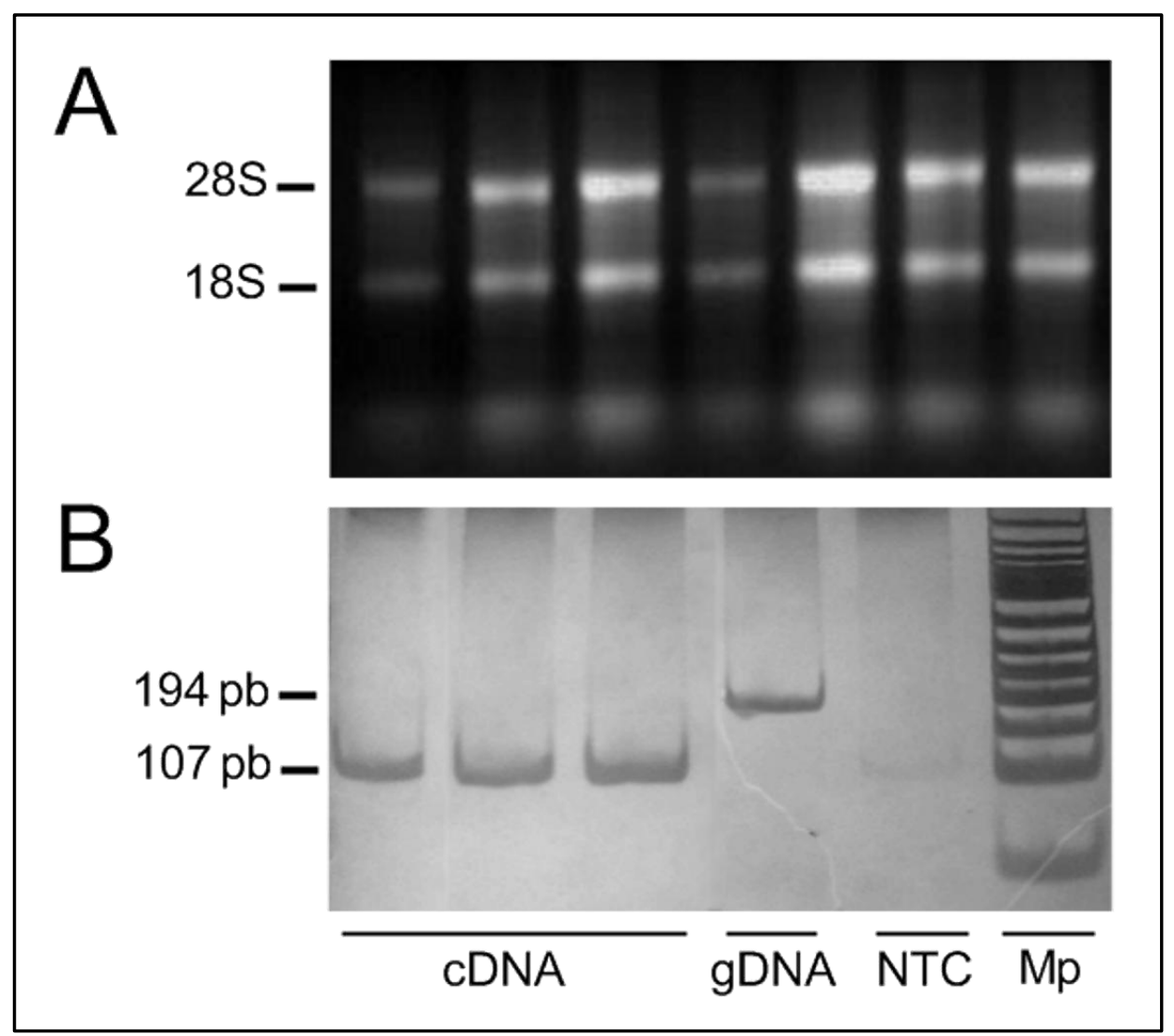

Figura 13 - Controle de qualidade do mRNA extraído. (A) Gel de agarose 1\% com isotiocianato corado com brometo de etídio, mostrando a presença das bandas correspondentes aos rRNA 18S e 28S. (B) PCR para determinar contaminação por gDNA usando oligonucleotídeos para o gene Actb. Nesse sistema o produto amplificado gerado a partir de gDNA tem um tamanho de 194 pb enquanto o produto amplificado a partir de uma matriz de cDNA tem um tamanho de $107 \mathrm{pb} .0$ produto amplificado foi aplicado em gel de poliacrilamida $8 \%$, corado com nitrato de prata. cDNA: DNA complementar; gDNA: DNA genômico; NTC: Controle sem amostra; Mp: Marcador de peso molecular de $50 \mathrm{pb}$.

O nível de expressão dos controles endógenos apresentou uma variabilidade média de 12,51\% na amostras analisadas. O valor de M atribuído pelo GeNorm foi 0,3579 (Tabela 2). 
Tabela 2 - Estabilidade média de expressão dos controles endógenos.

\begin{tabular}{lll}
\hline Gene & Coeficiente de Variação & M (GeNorm) \\
\hline Gusb & $12,20 \%$ & 0,3579 \\
Rpl19 & $12,82 \%$ & 0,3579 \\
Média & $12,51 \%$ & 0,3579 \\
\hline
\end{tabular}

\subsubsection{Detecção de outliers}

A amostra proveniente do hipocampo do rato 18 apresentava um Z-score $>1,71$ em três genes (Egrl, Rpl19, Gusb). Similarmente, essa amostra apresentava um valor 1,55 < Z $<1,71$ em sete genes (Arc, Creb1, Egr2, Fos, Nr4a1, Ppp2ca, Ppp2r2d). Esse valor semelhante na maioria dos genes possivelmente indica algum problema entre a extração do RNA e a confecção do cDNA, uma vez que o mesmo fenômeno não se repete para a amostra proveniente do córtex somestésico do mesmo rato. Dada esse observação a amostra 18HP foi excluída das análises. Outras amostras apresentavam Z-scores significantes para um dos genes alvo (16HP, 34CX, 39CX, 25HP, 35HP) ou dos controles endógenos (50CX), porém apresentavam um Z-score baixo nos demais. Essas amostras foram mantidas. Dessa maneira temos um número amostral de total de 30 animais divididos em 6 grupos de 5 ratos nas análises do córtex somestésico. No hipocampo o número amostral total é de 29 animais. Os grupos VC, VE, SE, SC e RC possuem 5 amostras cada um e o grupo RE apresenta 4 amostras. Esse padrão foi utilizado em todos os genes, com exceção do Egr $2^{13}$ devido a uma baixa expressão basal no hipocampo. Portanto a expressão de Egr2 no hipocampo foi analisada em 5 amostras dos grupos VE, SE e SC, 4 dos grupos RE e RC e 3 do grupo VC. Assim como para os outros genes, 30 amostras foram analisadas e divididas igualitariamente entre os grupos no córtex somestésico.

\subsubsection{Expressão gênica}

\subsubsection{Arc}

A expressão de $\operatorname{Arc}$ no hipocampo foi modulada pela exposição ao ambiente enriquecido no hipocampo (Tabela 3) $(F=13,35 ; d f=1 p=0,001)$. A expressão desse gene também foi modulada pela interação entre a exposição e o estágio de sono do rato (Figura 14A) $(F=10,63 ; d f=2 ; p=0,001)$. No entanto, não houve diferença na expressão de Arc em relação aos diferentes estágios de sono-vigília

\footnotetext{
${ }^{13}$ Veja a seção 5.3.4.6.
} 
(Tabela 4) $(F=1,66 ; d f=2 ; p=0,212)$. A interação entre os fatores se dá pelo aumento na expressão de Arc nos grupos VE e RE em relação ao grupo VC. Similarmente, a expressão de Arc tende a ser maior em VE e RE em relação à $\mathrm{RC}$.

Observamos o efeito significativo da exposição (Tabela 3$)(F=6,08 ; d f=1 ; p=0,021)$ e da interação entre exposição e estágio de sono na expressão de Arc no córtex somestésico (Figura 14B) ( $F=3,42$; $d f=2 ; p=0,049$ ). Entretanto, não observamos efeito significativo do fator estágio de sono (Tabela 5) $(F=0,99 ; d f=2 p=0,387)$. A expressão de $A r c$ aumentou significativamente no grupo VE em relação aos grupos VC e $\mathrm{SC}$ no córtex somestésico.

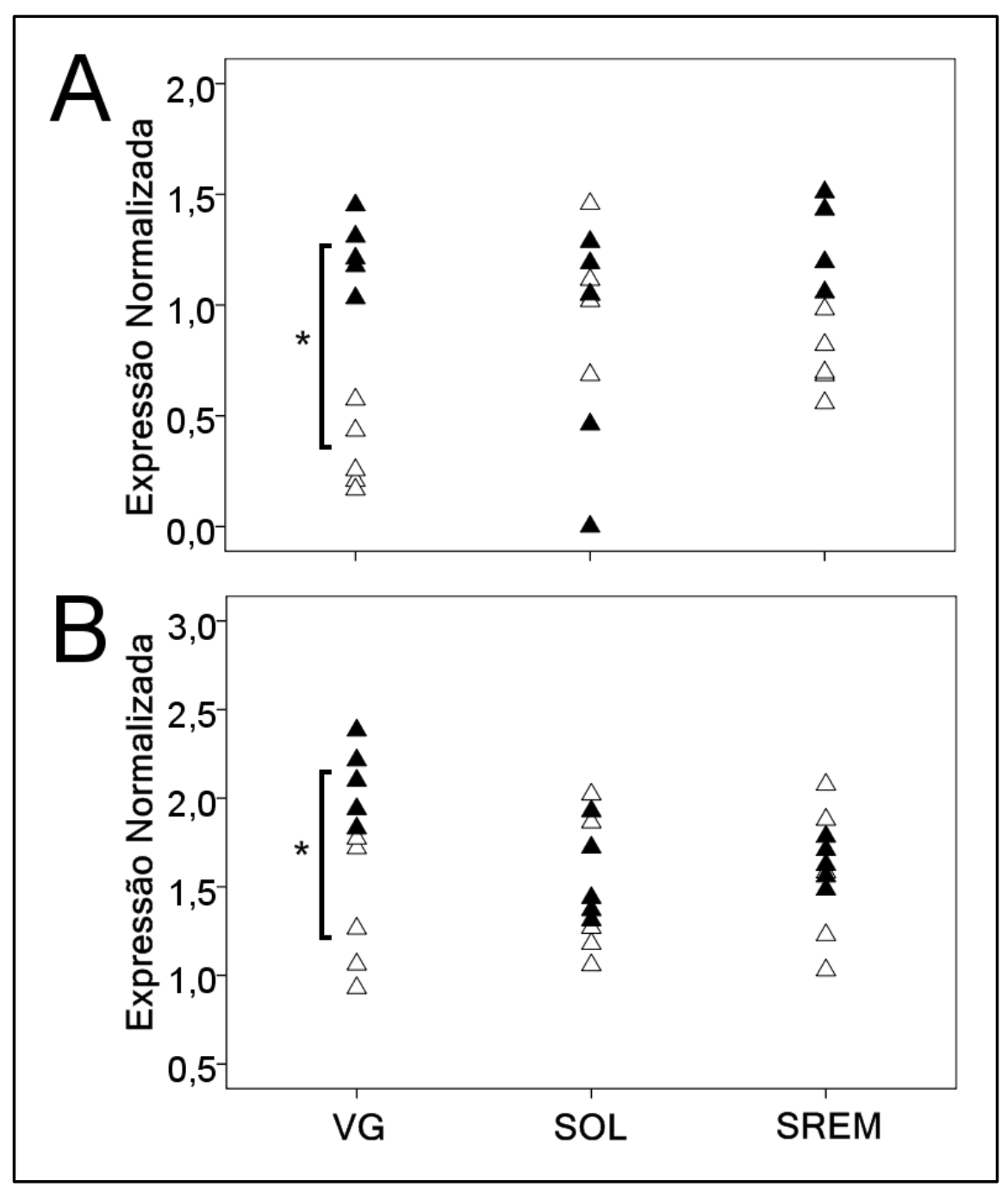

Figura 14 - Expressão do gene Arc determinada por PCR em tempo real no (A) hipocampo e (B) córtex somestésico de ratos. ${ }^{*} p<0,05$. VG: Vigília; SOL: sono de ondas lentas; SREM: sono REM. $(\triangle)$ Animais controle $(\boldsymbol{\Delta})$ Animais expostos. 
Tabela 3 - Modulação na expressão de genes relacionados à plasticidade neural pelo fator experiência relevante no córtex somestésico e hipocampo de ratos.

\begin{tabular}{|c|c|c|c|c|}
\hline \multirow[b]{2}{*}{ Gene } & \multicolumn{2}{|c|}{ Hipocampo } & \multicolumn{2}{|c|}{ Córtex Somestésico } \\
\hline & $\begin{array}{c}\text { Controle } \\
\text { (média } \pm \text { EPM) }\end{array}$ & $\begin{array}{c}\text { Exposto } \\
\text { (média } \pm \text { EPM) }\end{array}$ & $\begin{array}{c}\text { Controle } \\
\text { (média } \pm \text { EPM) }\end{array}$ & $\begin{array}{c}\text { Exposto } \\
\text { (média } \pm \mathbf{E P M )}\end{array}$ \\
\hline$\overline{A r c}{ }^{1}$ & $0,713 \pm 0,075$ & $1,110 \pm 0,078 * *$ & $1,462 \pm 0,085$ & $1,759 \pm 0,085 *$ \\
\hline$B d n f^{1}$ & $1,127 \pm 0,048$ & $1,086 \pm 0,050$ & $0,506 \pm 0,053$ & $0,946 \pm 0,053 * * *$ \\
\hline Camk4 ${ }^{1}$ & $0,708 \pm 0,082$ & $0,835 \pm 0,085$ & $1,094 \pm 0,044$ & $1,137 \pm 0,044$ \\
\hline Creb1 ${ }^{1}$ & $1,029 \pm 0,105$ & $1,462 \pm 0,110 * *$ & $1,782 \pm 0,056$ & $1,685 \pm 0,056$ \\
\hline$E g r 1^{1}$ & $1,318 \pm 0,154$ & $2,283 \pm 0,160 * * *$ & $3,404 \pm 0,103$ & $3,879 \pm 0,103 * *$ \\
\hline $\operatorname{Egr}^{2}$ & $1,008 \pm 0,288$ & $2,407 \pm 0,262 * *$ & $3,995 \pm 0,161$ & $5,737 \pm 0,161 * * *$ \\
\hline $\operatorname{Fos}^{1}$ & $0,956 \pm 0,090$ & $1,788 \pm 0,093 * * *$ & $2,289 \pm 0,107$ & $3,067 \pm 0,107 * * *$ \\
\hline$N r 4 a 1^{1}$ & $0,642 \pm 0,060$ & $0,855 \pm 0,062 *$ & $1,220 \pm 0,055$ & $1,321 \pm 0,055$ \\
\hline$P p p 2 c a^{1}$ & $0,628 \pm 0,061$ & $0,820 \pm 0,063 *$ & $0,974 \pm 0,054$ & $0,930 \pm 0,054$ \\
\hline $\operatorname{Ppp} 2 r 2 d^{1}$ & $0,397 \pm 0,069$ & $0,716 \pm 0,071 * *$ & $0,965 \pm 0,028$ & $1,035 \pm 0,028$ \\
\hline
\end{tabular}

${ }^{1}$ Controle-HP $n=15$; Exposto-HP $n=14$; Controle- $C X n=15$; Exposto- $C X n=15$.

${ }^{2}$ Controle-HP $n=12$; Exposto-HP $n=14$; Controle-CX $n=15$; Exposto-CX $n=15$.

${ }^{*}: p<0,05 ;{ }^{* *}: p<0,01 ;{ }^{* * *}: p<0,001$.

EPM: Erro Padrão; HP: hipocampo. CX: Córtex somestésico.

Tabela 4 - Modulação na expressão de genes relacionados à plasticidade neural pelo fator estágio de sono no hipocampo de ratos.

\begin{tabular}{|c|c|c|c|}
\hline Gene & $\begin{array}{c}\text { Vigília } \\
\text { (média } \pm \text { EPM) }\end{array}$ & $\begin{array}{l}\text { Sono de Ondas Lentas } \\
\text { (média } \pm \text { EPM) }\end{array}$ & $\begin{array}{c}\text { Sono REM } \\
\text { (média } \pm \text { EPM) }\end{array}$ \\
\hline$A r c^{1}$ & $0,781 \pm 0,092$ & $0,930 \pm 0,092$ & $1,023 \pm 0,097$ \\
\hline$B d n f^{1}$ & $1,208 \pm 0,058 *$ & $0,948 \pm 0,058$ & $1,163 \pm 0,062 *$ \\
\hline Camk4 ${ }^{1}$ & $0,577 \pm 0,101$ & $0,827 \pm 0,101$ & $0,909 \pm 0,107$ \\
\hline $\operatorname{Creb1}^{1}$ & $1,104 \pm 0,129$ & $1,288 \pm 0,129$ & $1,345 \pm 0,137$ \\
\hline$E g r 1^{1}$ & $1,421 \pm 0,188$ & $1,991 \pm 0,188$ & $1,990 \pm 0,200$ \\
\hline$E g r 2^{2}$ & $1,587 \pm 0,357$ & $1,615 \pm 0,309$ & $1,922 \pm 0,345$ \\
\hline $\operatorname{Fos}^{1}$ & $1,285 \pm 0,110$ & $1,388 \pm 0,110$ & $1,444 \pm 0,117$ \\
\hline$N r 4 a 1^{1}$ & $0,661 \pm 0,073$ & $0,761 \pm 0,073$ & $0,824 \pm 0,078$ \\
\hline Ppp2ca ${ }^{1}$ & $0,669 \pm 0,075$ & $0,726 \pm 0,075$ & $0,776 \pm 0,079$ \\
\hline$P p p 2 r 2 d^{1}$ & $0,376 \pm 0,084$ & $0,616 \pm 0,084$ & $0,676 \pm 0,089$ \\
\hline
\end{tabular}

\footnotetext{
1 Vigília $n=10$; Sono de Ondas Lentas $n=10$; Sono REM $n=9$.

${ }^{2}$ Vigília $n=8$; Sono de Ondas Lentas $n=10$; Sono REM $n=8$.

EPM: Erro Padrão. *: $p<0,05$ em relação ao sono de ondas lentas.
} 
Tabela 5 - Modulação na expressão de genes relacionados à plasticidade neural pelo fator estágio de sono no córtex somestésico de ratos.

\begin{tabular}{|c|c|c|c|}
\hline Gene & $\begin{array}{c}\text { Vigília } \\
\text { (média } \pm \text { EPM) }\end{array}$ & $\begin{array}{l}\text { Sono de Ondas Lentas } \\
\text { (média } \pm \text { EPM) }\end{array}$ & $\begin{array}{c}\text { Sono REM } \\
\text { (média } \pm \text { EPM) }\end{array}$ \\
\hline$A r c^{1}$ & $1,721 \pm 0,104$ & $1,515 \pm 0,104$ & $1,595 \pm 0,104$ \\
\hline$B d n f^{1}$ & $0,738 \pm 0,065$ & $0,699 \pm 0,065$ & $0,741 \pm 0,065$ \\
\hline Camk4 ${ }^{1}$ & $1,117 \pm 0,054$ & $1,085 \pm 0,054$ & $1,144 \pm 0,054$ \\
\hline $\operatorname{Creb1} 1^{1}$ & $1,732 \pm 0,068$ & $1,754 \pm 0,068$ & $1,716 \pm 0,068$ \\
\hline $\operatorname{Egrl}^{1}$ & $3,669 \pm 0,126$ & $3,584 \pm 0,126$ & $3,673 \pm 0,126$ \\
\hline $\operatorname{Egr}^{1}$ & $4,989 \pm 0,197$ & $4,787 \pm 0,197$ & $4,822 \pm 0,197$ \\
\hline Fos $^{1}$ & $2,798 \pm 0,131$ & $2,610 \pm 0,131$ & $2,627 \pm 0,131$ \\
\hline$N r 4 a 1^{1}$ & $1,402 \pm 0,067$ & $1,197 \pm 0,067$ & $1,213 \pm 0,067$ \\
\hline Ppp2ca ${ }^{1}$ & $0,942 \pm 0,066$ & $0,991 \pm 0,066$ & $0,923 \pm 0,066$ \\
\hline Ppp2r2d ${ }^{1}$ & $0,968 \pm 0,034$ & $1,009 \pm 0,034$ & $1,024 \pm 0,034$ \\
\hline
\end{tabular}

${ }^{1}$ Vigília $\mathrm{n}=10$; Sono de Ondas Lentas $\mathrm{n}=10$; Sono REM $\mathrm{n}=10$.

EPM: Erro Padrão.

\subsubsection{Bdnf}

Observamos uma diferença na expressão de $B d n f$ em relação aos estágios de sono no hipocampo (Tabela 4) $(F=5,47 ; d f=2 ; p=0,011)$. Nessa direção, o SOL apresenta expressão significativamente menor que o SREM $(p=0,049)$ e a vigília $(p=0,013)$. Por outro lado, não foi observado efeito da exposição (Tabela 3) $(F=0,35 ; d f=1 ; p=0560)$ nem da interação entre sono e exposição (Figura 15A) $(F=0,17 ; d f=2 ; p=0,983)$.

O perfil de expressão de $B d n f$ no córtex somestésico é diferente do hipocampo. Não observamos diferença na expressão de $B d n f$ entre os estágios de sono (Tabela 5) $(F=0,17 ; d f=2 ; p=0,882)$ e não ocorreu interação entre os dois fatores (Figura 15B) $(F=2,44 ; d f=2 ; p=0,109)$. Por outro lado observamos efeito significativo da exposição (Tabela 3$)(F=33,33 ; d f=1 ; p<0,001)$. 


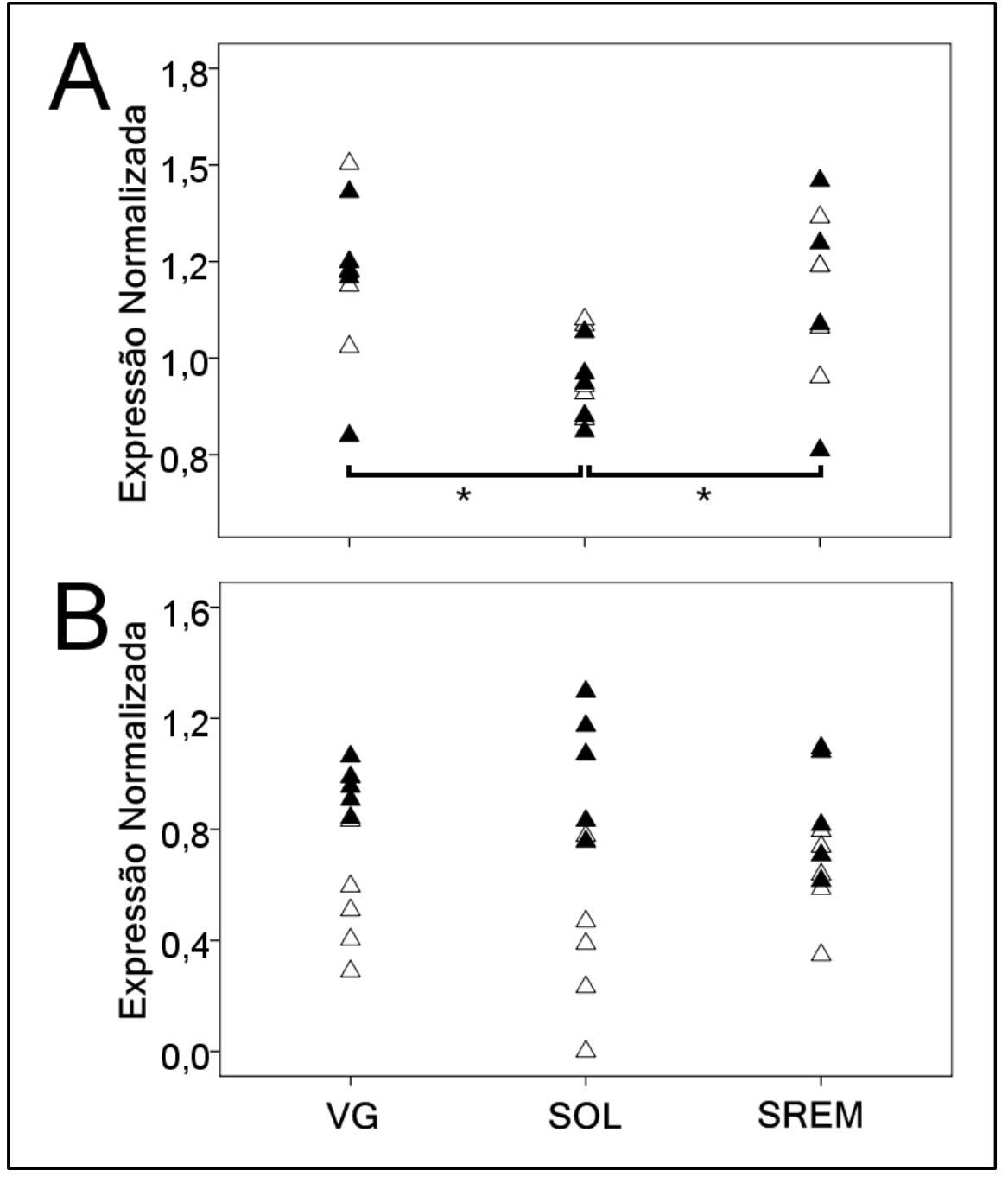

Figura 15 - Expressão do gene Bdnf determinada por PCR em tempo real no (A) hipocampo e (B) córtex somestésico de ratos. ${ }^{*} p<0,05$. VG: Vigília; SOL: sono de ondas lentas; SREM: sono REM. $(\triangle)$ Animais controle $(\mathbf{\Delta})$ Animais expostos.

\subsubsection{Camk4}

A expressão de Camk4 não foi modulada por nenhuma das condições estudadas. Dessa maneira, não encontramos efeito do estágio de sono (Tabela 4) $(F=5,64 ; d f=2 ; p=0,499)$, da exposição (Tabela 3) $(F=1,14 ; d f=1 ; p=0,297)$, ou da interação dos dois fatores no hipocampo (Figura 16A) $(F=2,59 ; d f=2 ; p=0,097)$. Similarmente, não se encontrou o efeito da exposição (Tabela 3$)(F=0,47$; $d f=1 ; p=0,500)$, do estágio de sono (Tabela 5) $(F=0,28 ; d f=2 ; p=0,756)$ ou da interação (Figura 16B) $(F=1,25 ; d f=2 ; p=0,304)$ no córtex somestésico. 


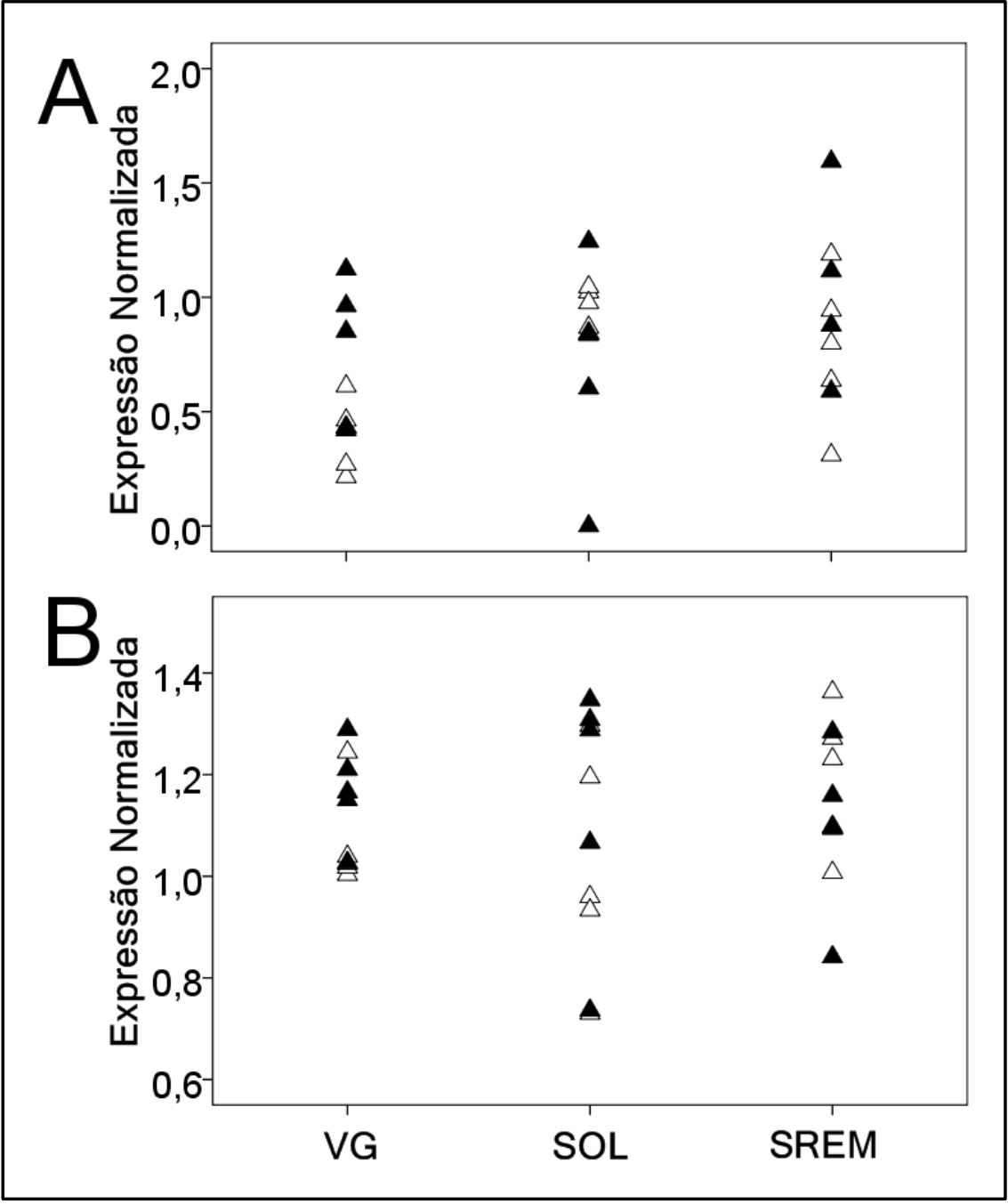

Figura 16 - Expressão do gene Camk4 determinada por PCR em tempo real no (A) hipocampo e (B) córtex somestésico de ratos. VG: Vigília; SOL: sono de ondas lentas; SREM: sono REM. ( $\triangle$ ) Animais controle $(\mathbf{\Delta})$ Animais expostos.

\subsubsection{Creb1}

A expressão de Crebl era modulada no hipocampo pela exposição ao ambiente enriquecido (Tabela 3) $(F=8,07 ; d f=1 ; p=0,009)$ e pela interação entre exposição e estágio de sono (Figura 17A) $(F=4,88 ; d f=2 ; p=0,017)$; porém, não era modulada pelo sono (Tabela 4$)(F=0,92 ; d f=2 ; p=0,414)$. Os animais pertencentes aos grupos VE e RE apresentam expressão de Crebl significativamente maior que o grupo $\mathrm{VC}$.

No córtex somestésico, não observamos efeito da exposição (Tabela 3) $(F=1,50 ; d f=1 ; p=0,233)$, estágio de sono (Tabela 5) $(F=0,08 ; d f=2 ; 0,927)$ ou interação entre eles (Figura 17B) $(F=2,04$; $d f=2 ; p=0,153)$ na expressão de Crebl. 


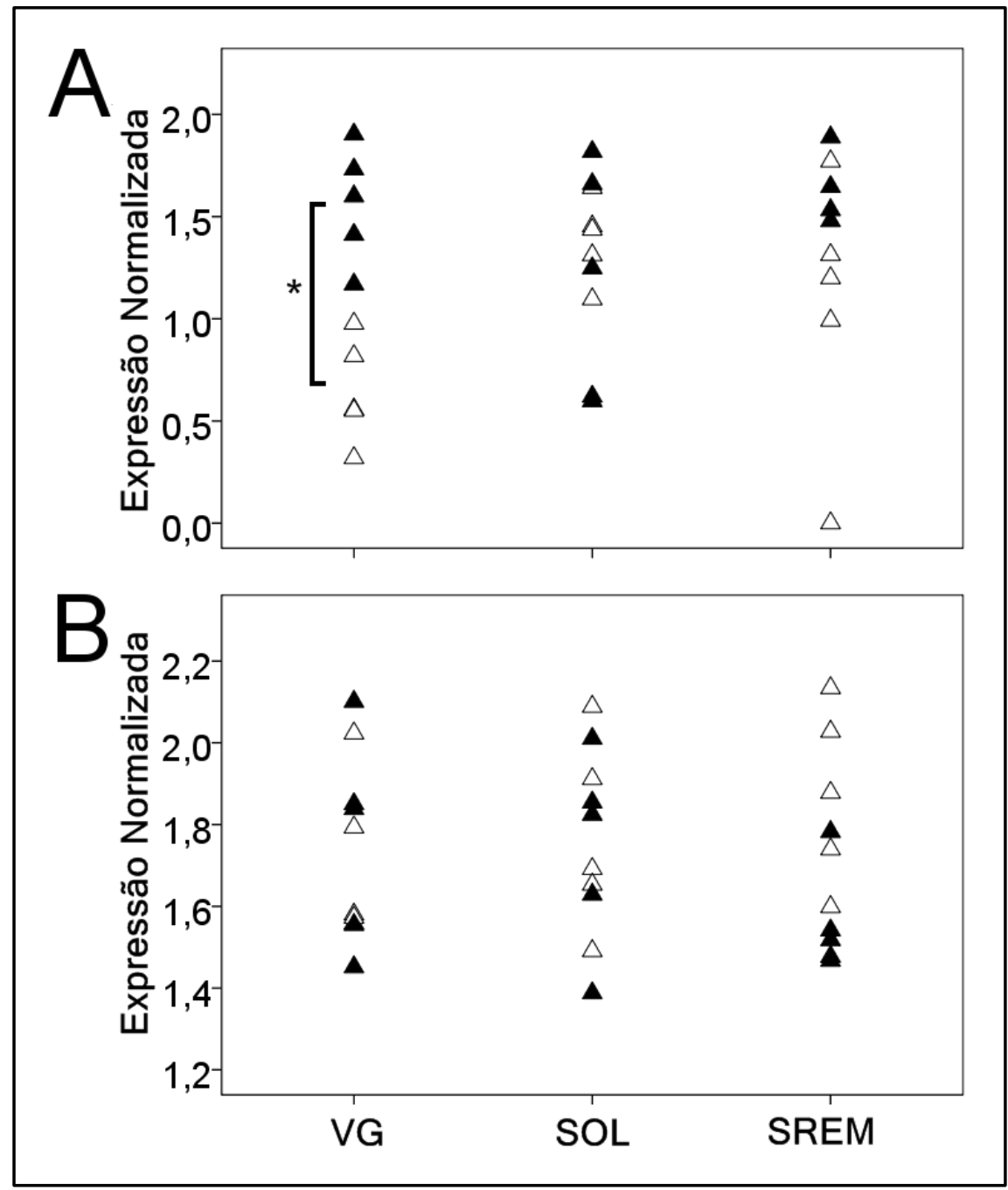

Figura 17 - Expressão do gene Creb1 determinada por PCR em tempo real no (A) hipocampo e (B) córtex somestésico de ratos. ${ }^{*} p<0,05$. VG: Vigília; SOL: sono de ondas lentas; SREM: sono REM. $(\triangle)$ Animais controle $(\mathbf{\Delta})$ Animais expostos.

\subsubsection{Egr1}

Observamos que a expressão de Egrl no hipocampo foi afetada pela exposição ao ambiente enriquecido (Tabela 3$)(F=18,76 ; d f=1 ; p<0,001)$. Similarmente, a expressão desse gene foi modulada pela interação entre a exposição e o estágio de sono do rato (Figura 18A) $(F=9,87 ; d f=2$; $p=0,001)$. No entanto não observamos o efeito isolado do estágio de sono (Tabela 4$)(F=2,97 ; d f=2$; $p=0,071)$. Os grupos VE, SE e RE apresentaram expressão significativamente maior que o grupo VC e o grupo RE, maior que RC.

No córtex somestésico, observamos o efeito da exposição (Tabela 3) $(F=11,03 ; d f=1 ; p=0,003)$. Entretanto não encontramos efeito do sono (Tabela 5) $(F=0,24 ; d f=2 ; p=0,786)$ ou da interação entre os dois fatores (Figura 18B) $(F=1,88 ; d f=2 ; p=0,175)$. 


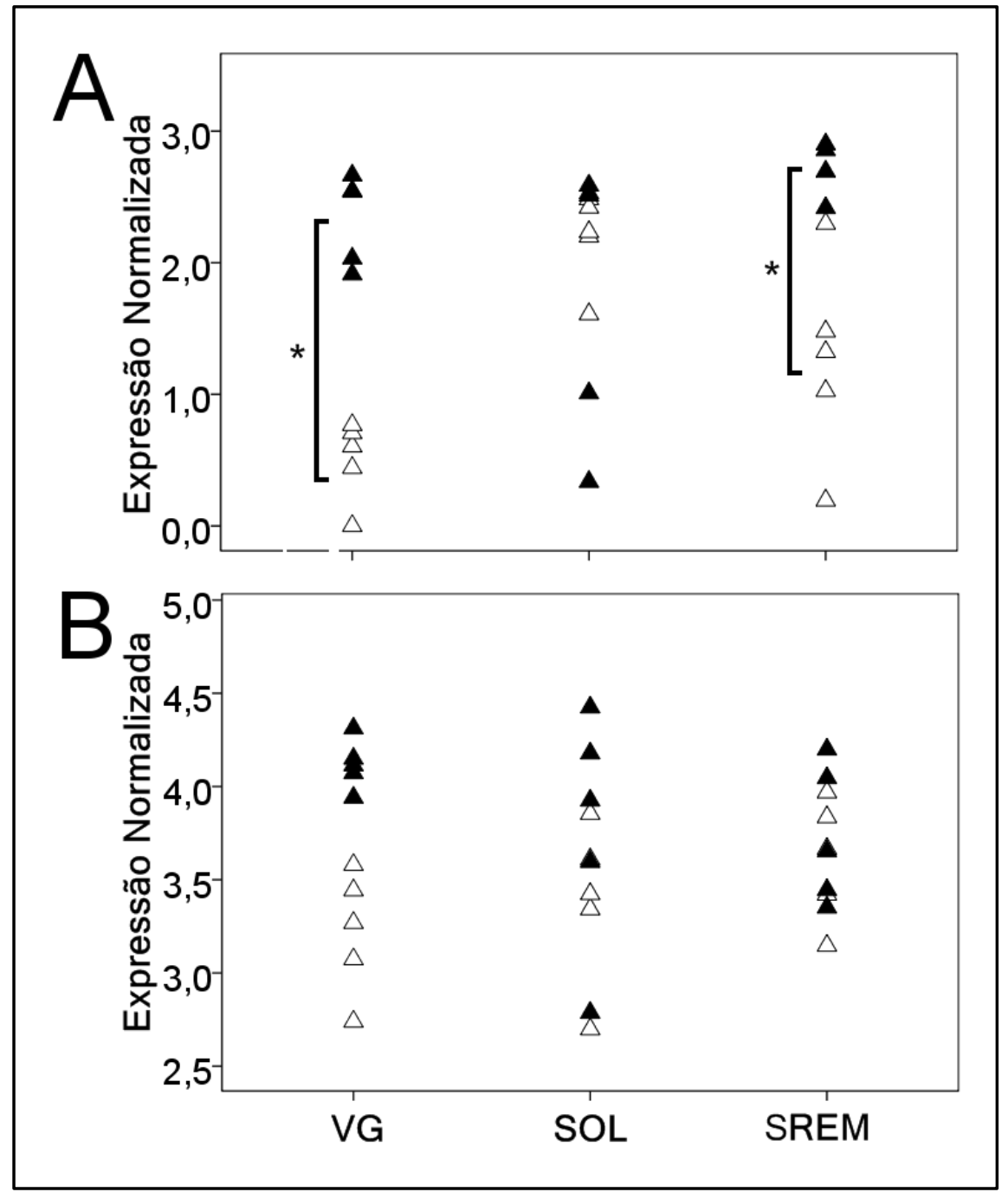

Figura 18 - Expressão do gene Egr1 determinada por PCR em tempo real no (A) hipocampo e (B) córtex somestésico de ratos. ${ }^{*} p<0,05$. VG: Vigília; SOL: sono de ondas lentas; SREM: sono REM. $(\triangle)$ Animais controle $(\mathbf{\Delta})$ Animais expostos.

\subsubsection{Egr2}

A expressão do gene $E g r 2$ foi modulada pelo ambiente enriquecido no hipocampo $(F=76,67 ; d f=1$; $p<0,001)$ e no córtex somestésico $(F=58,44 ; d f=1 ; p<0,001)$ (Tabela 3). Contudo, não foi modulada por sono no hipocampo (Tabela 4) $(F=0,29 ; d f=2 ; p=0,748)$ e córtex somestésico (Tabela 5) $(F=0,30 ; d f=2 ; p=0,744)$. Também não foi observada modulação da expressão de $E g r 2$ pela interação entre os dois fatores em ambas as regiões (Figura 19) (hipocampo $F=0,57 ; d f=2 ; p=0,573$; córtex $F=2,36 ; d f=2 ; p=0,116)$.

É importante salientar que a expressão de Egr2 no hipocampo é muito baixa, ficando no limiar de detecção do ensaio. A variabilidade observada foi grande e em três amostras não foi detectada a 
expressão de Egr2 (duas amostras VC e uma amostra RC). Contudo, a reprodutibilidade nas amostras provenientes do córtex somestésico era satisfatória devido a uma maior expressão basal.

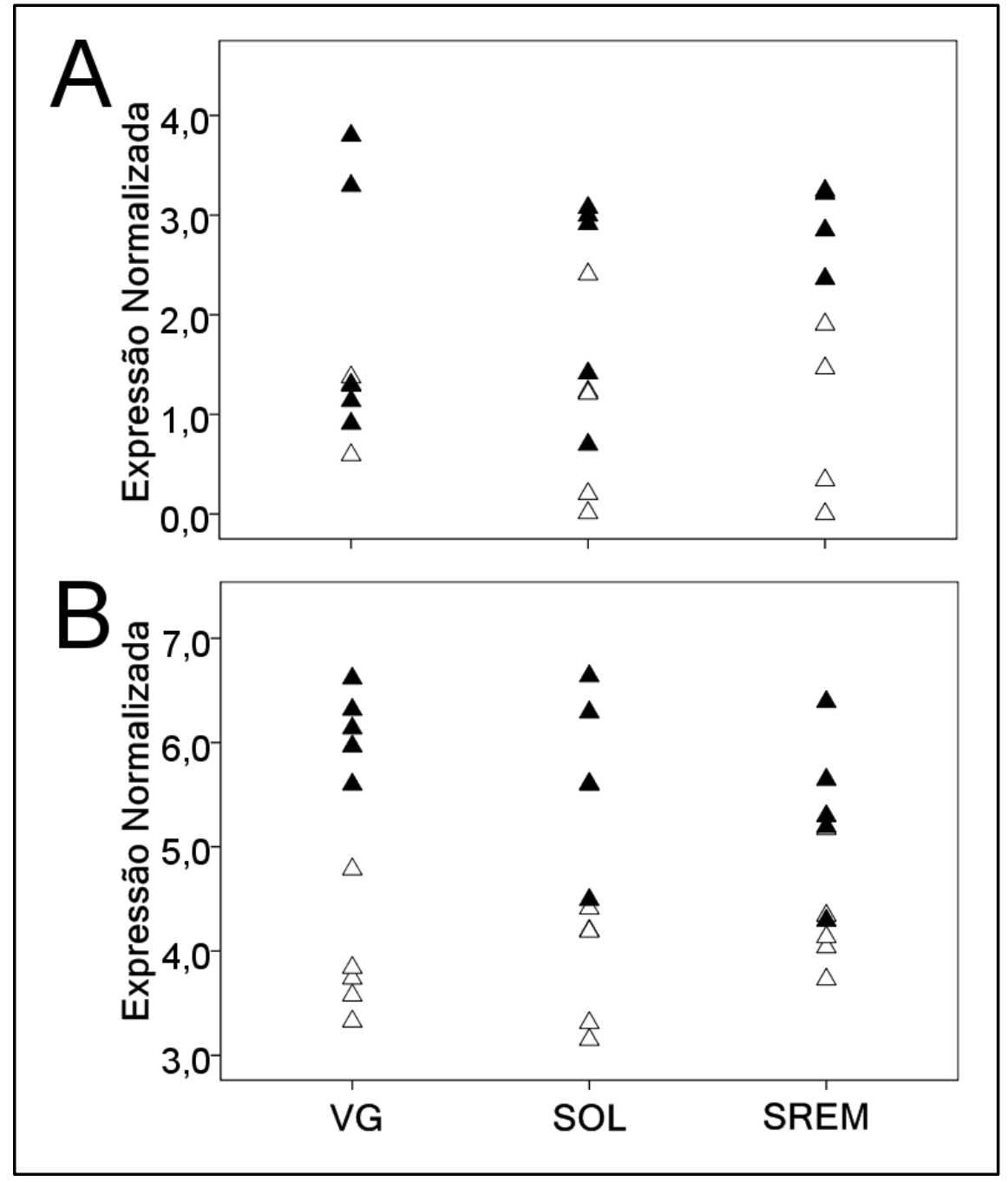

Figura 19 - Expressão do gene Egr2 determinada por PCR em tempo real no (A) hipocampo e (B) córtex somestésico de ratos. VG: Vigília; SOL: sono de ondas lentas; SREM: sono REM. ( $\triangle$ ) Animais controle $(\mathbf{\Delta})$ Animais expostos.

\subsubsection{Fos}

Observamos que o nível expressão de Fos no hipocampo foi dependente da exposição ao ambiente enriquecido (Tabela 3$)(F=40,77 ; d f=1 ; p<0,001)$. Além disso, esse nível de expressão teve efeito da interação entre a exposição e o sono (Figura 20A) $(F=7,01 ; d f=2 ; p=0,004)$, sem ser modulado pelo fator sono isoladamente (Tabela 4) $(F=0,51 ; d f=2 ; p=0,609)$. Em relação à interação, os grupos VE, SE e RE apresentaram expressão de Fos significativamente maior que o grupo VC. A expressão de Fos estava aumentada nos grupos VE e RE em comparação ao grupo RC. Por fim, o grupo VE apresentou expressão significativamente maior que o grupo SC. 


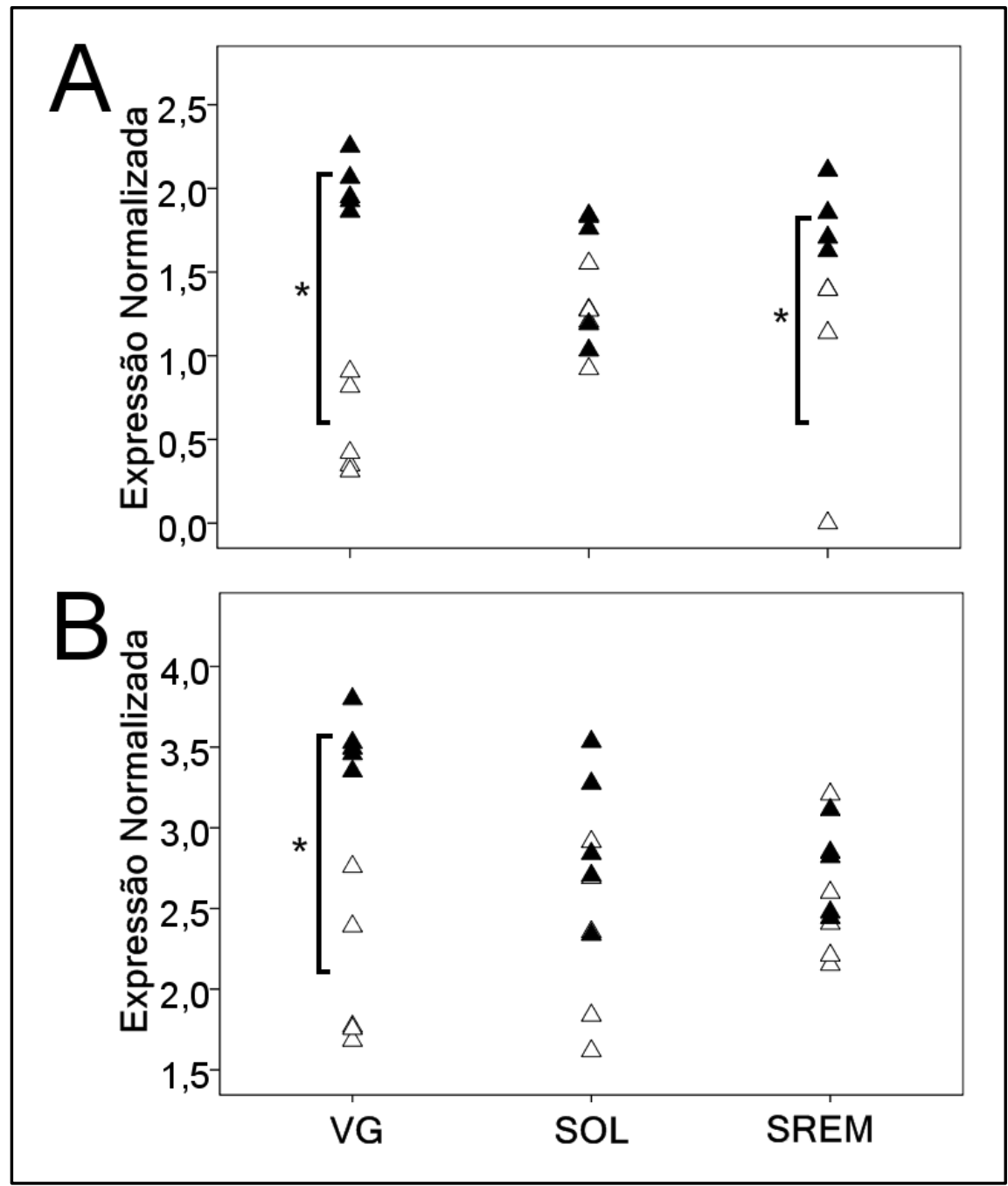

Figura 20 - Expressão do gene Fos determinada por PCR em tempo real no (A) hipocampo e (B) córtex somestésico de ratos. ${ }^{*} p<0,05$. VG: Vigília; SOL: sono de ondas lentas; SREM: sono REM. $(\triangle)$ Animais controle $(\mathbf{\Delta})$ Animais expostos.

No córtex somestésico, observamos um efeito significante em relação à exposição (Tabela 3) ( $F=$ $26,13 ; d f=1 ; p<0,001)$ e à interação entre os fatores (Figura 20B) $(F=5,60 ; d f=2 ; p=0,010)$, mas sem efeito do sono (Tabela 5) $(F=0,62 ; d f=2 ; p=0,545)$. A interação se dá pelo aumento de expressão de Fos no grupo SE em relação à VC e, do grupo VE em relação aos grupos controles (VC, SC, RC).

\subsubsection{Nr4a1}

Nossos achados mostraram que a expressão de $\mathrm{Nr} 4 a \mathrm{l}$ é modulada pela exposição no hipocampo (Tabela 3) $(F=6,02 ; d f=1 ; p=0,032)$. Também foi encontrada uma interação entre exposição e estágio de sono (Figura 21A) $(F=7,86 ; d f=2 ; p=0,003)$, porém não observamos o efeito do estágio de sono $($ Tabela 4$)(F=1,18 ; d f=2 ; p=0,326)$. 


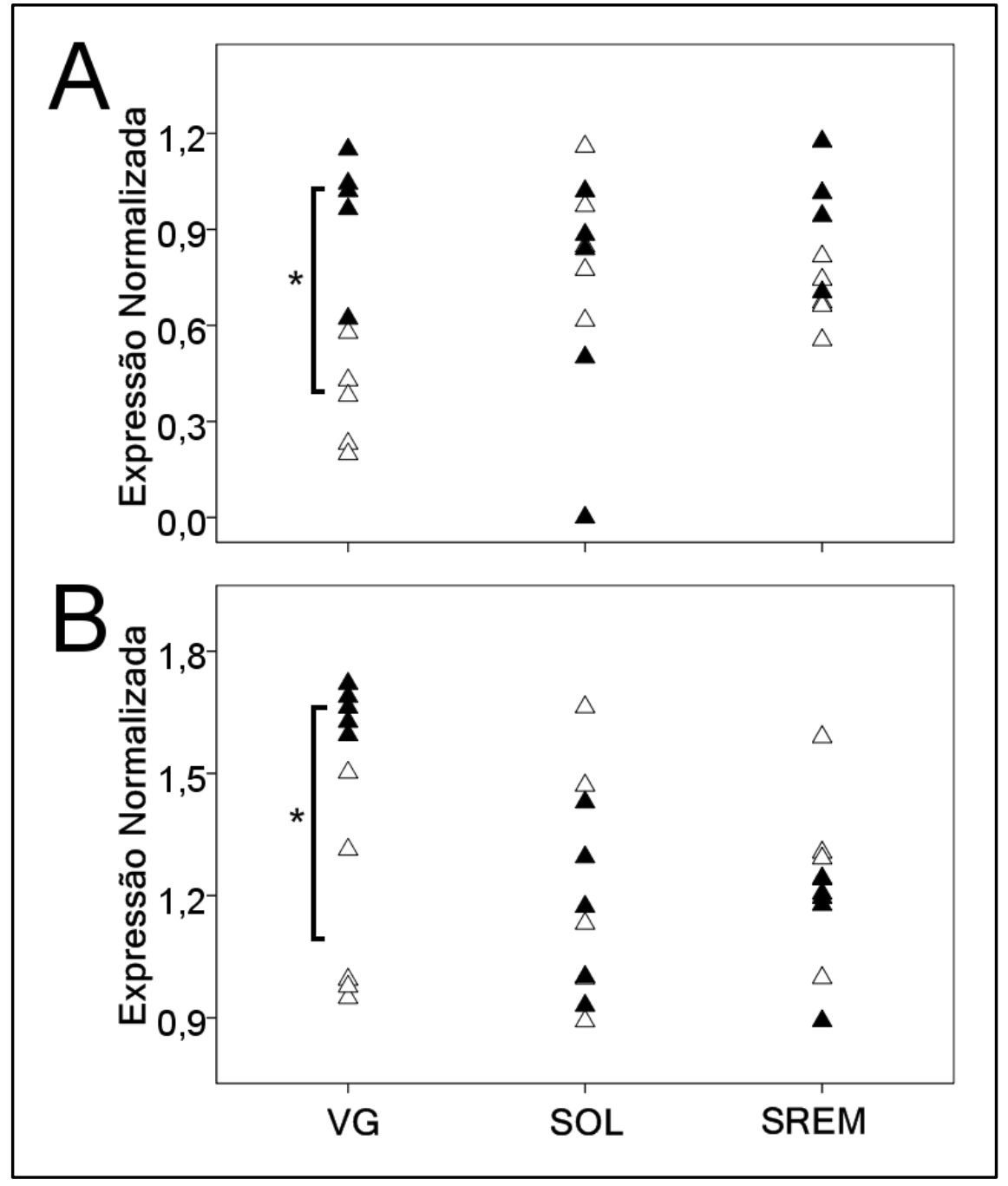

Figura 21 - Expressão do gene Nr4a1 determinada por PCR em tempo real no (A) hipocampo e (B) córtex somestésico de ratos. ${ }^{*} p<0,05$. VG: Vigília; SOL: sono de ondas lentas; SREM: sono REM. $(\triangle)$ Animais controle $(\mathbf{\Delta})$ Animais expostos.

No córtex somestésico, não observamos efeito da exposição (Tabela 3$)(F=1,66 ; d f=1 ; p=0,210)$ ou do estágio de sono (Tabela 5) $(F=2,82 ; d f=2 ; 0,080)$. No entanto, a interação entre os dois fatores foi significante (Figura 21B) $(F=6,95 ; d f=2 ; p=0,004)$.

Tanto no hipocampo quanto no córtex somestésico, o grupo VE apresentou aumento na expressão de $N r 4 a 1$ em relação ao grupo VC. Os níveis de $N r 4 a l$ encontravam-se elevados em RE em relação à VC no hipocampo. Por fim, o $N r 4 a 1$ foi significativamente mais expresso em VE que em SC no córtex somestésico.

\subsubsection{Ppp2ca}

Nossos resultados indicam que o nível de $P p p 2 c a$ teve efeito da exposição ao ambiente enriquecido (Tabela 3) $(F=4,70 ; d f=1 ; p=0,041)$ e da interação entre a exposição e o sono (Figura 22A) 
$(F=10,85 ; d f=2 ; p<0,001)$, entretanto, não houve efeito isolado do estágio de sono (Tabela 4) ( $F=0,48 ; d f=2, p=0,62)$. A expressão de $P p p 2 c a$ foi significantemente maior nos grupos VE e RE em relação ao grupo VC e do grupo RE em comparação ao grupo VC. Por fim, encontramos uma tendência de RE ser maior que RC.

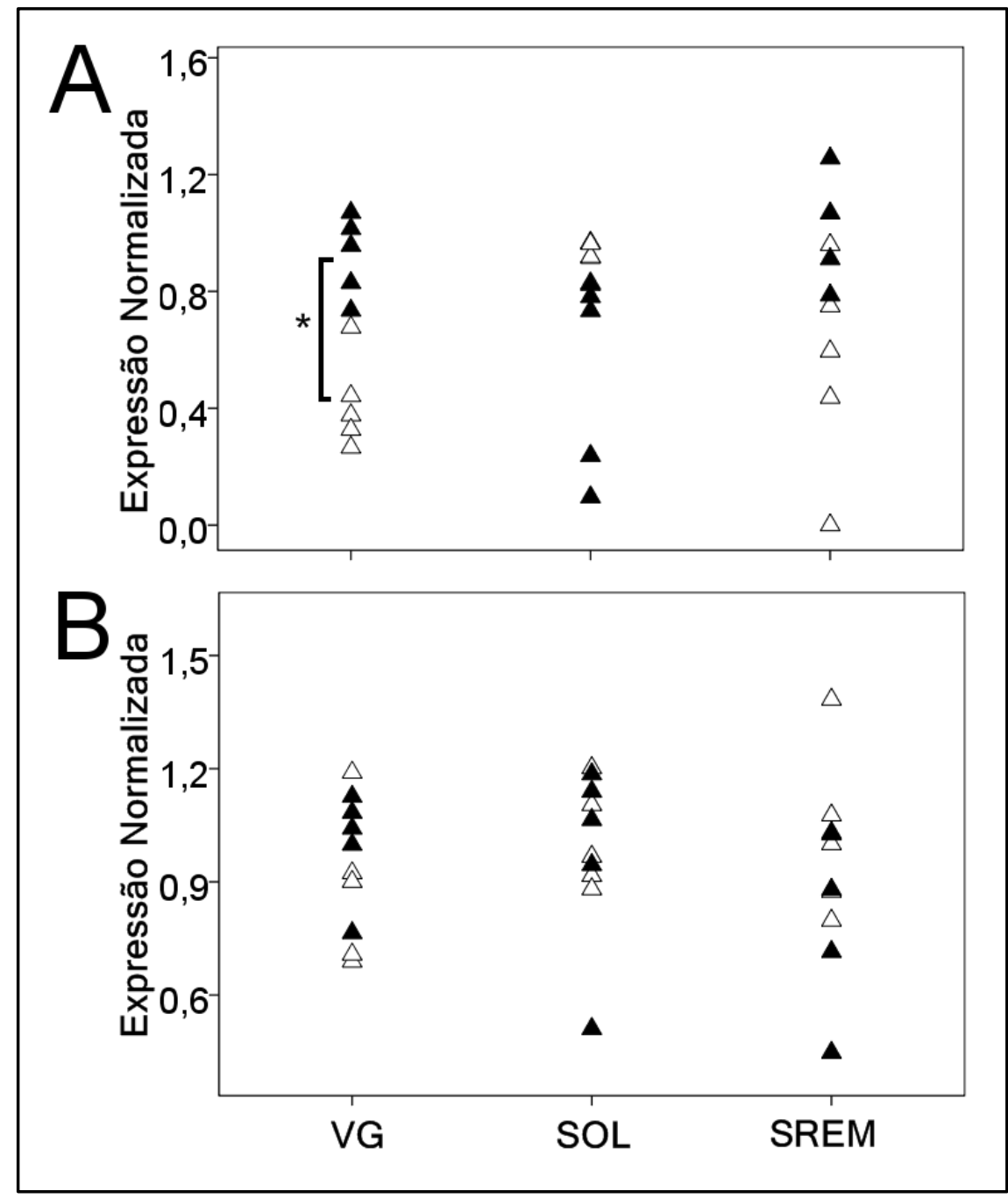

Figura 22 - Expressão do gene Ppp2ca determinada por PCR em tempo real no (A) hipocampo e (B) córtex somestésico de ratos. ${ }^{*} p<0,05$. VG: Vigília; SOL: sono de ondas lentas; SREM: sono REM. $(\triangle)$ Animais controle $(\boldsymbol{\Delta})$ Animais expostos.

Não observamos efeitos da exposição (Tabela 3$)(F=0,32 ; d f=1 ; p=0,575)$, estágio de sono (Tabela 5) $(F=0,28 ; d f=2 ; p=0,756)$ ou interação entre os fatores (Figura 22B) $(F=1,52 ; d f=2 ; p=0,239)$ no córtex somestésico.

\subsubsection{Ppp2r2d}

A exposição ao ambiente enriquecido aumentou significantemente a expressão do gene $\operatorname{Ppp} 2 r 2 d$ (Tabela 3) $(F=10,23 ; d f=1 ; p=0,004)$. Observamos uma tendência de efeito do sono (Tabela 4) 
$(F=3,39 ; d f=2 ; p=0,051)$ e uma interação significativa entre os dois fatores (Figura 23A) $(F=5,63$; $d f=2 ; p=0,010)$. A interação se dá pelo aumento de expressão desse gene no grupo RE em comparação à VC e RC. Por fim, VE tende a ser maior que o grupo VC.

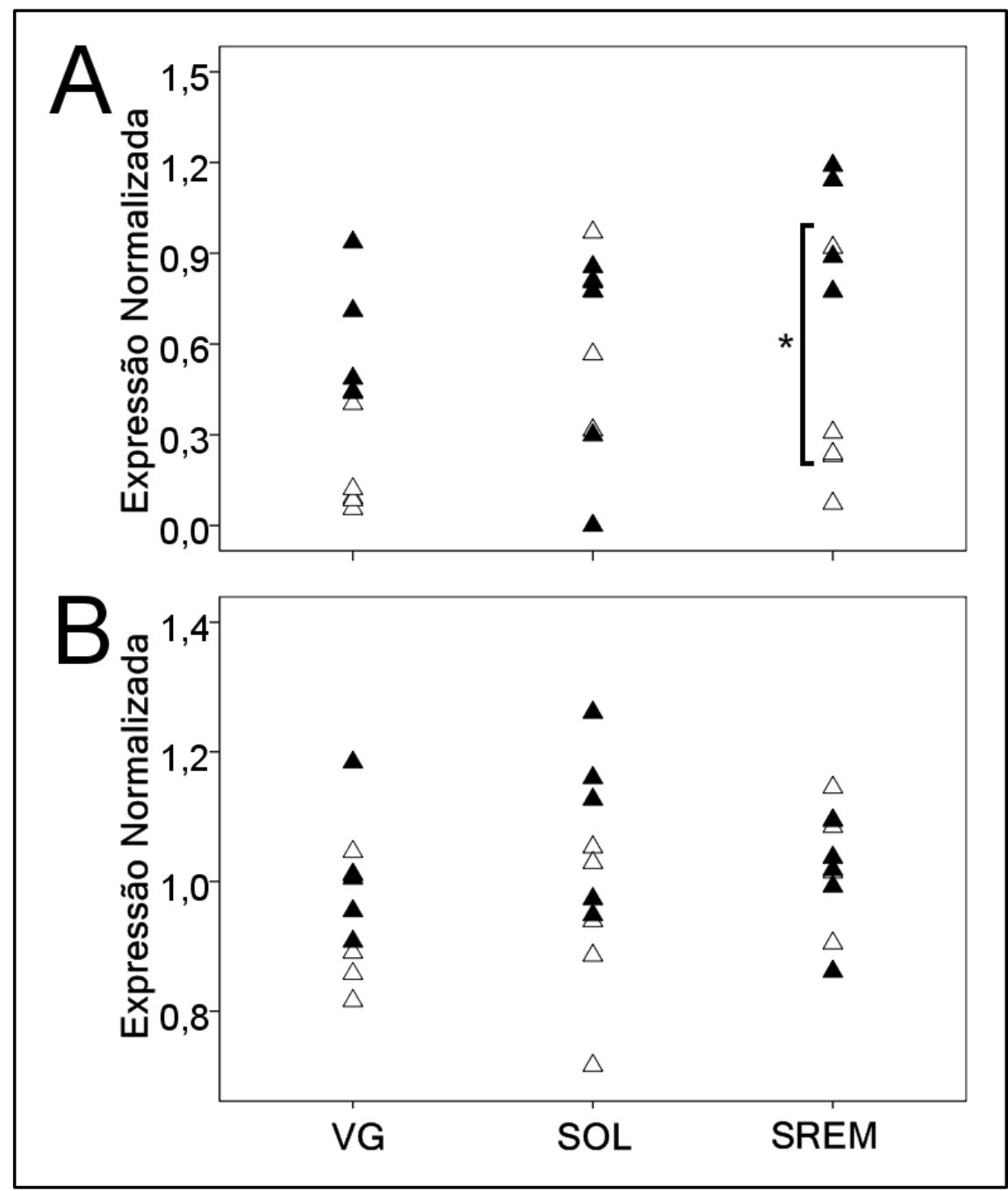

Figura 23 - Expressão do gene Ppp2r2d determinada por PCR em tempo real no (A) hipocampo e (B) córtex somestésico de ratos. ${ }^{*} p<0,05$. VG: Vigília; SOL: sono de ondas lentas; SREM: sono REM. $(\triangle)$ Animais controle $(\boldsymbol{\Delta})$ Animais expostos.

Não foram observados efeitos da exposição (Tabela 3) $(F=3,03 ; d f=1 ; p=0,095)$, estágio de sono (Tabela 5) $(F=0,71 ; d f=2 ; p=0,504)$ ou interação entre os fatores (Figura 23B) $(F=2,50 ; d f=2$; $p=0,104)$ no córtex somestésico. 


\section{Discussão}

\subsection{Exposição ao ambiente enriquecido e a expressão de genes relacionados à plasticidade}

No presente trabalho mostramos a modulação na expressão dos genes $\operatorname{Ppp} 2 r 2 d, \operatorname{Ppp} 2 r 2 c a, N r 4 a 1$, Fos, Egrl, Egr2, Crebl, Bdnf e Arc em tecido cerebral de ratos após breve exposição a um ambiente enriquecido (Tabela 3). Diversas linhas de evidência demonstram que o enriquecimento ambiental promove a plasticidade neuronal (HEBB, 1949; RONNBACK et al., 2005; KITANISHI et al., 2009). O incremento na plasticidade é comprovado pelo aumento na espessura do córtex, da arborização dendrítica, neurogênese, sinaptogênese, indução de LTP e LTD e melhora no desempenho de tarefas de memória após a exposição ao ambiente enriquecido (RONNBACK et al., 2005; NICHOLLS et al., 2008). Corroborando nossos achados, ratos mantidos em um ambiente enriquecido apresentavam aumento na expressão de Egrl Fos, Arc, Bdnf e CREB e esse aumento estava associado a melhoras em testes de memória espacial ou aversiva e à indução da LTP (FALKENBERG et al., 1992; NIKOLAEV et al., 2002; HUANG et al., 2006; TOSCANO; MCGLOTHAN; GUILARTE, 2006; KITANISHI et al., 2009). A exposição a um ambiente enriquecido promove aumento no número de espinhas dendríticas grandes e uma redução nas pequenas em células com expressão de ARC (KITANISHI et al., 2009) e aumento no número de novos neurônios expressando Egrl e Fos no hipocampo (TASHIRO; MAKINO; GAGE, 2007). Camundongos nocaute para $B d n f$ não apresentaram aumento na neurogênese (ROSSI et al., 2006) e possuem um menor aumento no número de espinhas dendríticas causadas por ambiente enriquecido que o animal selvagem (ZHU et al., 2009). O presente trabalho é o primeiro a demonstrar que enriquecimento ambiental influencia a expressão de subunidades da PP2A (Tabela 3). Diversas evidências sugerem que a PP2A exerce um papel central na indução da LTD (WINDER; SWEATT, 2001; NICHOLLS et al., 2008). No sistema nervoso a PP2A se localiza próximo às sinapses e associa-se a microtúbulos (VIQUEZ et al., 2006). Além disso, foi demonstrado que uma subunidade regulatória B' da PP2A em drosófila é necessária para o crescimento e morfologia normais da sinapse (VIQUEZ et al., 2006). À luz desses fatos sugerimos que as alterações na expressão do gene que codifica para a subunidade catalítica (Ppp2ca) e, principalmente, do gene que codifica para a subunidade regulatória B' delta (Ppp2r2d) seriam chave para as modificações morfológicas e no padrão de atividade neuronal observados após a exposição ao ambiente enriquecido. 


\subsection{A expressão de Bdnf é modulada pelo sono}

Nossos resultados mostram que os níveis de $B d n f$ estão aumentados no hipocampo durante o SREM e a VG em relação ao SOL (Figura 15A, Tabela 4), sem efeito da exposição (Tabela 3). O aumento nos níveis de $B d n f$ pode indicar o acumulo da expressão desse gene durante os estágios com dessincronização do EEG e uma redução durante o SOL. Na mesma linha, a injeção de BDNF aumenta a DP durante o SOL e injeção de anticorpos anti-BDNF acarretam no efeito oposto. Huber et al. (2007) relataram que os níveis de BDNF estão correlacionados com a atividade exploratória e ao DP no córtex de ratos adultos. Ontogeneticamente foi observado que os níveis de BDNF começam a responder à privação de sono no mesmo período pós-natal (P20) que a DP (HAIRSTON et al., 2004). Por fim, a administração intraventricular de BDNF em ratos aumenta a duração de SOL, sem afetar o SREM, entretanto o mesmo procedimento em coelhos, além de induzir o SOL, também induziu SREM (KUSHIKATA et al., 1999). Dada a relação entre DP e a intensidade e necessidade de sono (FARAGUNA et al., 2008) foi proposto que BDNF poderia estar implicado na regulação da homeostase do sono (FARAGUNA et al., 2008). Foi sugerido que o papel do BDNF na regulação da homeostase estaria intimamente ligado ao seu papel na plasticidade (FARAGUNA et al., 2008). No entanto essa ligação nos parece improvável em luz da ausência de efeito da exposição no hipocampo (Tabela 3). Por fim, é importante considerar que observamos o efeito da exposição (associado à plasticidade) no córtex (Tabela 3) e efeito do sono no hipocampo (Tabela 4), mas não foi observada interação entre os dois fatores em nenhuma das duas regiões (Figura 15). Essa dicotomia entre as duas regiões pode ser reflexo de erro tipo I (falso positivo) e necessita de mais investigações.

\subsection{A plasticidade sináptica está alterada durante o sono}

No presente trabalho demonstramos que a expressão dos genes Arc (Figura 14), Crebl (Figura 17), Egrl (Figura 18), Fos (Figura 20), Nr4al (Figura 21), Ppp2ca (Figura 22) e Ppp2r2d (Figura 23) foi induzida por exposição ao ambiente enriquecido, sendo modulada pelo sono. A expressão desses genes, com exceção de Ppp2r2d, apresentou um aumento após a exposição durante a VG (Figuras $14,17,18,20,21,22,23)$. Essa observação é consoante aos dados de privação de sono que demonstram um aumento na expressão de genes relacionados à plasticidade sináptica após momentos extensos de VG (O'HARA et al., 1993; CIRELLI; TONONI, 2000a; b; TAISHI et al., 2001; CIRELLI et al., 2004; TERAO et al., 2006; HUBER et al., 2007; TERAO et al., 2008). Ademais a expressão de Egrl e Arc está aumentada em animais que foram privados de sono por 
gentle handling e exposição a objetos novos em relação a animais que ficaram o mesmo tempo em VG espontânea. (CIRELLI; TONONI, 2000a; b).

Os nossos experimentos revelaram que a exposição ao ambiente enriquecido gera um aumento na expressão de Egrl (Figura 18), Fos (Figura 20) e Ppp2r2d (Figura 23) durante SREM. Similarmente, a expressão dos genes Arc (Figura 14), Crebl (Figura 17), Nr4al (Figura 21) e Ppp2ca (Figura 22) foi maior no grupo RE em relação à VC. Esses resultados sugerem uma forte reindução para Ppp2r2d, Egrl e Fos e uma mais fraca para os outros genes durante o SREM. Nossos resultados corroboram achados anteriores que demonstraram a reindução na expressão de Arc, Egrl, e da forma fosforilada da proteína CREB durante SREM após a exposição a um ambiente enriquecido, treinamento em tarefa comportamental ou indução de LTP no hipocampo (RIBEIRO et al., 1999; RIBEIRO et al., 2002; RIBEIRO et al., 2004a; ULLOOR; DATTA, 2005; DATTA et al., 2008). Entretanto essas observações estão em desacordo com resultados de privação de sono (O'HARA et al., 1993; CIRELLI; TONONI, 2000b; a; TAISHI et al., 2001; CIRELLI et al., 2004; TERAO et al., 2006; HUBER et al., 2007; TERAO et al., 2008).

Acreditamos que a explicação da dicotomia entre os nossos resultados e aqueles de privação de sono está intrinsecamente ligada às abordagens experimentais utilizadas. Nesse sentido Tononi e Cirelli (2006, tradução nossa) afirmaram que

[...] mudanças plásticas ocorrerão durante toda a vida em vigília, mesmo que não estivermos em alerta ou fazendo escolhas comportamentais, engajados ou não em paradigmas de aprendizado. Afinal sinapses e neurônios não sabem se eles estão engajados em paradigmas de aprendizado, mas apenas se um forte disparo présináptico é acompanhado de uma despolarização pós-sináptica ou o disparo na presença de níveis apropriados de neuromoduladores.

Com essa afirmação justificam a ausência de manipulações na plasticidade sináptica ou uso de testes comportamentais nos experimentos propostos pelo grupo. Nós não concordamos com essa posição. Apesar de não ser necessário um treinamento específico para que adquiramos informações a respeito do ambiente que nos cerca, é claro que animais ou seres humanos que foram criados em situações propícias ao aprendizado, como o paradigma de enriquecimento ambiental, apresentam maior flexibilidade no comportamento e alterações na fisiologia e morfologia do sistema nervoso central (HEBB, 1949; GIUDITTA et al., 1995; VAN PRAAG; KEMPERMANN; GAGE, 2000). Outro ponto que consideramos importante para a diferença observada é a ausência de separação dos estados de sono nos trabalhos que utilizaram privação de sono. Nessa direção durante o SOL e SREM os animais apresentam características diferentes no comportamento, variáveis fisiológicas (p. ex. termorregulação) e, principalmente, nos padrões eletrofisiológicos (TIMO-IARIA et al., 1970; 
GOTTESMANN, 1996; FANSELOW; NICOLELIS, 1999; RIBEIRO et al., 2002). Há um número crescente de evidências mostrando que ambos os estágios são importantes para a consolidação de memórias. Por fim, cada estágio tem sido associado à consolidação de diferentes características do estímulo e de diferentes tarefas (STICKGOLD et al., 2000b; FOGEL et al., 2007; SCHABUS, 2009). O SOL corresponde a aproximadamente $80 \%$ de toda a duração do sono nos mamíferos (Figura 11A) (TIMO-IARIA et al., 1970; FRANK et al., 2001). Nesse sentido, ao se comparar animais privados de sono a outros cujo sono foi ad libitum, o que está sendo comparado é a influência do SOL. Dessa maneira o que foi observado nos trabalhos de privação de sono é a diminuição nos níveis de genes relacionados à plasticidade influenciada pelo SOL.

Fos e Egrl são genes imediatos ativados pela sinalização intracelular por $\mathrm{Ca}^{2+}$. Em resposta ao aumento do nível de cálcio intracelular foi observado um aumento na ativação da CAMK2 seguido pela via da MAPK. A ativação dessa via cumularia na fosforilação de CREB que por sua vez induziria a um aumento na expressão de Fos e Egrl. Nessa direção resultados preliminares de Pereira et al. (2009) sugerem um aumento na fosforilação (ativação) de CAMK2 no primeiro episódio de SREM no giro denteado do hipocampo após a exposição a um ambiente enriquecido. Similarmente, a expressão de pCREB estava aumentada após um protocolo comportamental de esquiva ativa de duas vias e correlacionada ao tempo SREM após a indução de ondas PGO (ULLOOR; DATTA, 2005; DATTA et al., 2008).

Observamos um aumento significante da expressão de Crebl após a exposição ao ambiente enriquecido durante a VG, porém durante o SREM o efeito foi modesto (Figura 18). CREB é considerado um fator de transcrição constitutivo (HERDEGEN; LEAH, 1998), ou seja, cuja regulação é feita principalmente por modificações pós-traducionais. Esses achados mostram que a expressão de Crebl também pode ser induzida após estimulação, porém o efeito pequeno na expressão de Crebl durante o SREM reforça a necessidade das modificações pós-traducionais na ativação de CREB.

O achado mais importante do presente trabalho foi a indução de Ppp2r2d durante o SREM, e da Ppp2ca durante a VG. A expressão de Ppp2r2d foi maior no grupo RE em relação aos grupos VC e RC. Por outro lado, a expressão de Ppp2ca foi maior nos grupos VE e RE em relação ao VC. Ao nosso conhecimento, esse é o primeiro trabalho que demonstra alterações na expressão de subunidades de PP2A em relação ao ciclo sono-vigília em mamíferos. O aumento na expressão das subunidades de PP2A poderia ser mediado via CREB. Nessa direção foi observado que a expressão de Ppp2ca em células T é ativada por pCREB (SUNAHORI; JUANG; TSOKOS, 2009). Ademais, 
mutações nos genes que codificam para a PP2A e CREB bloqueiam a indução do sono por novidade na mosca da fruta (GANGULY-FITZGERALD et al., 2006). No entanto trabalhos adicionais serão necessários para elucidar os mecanismos que promovem alterações no nível de expressão das subunidades da PP2A durante o sono e quais são os impactos dessa maior expressão gênica nos níveis da proteína. É necessário salientar que em nosso trabalho os grupos designados como SREM também apresentavam momentos de SOL e VG e que escolhemos apenas um intervalo de tempo após o evento de interesse $(30 \mathrm{~min})$ para medir os níveis de expressão gênica. Portanto não podemos excluir a possibilidade de o SOL também influenciar a expressão dos genes analisados.

A reindução na expressão de genes que codificam para a PP2A, uma proteína relacionada à indução de LTD (WINDER; SWEATT, 2001; NICHOLLS et al., 2008), sugere que durante SREM ocorram fenômenos de diminuição na força sináptica em algumas redes neurais. Essa indução ocorreria em paralelo ao aumento de força sináptica em outras redes como demonstrado pelo aumento na expressão de genes relacionados à LTP, tais como Fos e Egrl (HERDEGEN; LEAH, 1998; ALBERINI, 2009). A modulação da plasticidade nos dois sentidos é essencial para o processamento e armazenamento de informações no sistema nervoso central (JONES et al., 2001; NICHOLLS et al., 2008). Outras evidências que a plasticidade sináptica é potencializada e deprimida concomitantemente durante o sono foram observadas no protocolo de privação de luz monocular em gatos recém-nascidos. Foi observado que a privação monocular promove indução de LTD no córtex visual contralateral ao olho privado (HEYNEN et al., 2003) e de LTP no córtex ipsilateral (SAWTELL et al., 2003). Similarmente a privação total de sono ou privação seletiva a SREM promove uma diminuição no tamanho dos neurônios do núcleo geniculado lateral que recebem projeções do olho ocluído (POMPEIANO; POMPEIANO; CORVAJA, 1995; OKSENBERG et al., 1996). Por outro lado a inibição das ondas PGO promove um aumento no tamanho dos neurônios do núcleo geniculado lateral do olho não-ocluído (SHAFFERY et al., 1999). Por fim, foi observado que seis horas de sono após igual tempo de privação monocular no escuro promovem aumento na dominância ocular de maneira semelhante ao mesmo tempo de privação monocular efetiva (animal acordado mantido em ambiente iluminado) (FRANK et al., 2001).

Dados os tempos pós-exposição e pós-sono utilizados observamos que a expressão dos genes relacionados à plasticidade sináptica é primariamente modulada no hipocampo após os primeiros ciclos de sono. Especificamente, observamos que a exposição ao ambiente enriquecido foi efetiva para induzir a expressão de oito dos 10 genes analisados (Arc, Creb1, Egr1, Egr2, Fos, Nr4al, Ppp2ca, Ppp2r2d) (Tabela 3) no hipocampo enquanto no córtex apenas 5 foram modulados (Arc, 
Bdnf, Egrl, Egr2, Fos) (Tabela 3). Além disso, não observamos a reindução da expressão dos genes relacionados à plasticidade neural durante o sono REM no córtex. Foi demonstrado que a expressão de Egrl após a indução de LTP na via perforante medial do hipocampo se concentrava inicialmente em regiões hipocampais e com a progressão dos ciclos de sono era transferida para o córtex cerebral (RIBEIRO et al., 2002). Diferentes linhas de evidência mostram que, apesar dos diversos tipos de memória inicialmente dependerem do hipocampo, tais memórias gradualmente se tornam independentes dessa estrutura e passam a depender progressivamente mais do córtex cerebral para um armazenamento de longa duração (SCOVILLE; MILNER, 1957; ZOLA-MORGAN; SQUIRE, 1993; BORN et al., 2006). Nessa linha de idéias diversos pesquisadores sugerem que o sono seja um momento propício para a transmissão e consolidação de informações do hipocampo para o córtex (RIBEIRO et al., 2002; BORN et al., 2006). Portanto essa transmissão pode ser causada pelo aumento nos níveis de expressão de genes relacionados à plasticidade no córtex ao longo dos diversos ciclos de sono (RIBEIRO et al., 2002).

Atualmente, duas teorias estão sendo discutidas em relação a como o sono promove a consolidação de memórias dependentes do hipocampo. Uma assume que a melhora na memória é uma consequência indireta de uma redução global na conectividade sináptica induzida pela atividade oscilatória lenta durante o SOL, que aumenta a razão sinal ruído para informação recém-codificada (TONONI; CIRELLI, 2003). A outra teoria assume que a consolidação de memórias envolve uma reativação das memórias recém-codificadas no hipocampo durante o SOL, promovendo flutuações no nível de $\mathrm{Ca}^{2+}$ levando a alteração nas cascatas de sinalização. Esse passo seria seguido por alterações estruturais durante o SREM levando a um aumento na conectividade nas sinapses ativas e reduzindo a conectividade nas sinapses inativas para armazenamento de memórias de longa duração (RIBEIRO; NICOLELIS, 2004). Os resultados apresentados aqui reforçam a teoria que sugere uma reativação na atividade cerebral durante o sono e, pela primeira vez, mostram evidências experimentais que a potencialização e depressão da plasticidade sináptica ocorrem concomitantemente durante o sono. 


\section{Conclusão}

Demonstramos que a exposição a um ambiente enriquecido promove um aumento na expressão de Nr4al, Fos, Egrl, Egr2, Crebl, Bdnf e Arc, e pela primeira vez de Ppp2r2d, Ppp2r2ca, em cérebro de ratos adultos. Esses genes têm um papel central na plasticidade sináptica dependente de atividade. Na mesma direção foi demonstrado que são importantes para a reorganização da estrutural do sistema nervoso. Portanto a indução desses genes pode ser chave para as modificações morfológicas e na atividade neuronal observadas após a exposição ao ambiente enriquecido.

Mostramos que a expressão de $B d n f$ no hipocampo está aumentada durante os estágios caracterizados pela dessincronização da atividade elétrica do encéfalo (VG e SREM). Essa observação sugere que $B d n f$ se acumula durante esses estágios e reduz durante o SOL. Portanto $B d n f$ poderia ser um marcador da homeostase do sono. Uma vez que a exposição ao ambiente enriquecido foi ineficaz para modular a expressão de $B d n f$ sugerimos que o papel desse gene/proteína na homeostase do sono deve estar dissociado do seu papel na plasticidade sináptica.

Por fim, o nosso trabalho mostra que ocorre a reindução de genes relacionados potencialização sináptica durante SREM (Egrl, Fos). E, pela primeira vez, mostra a reindução de um gene $($ Ppp2r2d) que codifica para uma proteína relacionada à depressão da atividade sináptica (PP2A). Esses resultados reforçam a necessidade de uma reativação na atividade cerebral durante o sono e, pela primeira vez, mostram evidências experimentais que a potencialização e a depressão da plasticidade sináptica ocorrem concomitantemente durante o sono. 


\section{Referências ${ }^{14}$}

AICARDI, G.; ARGILlI, E.; CAPPELlO, S.; SANTI, S.; RICCIO, M.; THOENEN, H.; CANOSSA, M. Induction of long-term potentiation and depression is reflected by corresponding changes in secretion of endogenous brain-derived neurotrophic factor. Proc Natl Acad Sci U S A, v. 101, n. 44, p. 15788-15792, 2004.

ALBERINI, C. M. Transcription factors in long-term memory and synaptic plasticity. Physiol Rev, v. 89, n. 1, p. 121-145, 2009.

AMBROSINI, M. V.; SADILE, A. G.; GIRONI CARNEVALE, U. A.; MATTIACCIO, A.; GIUDITTA, A. The sequential hypothesis on sleep function. II. A correlative study between sleep variables and newly synthesized brain DNA. Physiol Behav, v. 43, n. 3, p. 339-350, 1988.

AMIN, E.; PEARCE, J. M.; BROWN, M. W.; AGGLETON, J. P. Novel temporal configurations of stimuli produce discrete changes in immediate-early gene expression in the rat hippocampus. Eur J Neurosci, v. 24, n. 9, p. 2611-2621, 2006.

ASERINSKY, E.; KLEITMAN, N. Regularly occurring periods of eye motility, and concomitant phenomena, during sleep. Science, v. 118, n. 3062, p. 273-274, 1953.

ATON, S. J.; SEIBT, J.; DUMOULIN, M.; JHA, S. K.; STEINMETZ, N.; COLEMAN, T.; NAIDOO, N.; FRANK, M. G. Mechanisms of sleep-dependent consolidation of cortical plasticity. Neuron, v. 61, n. 3, p. 454-466, 2009.

BADING, H.; SEGAL, M. M.; SUCHER, N. J.; DUDEK, H.; LIPTON, S. A.; GREENBERG, M. E. N-methyl-D-aspartate receptors are critical for mediating the effects of glutamate on intracellular calcium concentration and immediate early gene expression in cultured hippocampal neurons. Neuroscience, v. 64, n. 3, p. 653-664, 1995.

BARRIGA-IBARS, C.; RODRIGUEZ-MORATINOS, A. B.; ESTEBAN, S.; RIAL, R. V. Interrelaciones entre el sueno y el estado inmune. Rev Neurol, v. 40, n. 9, p. 548-556, 2005.

BAUMGARTEL, K.; GENOUX, D.; WELZL, H.; TWEEDIE-CULLEN, R. Y.; KOSHIBU, K.; LIVINGSTONE-ZATCHEJ, M.; MAMIE, C.; MANSUY, I. M. Control of the establishment of aversive memory by calcineurin and Zif268. Nat Neurosci, v. 11, n. 5, p. 572-578, 2008.

BEERSMA, D. G.; GORDIJN, M. C. Circadian control of the sleep-wake cycle. Physiol Behav, v. 90, n. 2-3, p. 190-195, 2007.

BELMEGUENAI, A.; HANSEL, C. A role for protein phosphatases 1, 2A, and 2B in cerebellar long-term potentiation. J Neurosci, v. 25, n. 46, p. 10768-10772, 2005.

BENINGTON, J. H.; FRANK, M. G. Cellular and molecular connections between sleep and synaptic plasticity. Prog Neurobiol, v. 69, n. 2, p. 71-101, 2003.

\footnotetext{
${ }^{14}$ De acordo com a Associação Brasileira de Normas Técnicas. NBR 6023.
} 
BERGER, H. Über das elektrenkephalogramm des Menschen. Arch Psychiatr Nervenkr, v. 87 , n., p. 527-570, 1929.

BERTAINA, V.; DESTRADE, C. Differential time courses of c-fos mRNA expression in hippocampal subfields following acquisition and recall testing in mice. Brain Res Cogn Brain Res, v. 2, n. 4, p. 269-275, 1995.

BEUCKMANN, C. T.; YANAGISAWA, M. Orexins: from neuropeptides to energy homeostasis and sleep/wake regulation. J Mol Med, v. 80, n. 6, p. 329-342, 2002.

BITO, H.; DEISSEROTH, K.; TSIEN, R. W. CREB phosphorylation and dephosphorylation: a $\mathrm{Ca}(2+)$ - and stimulus duration-dependent switch for hippocampal gene expression. Cell, v. 87, n. 7, p. 1203-1214, 1996.

BOBILlIER, P.; SAKAI, F.; SEGUIN, S.; JOUVET, M. Deprivation of paradoxical sleep and in vitro cerebral protein synthesis in the rat. Life Sci II, v. 10, n. 23, p. 1349-1357, 1971.

BORBELY, A. A. A two process model of sleep regulation. Hum Neurobiol, v. 1, n. 3, p. 195-204, 1982

BORN, J.; RASCH, B.; GAIS, S. Sleep to remember. Neuroscientist, v. 12, n. 5, p. 410-424, 2006.

BOURTCHULADZE, R.; FRENGUELLI, B.; BLENDY, J.; CIOFFI, D.; SCHUTZ, G.; SILVA, A. J. Deficient long-term memory in mice with a targeted mutation of the cAMPresponsive element-binding protein. Cell, v. 79, n. 1, p. 59-68, 1994.

BRAMHAM, C. R.; WORLEY, P. F.; MOORE, M. J.; GUZOWSKI, J. F. The immediate early gene arc/arg3.1: regulation, mechanisms, and function. J Neurosci, v. 28, n. 46, p. 11760-11767, 2008.

BUNNEY, J. N.; POTKIN, S. G. Circadian abnormalities, molecular clock genes and chronobiological treatments in depression. Br Med Bull, v. 86, n., p. 23-32, 2008.

CARTWRIGHT, R. D. The role of sleep in changing our minds: a psychologist's discussion of papers on memory reactivation and consolidation in sleep. Learn Mem, v. 11, n. 6, p. 660663, 2004.

CHAO, C. C.; MA, Y. L.; LEE, E. H. Protein kinase CK2 impairs spatial memory formation through differential cross talk with PI-3 kinase signaling: activation of Akt and inactivation of SGK1. J Neurosci, v. 27, n. 23, p. 6243-6248, 2007.

CHEN, C.; HARDY, M.; ZHANG, J.; LAHOSTE, G. J.; BAZAN, N. G. Altered NMDA receptor trafficking contributes to sleep deprivation-induced hippocampal synaptic and cognitive impairments. Biochem Biophys Res Commun, v. 340, n. 2, p. 435-440, 2006.

CIRELLI, C. A molecular window on sleep: changes in gene expression between sleep and wakefulness. Neuroscientist, v. 11, n. 1, p. 63-74, 2005. 
CIRELLI, C.; GUTIERREZ, C. M.; TONONI, G. Extensive and divergent effects of sleep and wakefulness on brain gene expression. Neuron, v. 41, n. 1, p. 35-43, 2004.

CIRELLI, C.; TONONI, G. Changes in anti-phosphoserine and anti-phosphothreonine antibody binding during the sleep-waking cycle and after lesions of the locus coeruleus. Sleep Res Online, v. 1, n. 1, p. 11-18, 1998.

CIRELLI, C.; TONONI, G. Differential expression of plasticity-related genes in waking and sleep and their regulation by the noradrenergic system. J Neurosci, v. 20, n. 24, p. 91879194., 2000a.

CIRELLI, C.; TONONI, G. Gene expression in the brain across the sleep-waking cycle. Brain Res, v. 885, n. 2, p. 303-321., 2000b.

COLE, A. J.; SAFFEN, D. W.; BARABAN, J. M.; WORLEY, P. F. Rapid increase of an immediate early gene messenger RNA in hippocampal neurons by synaptic NMDA receptor activation. Nature, v. 340, n. 6233, p. 474-476., 1989.

CONDORELLI, D. F.; DELL'ALBANI, P.; AMICO, C.; LUKASIUK, K.; KACZMAREK, L.; GIUFFRIDA-STELLA, A. M. Glutamate receptor-driven activation of transcription factors in primary neuronal cultures. Neurochem Res, v. 19, n. 4, p. 489-499, 1994.

DATTA, S. Avoidance task training potentiates phasic pontine-wave density in the rat: A mechanism for sleep-dependent plasticity. J Neurosci, v. 20, n. 22, p. 8607-8613, 2000.

DATTA, S.; LI, G.; AUERBACH, S. Activation of phasic pontine-wave generator in the rat: a mechanism for expression of plasticity-related genes and proteins in the dorsal hippocampus and amygdala. Eur J Neurosci, v. 27, n. 7, p. 1876-1892, 2008.

DAVIS, C. J.; MEIGHAN, P. C.; TAISHI, P.; KRUEGER, J. M.; HARDING, J. W.; WRIGHT, J. W. REM sleep deprivation attenuates actin-binding protein cortactin: a link between sleep and hippocampal plasticity. Neurosci Lett, v. 400, n. 3, p. 191-196, 2006.

DAVIS, S.; VANHOUTTE, P.; PAGES, C.; CABOCHE, J.; LAROCHE, S. The MAPK/ERK cascade targets both Elk-1 and cAMP response element-binding protein to control long-term potentiation-dependent gene expression in the dentate gyrus in vivo. J Neurosci, v. 20, n. 12, p. 4563-4572, 2000.

DESTENO, D. A.; SCHMAUSS, C. Induction of early growth response gene 2 expression in the forebrain of mice performing an attention-set-shifting task. Neuroscience, v. 152, n. 2, p. 417-428, 2008.

ECONOMO, C. V. Sleep as a problem of localization. J Nerv Ment Dis, v. 71, n. 3, p. 249259, 1930.

EYRE, M. D.; RICHTER-LEVIN, G.; AVITAL, A.; STEWART, M. G. Morphological changes in hippocampal dentate gyrus synapses following spatial learning in rats are transient.

Eur J Neurosci, v. 17, n. 9, p. 1973-1980, 2003. 
FALKENBERG, T.; MOHAMMED, A. K.; HENRIKSSON, B.; PERSSON, H.; WINBLAD, B.; LINDEFORS, N. Increased expression of brain-derived neurotrophic factor mRNA in rat hippocampus is associated with improved spatial memory and enriched environment. Neurosci Lett, v. 138, n. 1, p. 153-156, 1992.

FANSELOW, E. E.; NICOLELIS, M. A. Behavioral modulation of tactile responses in the rat somatosensory system. J Neurosci, v. 19, n. 17, p. 7603-7616, 1999.

FARAGUNA, U.; VYAZOVSKIY, V. V.; NELSON, A. B.; TONONI, G.; CIRELLI, C. A causal role for brain-derived neurotrophic factor in the homeostatic regulation of sleep. $\mathbf{J}$ Neurosci, v. 28, n. 15, p. 4088-4095, 2008.

FIGUROV, A.; BODDEKE, H.; MULLER, D. Enhancement of AMPA-mediated synaptic transmission by the protein phosphatase inhibitor calyculin A in rat hippocampal slices. Eur $\mathbf{J}$ Neurosci, v. 5, n. 8, p. 1035-1041, 1993.

FINKBEINER, S.; TAVAZOIE, S. F.; MALORATSKY, A.; JACOBS, K. M.; HARRIS, K. M.; GREENBERG, M. E. CREB: a major mediator of neuronal neurotrophin responses. Neuron, v. 19, n. 5, p. 1031-1047, 1997.

FLEISCHMANN, A.; HVALBY, O.; JENSEN, V.; STREKALOVA, T.; ZACHER, C.; LAYER, L. E.; KVELLO, A.; RESCHKE, M.; SPANAGEL, R.; SPRENGEL, R.; WAGNER, E. F.; GASS, P. Impaired long-term memory and NR2A-type NMDA receptordependent synaptic plasticity in mice lacking c-Fos in the CNS. J Neurosci, v. 23, n. 27, p. 9116-9122, 2003.

FOGEL, S. M.; SMITH, C. T.; COTE, K. A. Dissociable learning-dependent changes in REM and non-REM sleep in declarative and procedural memory systems. Behav Brain Res, v., n., p., 2007.

FRANK, M. G.; ISSA, N. P.; STRYKER, M. P. Sleep enhances plasticity in the developing visual cortex. Neuron, v. 30, n. 1, p. 275-287., 2001.

FRANKEN, P.; DIJK, D. J. Circadian clock genes and sleep homeostasis. Eur J Neurosci, v. 29, n. 9, p. 1820-1829, 2009.

FU, J.; LI, P.; OUYANG, X.; GU, C.; SONG, Z.; GAO, J.; HAN, L.; FENG, S.; TIAN, S.; HU, B. Rapid eye movement sleep deprivation selectively impairs recall of fear extinction in hippocampus-independent tasks in rats. Neuroscience, v. 144, n. 4, p. 1186-1192, 2007.

FUJIHARA, H.; SEI, H.; MORITA, Y.; UETA, Y.; MORITA, K. Short-term sleep disturbance enhances brain-derived neurotrophic factor gene expression in rat hippocampus by acting as internal stressor. J Mol Neurosci, v. 21, n. 3, p. 223-232, 2003.

FUKUNAGA, K.; MULLER, D.; OHMITSU, M.; BAKO, E.; DEPAOLI-ROACH, A. A.; MIYAMOTO, E. Decreased protein phosphatase 2A activity in hippocampal long-term potentiation. J Neurochem, v. 74, n. 2, p. 807-817, 2000.

FUKUSHIMA, H.; MAEDA, R.; SUZUKI, R.; SUZUKI, A.; NOMOTO, M.; TOYODA, H.; WU, L. J.; XU, H.; ZHAO, M. G.; UEDA, K.; KITAMOTO, A.; MAMIYA, N.; YOSHIDA, 
T.; HOMMA, S.; MASUSHIGE, S.; ZHUO, M.; KIDA, S. Upregulation of calcium/calmodulin-dependent protein kinase IV improves memory formation and rescues memory loss with aging. J Neurosci, v. 28, n. 40, p. 9910-9919, 2008.

GAAB, N.; PAETZOLD, M.; BECKER, M.; WALKER, M. P.; SCHLAUG, G. The influence of sleep on auditory learning: a behavioral study. Neuroreport, v. 15, n. 4, p. 731-734, 2004.

GANGULY-FITZGERALD, I.; DONLEA, J.; SHAW, P. J. Waking experience affects sleep need in Drosophila. Science, v. 313, n. 5794, p. 1775-1781, 2006.

GASS, J. T.; OLIVE, M. F. Transcriptional profiling of the rat frontal cortex following administration of the mGlu5 receptor antagonists MPEP and MTEP. Eur J Pharmacol, v. 584, n. 2-3, p. 253-262, 2008.

GHOSH, A.; GINTY, D. D.; BADING, H.; GREENBERG, M. E. Calcium regulation of gene expression in neuronal cells. J Neurobiol, v. 25, n. 3, p. 294-303, 1994.

GIUDITTA, A.; AMBROSINI, M. V.; MONTAGNESE, P.; MANDILE, P.; COTUGNO, M.; ZUCCONI, G. G.; VESCIA, S. The sequential hypothesis of the function of sleep. Behav Brain Res, v. 69, n. 1-2, p. 157-166, 1995.

GIUDITTA, A.; AMBROSINI, M. V.; SCARONI, R.; CHIURULLA, C.; SADILE, A. Effect of sleep on cerebral DNA synthesized during shuttle-box avoidance training. Physiol Behav, v. 34, n. 5, p. 769-778, 1985.

GIUDITTA, A.; RUTIGLIANO, B.; VITALE-NEUGEBAUER, A. Influence of synchronized sleep on the biosynthesis of RNA in two nuclear classes isolated from rabbit cerebral cortex. $\mathbf{J}$ Neurochem, v. 35, n. 6, p. 1259-1266, 1980.

GOTTESMANN, C. The transition from slow-wave sleep to paradoxical sleep: evolving facts and concepts of the neurophysiological processes underlying the intermediate stage of sleep. Neurosci Biobehav Rev, v. 20, n. 3, p. 367-387, 1996.

GRAVES, L. A.; HELLMAN, K.; VEASEY, S.; BLENDY, J. A.; PACK, A. I.; ABEL, T. Genetic evidence for a role of CREB in sustained cortical arousal. J Neurophysiol, v. 90, n. 2, p. 1152-1159, 2003.

GREENE, R.; SIEGEL, J. Sleep: a functional enigma. Neuromolecular Med, v. 5, n. 1, p. 59-68, 2004.

GUAN, Z.; PENG, X.; FANG, J. Sleep deprivation impairs spatial memory and decreases extracellular signal-regulated kinase phosphorylation in the hippocampus. Brain Res, v. 1018, n. 1, p. 38-47, 2004.

GUZMAN-MARIN, R.; YING, Z.; SUNTSOVA, N.; METHIPPARA, M.; BASHIR, T.; SZYMUSIAK, R.; GOMEZ-PINILLA, F.; MCGINTY, D. Suppression of hippocampal plasticity-related gene expression by sleep deprivation in rats. J Physiol, v. 575, n. Pt 3, p. 807-819, 2006. 
GUZOWSKI, J. F. Insights into immediate-early gene function in hippocampal memory consolidation using antisense oligonucleotide and fluorescent imaging approaches. Hippocampus, v. 12, n. 1, p. 86-104, 2002.

GUZOWSKI, J. F.; SETLOW, B.; WAGNER, E. K.; MCGAUGH, J. L. Experiencedependent gene expression in the rat hippocampus after spatial learning: a comparison of the immediate-early genes Arc, c-fos, and zif268. J Neurosci, v. 21, n. 14, p. 5089-5098, 2001.

HAIRSTON, I. S.; PEYRON, C.; DENNING, D. P.; RUBY, N. F.; FLORES, J.; SAPOLSKY, R. M.; HELLER, H. C.; O'HARA, B. F. Sleep deprivation effects on growth factor expression in neonatal rats: a potential role for BDNF in the mediation of delta power. J Neurophysiol, v. 91, n. 4, p. 1586-1595, 2004.

HANDA, R. J.; NUNLEY, K. M.; BOLLNOW, M. R. Induction of c-fos mRNA in the brain and anterior pituitary gland by a novel environment. Neuroreport, v. 4, n. 9, p. 1079-1082, 1993.

HEBB, D. O. The organization of behavior; a neuropsychological theory. New York: Wiley, 1949. xix, 335 p. p.

HELLEMANS, J.; MORTIER, G.; DE PAEPE, A.; SPELEMAN, F.; VANDESOMPELE, J. qBase relative quantification framework and software for management and automated analysis of real-time quantitative PCR data. Genome Biol, v. 8, n. 2, p. R19, 2007.

HENNEVIN, E.; HARS, B.; MAHO, C.; BLOCH, V. Processing of learned information in paradoxical sleep: relevance for memory. Behav Brain Res, v. 69, n. 1-2, p. 125-135., 1995.

HERDEGEN, T.; LEAH, J. D. Inducible and constitutive transcription factors in the mammalian nervous system: control of gene expression by Jun, Fos and Krox, and CREB/ATF proteins. Brain Res Brain Res Rev, v. 28, n. 3, p. 370-490, 1998.

HESS, U. S.; LYNCH, G.; GALL, C. M. Changes in c-fos mRNA expression in rat brain during odor discrimination learning: differential involvement of hippocampal subfields CA1 and CA3. J Neurosci, v. 15, n. 7 Pt 1, p. 4786-4795, 1995.

HEURTEAUX, C.; MESSIER, C.; DESTRADE, C.; LAZDUNSKI, M. Memory processing and apamin induce immediate early gene expression in mouse brain. Brain Res Mol Brain Res, v. 18, n. 1-2, p. 17-22, 1993.

HEYNEN, A. J.; YOON, B. J.; LIU, C. H.; CHUNG, H. J.; HUGANIR, R. L.; BEAR, M. F. Molecular mechanism for loss of visual cortical responsiveness following brief monocular deprivation. Nat Neurosci, v. 6, n. 8, p. 854-862, 2003.

HO, N.; LIAUW, J. A.; BLAESER, F.; WEI, F.; HANISSIAN, S.; MUGLIA, L. M.; WOZNIAK, D. F.; NARDI, A.; ARVIN, K. L.; HOLTZMAN, D. M.; LINDEN, D. J.; ZHUO, M.; MUGLIA, L. J.; CHATILA, T. A. Impaired synaptic plasticity and cAMP response element-binding protein activation in $\mathrm{Ca} 2+/$ calmodulin-dependent protein kinase type IV/Gr-deficient mice. J Neurosci, v. 20, n. 17, p. 6459-6472, 2000. 
HOBSON, J. A. Sleep is of the brain, by the brain and for the brain. Nature, v. 437, n. 7063, p. 1254-1256, 2005.

HU, P.; STYLOS-ALLAN, M.; WALKER, M. P. Sleep facilitates consolidation of emotional declarative memory. Psychol Sci, v. 17, n. 10, p. 891-898, 2006.

HUANG, F. L.; HUANG, K. P.; WU, J.; BOUCHERON, C. Environmental enrichment enhances neurogranin expression and hippocampal learning and memory but fails to rescue the impairments of neurogranin null mutant mice. J Neurosci, v. 26, n. 23, p. 6230-6237, 2006.

HUBER, R.; GHILARDI, M. F.; MASSIMINI, M.; TONONI, G. Local sleep and learning. Nature, v. 430, n. 6995, p. 78-81, 2004.

HUBER, R.; TONONI, G.; CIRELLI, C. Exploratory behavior, cortical BDNF expression, and sleep homeostasis. Sleep, v. 30, n. 2, p. 129-139, 2007.

HUGHES, P.; DRAGUNOW, M. Activation of pirenzepine-sensitive muscarinic receptors induces a specific pattern of immediate-early gene expression in rat brain neurons. Brain Res Mol Brain Res, v. 24, n. 1-4, p. 166-178, 1994.

HUMPHRIES, A.; WELlER, J.; KLEIN, D.; BALER, R.; CARTER, D. A. NGFI-B (Nurr77/Nr4a1) orphan nuclear receptor in rat pinealocytes: circadian expression involves an adrenergic-cyclic AMP mechanism. J Neurochem, v. 91, n. 4, p. 946-955, 2004.

INTERNATIONAL COMMITTEE ON STANDARDIZED GENETIC NOMENCLATURE FOR MICE; RAT GENOME AND NOMENCLATURE COMMITTEE. Guidelines for Nomenclature of Genes, Genetic Markers, Alleles, and Mutations in Mouse and Rat. 2009. Disponível em: <http://www.informatics.jax.org/mgihome/nomen/gene.shtml>. Acesso em: 25 dez. 2009

JENKINS, J. G.; DALLENBACH, K. M. Obliviscence during sleep and waking. Am J Psychol, v. 35, n., p. 605-612, 1924.

JONES, M. W.; ERRINGTON, M. L.; FRENCH, P. J.; FINE, A.; BLISS, T. V.; GAREL, S.; CHARNAY, P.; BOZON, B.; LAROCHE, S.; DAVIS, S. A requirement for the immediate early gene Zif268 in the expression of late LTP and long-term memories. Nat Neurosci, v. 4, n. 3, p. 289-296., 2001.

KANG-PARK, M. H.; SARDA, M. A.; JONES, K. H.; MOORE, S. D.; SHENOLIKAR, S.; CLARK, S.; WILSON, W. A. Protein phosphatases mediate depotentiation induced by highintensity theta-burst stimulation. J Neurophysiol, v. 89, n. 2, p. 684-690, 2003.

KANG, H.; SUN, L. D.; ATKINS, C. M.; SODERLING, T. R.; WILSON, M. A.; TONEGAWA, S. An important role of neural activity-dependent CaMKIV signaling in the consolidation of long-term memory. Cell, v. 106, n. 6, p. 771-783, 2001.

KARNI, A.; TANNE, D.; RUBENSTEIN, B. S.; ASKENASY, J. J.; SAGI, D. Dependence on REM sleep of overnight improvement of a perceptual skill. Science, v. 265, n. 5172, p. 679-682., 1994. 
KIM, E. Y.; EDERY, I. Balance between DBT/CKIepsilon kinase and protein phosphatase activities regulate phosphorylation and stability of Drosophila CLOCK protein. Proc Natl Acad Sci U S A, v. 103, n. 16, p. 6178-6183, 2006.

KITANISHI, T.; IKEGAYA, Y.; MATSUKI, N.; YAMADA, M. K. Experience-dependent, rapid structural changes in hippocampal pyramidal cell spines. Cereb Cortex, v. 19, n. 11, p. 2572-2578, 2009.

KLANN, E. Metaplastic protein phosphatases. Learn Mem, v. 9, n. 4, p. 153-155, 2002.

KNAPSKA, E.; KACZMAREK, L. A gene for neuronal plasticity in the mammalian brain: Zif268/Egr-1/NGFI-A/Krox-24/TIS8/ZENK? Prog Neurobiol, v. 74, n. 4, p. 183-211, 2004.

KUCZEWSKI, N.; PORCHER, C.; LESSMANN, V.; MEDINA, I.; GAIARSA, J. L. Activity-dependent dendritic release of BDNF and biological consequences. Mol Neurobiol, v. 39, n. 1, p. 37-49, 2009.

KURIYAMA, K.; STICKGOLD, R.; WALKER, M. P. Sleep-dependent learning and motorskill complexity. Learn Mem, v. 11, n. 6, p. 705-713, 2004.

KUSHIKATA, T.; FANG, J.; KRUEGER, J. M. Brain-derived neurotrophic factor enhances spontaneous sleep in rats and rabbits. Am J Physiol, v. 276, n. 5 Pt 2, p. R1334-1338, 1999.

LAM, B. Y.; ZHANG, W.; ENTICKNAP, N.; HAGGIS, E.; CADER, M. Z.; CHAWLA, S. Inverse regulation of plasticity-related immediate early genes by calcineurin in hippocampal neurons. J Biol Chem, v. 284, n. 18, p. 12562-12571, 2009.

LEE, K. H.; CHATILA, T. A.; RAM, R. A.; THOMPSON, R. F. Impaired memory of eyeblink conditioning in CaMKIV KO mice. Behav Neurosci, v. 123, n. 2, p. 438-442, 2009.

LEREA, L. S.; MCNAMARA, J. O. Ionotropic glutamate receptor subtypes activate c-fos transcription by distinct calcium-requiring intracellular signaling pathways. Neuron, v. 10, n. 1, p. 31-41, 1993.

LESKU, J. A.; ROTH, T. C., 2ND; AMLANER, C. J.; LIMA, S. L. A phylogenetic analysis of sleep architecture in mammals: the integration of anatomy, physiology, and ecology. Am Nat, v. 168, n. 4, p. 441-453, 2006.

LIN, J. T.; KORNHAUSER, J. M.; SINGH, N. P.; MAYO, K. E.; TAKAHASHI, J. S. Visual sensitivities of nur77 (NGFI-B) and zif268 (NGFI-A) induction in the suprachiasmatic nucleus are dissociated from c-fos induction and behavioral phase-shifting responses. Brain Res Mol Brain Res, v. 46, n. 1-2, p. 303-310, 1997.

LINDECKE, A.; KORTE, M.; ZAGREBELSKY, M.; HOREJSCHI, V.; ELVERS, M.; WIDERA, D.; PRULLAGE, M.; PFEIFFER, J.; KALTSCHMIDT, B.; KALTSCHMIDT, C. Long-term depression activates transcription of immediate early transcription factor genes: involvement of serum response factor/Elk-1. Eur J Neurosci, v. 24, n. 2, p. 555-563, 2006. 
LOOMIS, A. L.; HARVEY, E. N.; HOBART, G. A. Cerebral states during sleep, as studied by human brain potentials. J Exp Psychol, v. 21, n. 2, p. 127-144, 1937.

LOUIE, K.; WILSON, M. A. Temporally structured replay of awake hippocampal ensemble activity during rapid eye movement sleep. Neuron, v. 29, n. 1, p. 145-156., 2001.

LYNCH, M. A. Long-term potentiation and memory. Physiol Rev, v. 84, n. 1, p. 87-136, 2004.

MALENKA, R. C.; BEAR, M. F. LTP and LTD: an embarrassment of riches. Neuron, v. 44, n. 1, p. 5-21, 2004.

MALKANI, S.; ROSEN, J. B. Induction of NGFI-B mRNA following contextual fear conditioning and its blockade by diazepam. Brain Res Mol Brain Res, v. 80, n. 2, p. 153$165,2000 a$.

MALKANI, S.; ROSEN, J. B. Specific induction of early growth response gene 1 in the lateral nucleus of the amygdala following contextual fear conditioning in rats. Neuroscience, v. 97, n. 4, p. 693-702, 2000b.

MAQUET, P.; LAUREYS, S.; PEIGNEUX, P.; FUCHS, S.; PETIAU, C.; PHILLIPS, C.; AERTS, J.; DEL FIORE, G.; DEGUELDRE, C.; MEULEMANS, T.; LUXEN, A.; FRANCK, G.; VAN DER LINDEN, M.; SMITH, C.; CLEEREMANS, A. Experience-dependent changes in cerebral activation during human REM sleep. Nat Neurosci, v. 3, n. 8, p. 831836., 2000.

MARET, S.; DORSAZ, S.; GURCEL, L.; PRADERVAND, S.; PETIT, B.; PFISTER, C.; HAGENBUCHLE, O.; O'HARA, B. F.; FRANKEN, P.; TAFTI, M. Homer1a is a core brain molecular correlate of sleep loss. Proc Natl Acad Sci U S A, v. 104, n. 50, p. 20090-20095, 2007.

MARSHALL, L.; HELGADOTTIR, H.; MOLLE, M.; BORN, J. Boosting slow oscillations during sleep potentiates memory. Nature, v. 444, n. 7119, p. 610-613, 2006.

MCDERMOTT, C. M.; HARDY, M. N.; BAZAN, N. G.; MAGEE, J. C. Sleep deprivationinduced alterations in excitatory synaptic transmission in the CA1 region of the rat hippocampus. J Physiol, v. 570, n. Pt 3, p. 553-565, 2006.

MCNAUGHTON, B. L.; MIZUMORI, S. J.; BARNES, C. A.; LEONARD, B. J.; MARQUIS, M.; GREEN, E. J. Cortical representation of motion during unrestrained spatial navigation in the rat. Cereb Cortex, v. 4, n. 1, p. 27-39, 1994.

MELANDER GRADIN, H.; MARKLUND, U.; LARSSON, N.; CHATILA, T. A.; GULLBERG, M. Regulation of microtubule dynamics by Ca2+/calmodulin-dependent kinase IV/Gr-dependent phosphorylation of oncoprotein 18. Mol Cell Biol, v. 17, n. 6, p. 3459-3467, 1997.

MORRIS, M. E.; VISWANATHAN, N.; KUHLMAN, S.; DAVIS, F. C.; WEITZ, C. J. A screen for genes induced in the suprachiasmatic nucleus by light. Science, v. 279, n. 5356, p. 1544-1547, 1998. 
MORUZZI, G.; MAGOUN, H. W. Brain stem reticular formation and activation of the EEG. Electroencephalogr Clin Neurophysiol, v. 1, n. 4, p. 455-473, 1949.

MOTULSKY, H. Detecting Outliers. GraphPad Insight, v., n.14, 1997. Disponível em: <http://www.graphpad.com/articles/outlier.htm>. Acesso em: 20 Mai. 2009

NAKANISHI, H.; SUN, Y.; NAKAMURA, R. K.; MORI, K.; ITO, M.; SUDA, S.; NAMBA, H.; STORCH, F. I.; DANG, T. P.; MENDELSON, W.; MISHKIN, M.; KENNEDY, C.; GILLIN, J. C.; SMITH, C. B.; SOKOLOFF, L. Positive correlations between cerebral protein synthesis rates and deep sleep in Macaca mulatta. Eur J Neurosci, v. 9, n. 2, p. 271-279, 1997.

NELSON, S. E.; DURICKA, D. L.; CAMPBELL, K.; CHURCHILL, L.; KRUEGER, J. M. Homer1a and $1 \mathrm{bc}$ levels in the rat somatosensory cortex vary with the time of day and sleep loss. Neurosci Lett, v. 367, n. 1, p. 105-108, 2004.

NEUNER-JEHLE, M.; RHYNER, T. A.; BORBELY, A. A. Sleep deprivation differentially alters the mRNA and protein levels of neurogranin in rat brain. Brain Res, v. 685, n. 1-2, p. 143-153, 1995.

NICHOLLS, R. E.; ALARCON, J. M.; MALLERET, G.; CARROLL, R. C.; GRODY, M.; VRONSKAYA, S.; KANDEL, E. R. Transgenic mice lacking NMDAR-dependent LTD exhibit deficits in behavioral flexibility. Neuron, v. 58, n. 1, p. 104-117, 2008.

NIKOLAEV, E.; KACZMAREK, L.; ZHU, S. W.; WINBLAD, B.; MOHAMMED, A. H. Environmental manipulation differentially alters c-Fos expression in amygdaloid nuclei following aversive conditioning. Brain Res, v. 957, n. 1, p. 91-98, 2002.

NIKOLAEV, E.; KAMINSKA, B.; TISCHMEYER, W.; MATTHIES, H.; KACZMAREK, L. Induction of expression of genes encoding transcription factors in the rat brain elicited by behavioral training. Brain Res Bull, v. 28, n. 3, p. 479-484., 1992.

NISHIDA, M.; WALKER, M. P. Daytime naps, motor memory consolidation and regionally specific sleep spindles. PLoS ONE, v. 2, n., p. e341, 2007.

O'DELL, T. J.; KANDEL, E. R. Low-frequency stimulation erases LTP through an NMDA receptor-mediated activation of protein phosphatases. Learn Mem, v. 1, n. 2, p. 129-139, 1994.

O'HARA, B. F.; YOUNG, K. A.; WATSON, F. L.; HELLER, H. C.; KILDUFF, T. S. Immediate early gene expression in brain during sleep deprivation: preliminary observations. Sleep, v. 16, n. 1, p. 1-7, 1993.

OGITA, K.; YONEDA, Y. Selective potentiation of DNA binding activities of both activator protein 1 and cyclic AMP response element binding protein through in vivo activation of $\mathrm{N}$ methyl-D-aspartate receptor complex in mouse brain. J Neurochem, v. 63, n. 2, p. 525-534, 1994. 
OHMSTEDE, C. A.; JENSEN, K. F.; SAHYOUN, N. E. Ca2+/calmodulin-dependent protein kinase enriched in cerebellar granule cells. Identification of a novel neuronal calmodulindependent protein kinase. J Biol Chem, v. 264, n. 10, p. 5866-5875, 1989.

OKSENBERG, A.; SHAFFERY, J. P.; MARKS, G. A.; SPECIALE, S. G.; MIHAILOFF, G.; ROFFWARG, H. P. Rapid eye movement sleep deprivation in kittens amplifies LGN cell-size disparity induced by monocular deprivation. Brain Res Dev Brain Res, v. 97, n. 1, p. 51-61, 1996.

PAVLIDES, C.; WINSON, J. Influences of hippocampal place cell firing in the awake state on the activity of these cells during subsequent sleep episodes. J. Neurosci., v. 9, n. 8, p. 2907-2918., 1989.

PAXINOS, G.; WATSON, C. The Rat Brain in Stereotaxic Coordinates. San Diego: Academic Press, 1997. xxxiii, [78] of plates p.

PEREIRA, C. M.; COTA, V. R.; SANTOS, S.; DIAS, G.; SOUZA, A. C.; RIBEIRO, S.; NICOLELIS, M. A. L. Experience-dependent reactivation of the calcium signal transduction pathway in the rat hippocampus during sleep In: Neuroscience Meeting, 2009, Chicago: Proceedings. Chicago: Society for Neuroscience, 2009, Disponível em $<$ http://www.abstractsonline.com/plan/start.aspx?mkey $=\{081 F 7976-E 4 C D-4 F 3 D-A 0 A F-$ E8387992A658\}>. Acesso em 12 nov. 2009.

PI, H. J.; LISMAN, J. E. Coupled phosphatase and kinase switches produce the tristability required for long-term potentiation and long-term depression. J Neurosci, v. 28, n. 49, p. 13132-13138, 2008.

PINATO, G.; PEGORARO, S.; VISENTINI, M.; RUARO, M. E.; TORRE, V. Elevation of somatic $\mathrm{Ca} 2+$ upregulates genes Nr4a1 and Egr2, but not Bdnf and Arc. Neuroreport, v. 20, n. 9 , p. 869-874, 2009.

PINAUD, R. Experience-dependent immediate early gene expression in the adult central nervous system: evidence from enriched-environment studies. Int J Neurosci, v. 114, n. 3, p. 321-333, 2004.

POIRIER, R.; CHEVAL, H.; MAILHES, C.; CHARNAY, P.; DAVIS, S.; LAROCHE, S. Paradoxical role of an egr transcription factor family member, egr $2 / \mathrm{krox} 20$, in learning and memory. Front Behav Neurosci, v. 1, n., p. 6, 2007.

POIRIER, R.; CHEVAL, H.; MAILHES, C.; GAREL, S.; CHARNAY, P.; DAVIS, S.; LAROCHE, S. Distinct functions of egr gene family members in cognitive processes. Front Neurosci, v. 2, n. 1, p. 47-55, 2008.

POLS, T. W.; BONTA, P. I.; DE VRIES, C. J. NR4A nuclear orphan receptors: protective in vascular disease? Curr Opin Lipidol, v. 18, n. 5, p. 515-520, 2007.

POMPEIANO, O.; POMPEIANO, M.; CORVAJA, N. Effects of sleep deprivation on the postnatal development of visual-deprived cells in the cat's lateral geniculate nucleus. Arch Ital Biol, v. 134, n. 1, p. 121-140, 1995. 
QIN, Y. L.; MCNAUGHTON, B. L.; SKAGGS, W. E.; BARNES, C. A. Memory reprocessing in corticocortical and hippocampocortical neuronal ensembles. Philos Trans $\mathbf{R}$ Soc Lond B Biol Sci, v. 352, n. 1360, p. 1525-1533., 1997.

RAMAKERS, C.; RUIJTER, J. M.; DEPREZ, R. H.; MOORMAN, A. F. Assumption-free analysis of quantitative real-time polymerase chain reaction (PCR) data. Neurosci Lett, v. 339 , n. 1, p. 62-66, 2003.

RAMM, P.; SMITH, C. T. Rates of cerebral protein synthesis are linked to slow wave sleep in the rat. Physiol Behav, v. 48, n. 5, p. 749-753, 1990.

RAMON, F.; HERNANDEZ-FALCON, J.; NGUYEN, B.; BULLOCK, T. H. Slow wave sleep in crayfish. Proc Natl Acad Sci U S A, v. 101, n. 32, p. 11857-11861, 2004.

RASCH, B.; BUCHEL, C.; GAIS, S.; BORN, J. Odor cues during slow-wave sleep prompt declarative memory consolidation. Science, v. 315, n. 5817, p. 1426-1429, 2007.

RECHTSCHAFFEN, A. Current perspectives on the function of sleep. Perspect Biol Med, v. 41, n. 3, p. 359-390, 1998.

RECTOR, D. M.; SCHEI, J. L.; VAN DONGEN, H. P.; BELENKY, G.; KRUEGER, J. M. Physiological markers of local sleep. Eur J Neurosci, v. 29, n. 9, p. 1771-1778, 2009.

REPPERT, S. M.; WEAVER, D. R. Coordination of circadian timing in mammals. Nature, v. 418, n. 6901, p. 935-941, 2002.

RIBEIRO, S.; GERVASONI, D.; SOARES, E. S.; ZHOU, Y.; LIN, S. C.; PANTOJA, J.; LAVINE, M.; NICOLELIS, M. A. L. Long-lasting novelty-induced neuronal reverberation during slow-wave sleep in multiple forebrain areas. PLoS Biology, v. 2, n. 1, p. 126-137, 2004a.

RIBEIRO, S.; GERVASONI, D.; SOARES, E. S.; ZHOU, Y.; LIN, S. C.; PANTOJA, P.; LAVINE, M.; NICOLELIS, M. Long-lasting novelty-induced neuronal reverberation during slow-wave sleep in multiple forebrain areas. PLoS Biology, v. 2, n. 1, p. 126-137, 2004b.

RIBEIRO, S.; GOYAL, V.; MELLO, C. V.; PAVLIDES, C. Brain gene expression during REM sleep depends on prior waking experience. Learn Mem, v. 6, n. 5, p. 500-508., 1999.

RIBEIRO, S.; MELLO, C. V.; VELHO, T.; GARDNER, T. J.; JARVIS, E. D.; PAVLIDES, C. Induction of hippocampal long-term potentiation during waking leads to increased extrahippocampal zif-268 expression during ensuing rapid-eye- movement sleep. J Neurosci, v. 22, n. 24, p. 10914-10923., 2002.

RIBEIRO, S.; NICOLELIS, M. A. L. Reverberation, storage and postsynaptic propagation of memories during sleep. Learn. Mem., v. 11, n. 6, p. 686-696, 2004.

RIBEIRO, S.; SHI, X.; ENGELHARD, M.; ZHOU, Y.; ZHANG, H.; GERVASONI, D.; LIN, S. C.; WADA, K.; LEMOS, N. A.; NICOLELIS, M. A. Novel Experience Induces Persistent Sleep-Dependent Plasticity in the Cortex but not in the Hippocampus. Front Neurosci, v. 1, n. 1, p. 43-55, 2007. 
ROGERS, N. L.; DORRIAN, J.; DINGES, D. F. Sleep, waking and neurobehavioural performance. Front Biosci, v. 8, n., p. s1056-1067, 2003.

RONNBACK, A.; DAHLQVIST, P.; BERGSTROM, S. A.; OLSSON, T. Diurnal effects of enriched environment on immediate early gene expression in the rat brain. Brain Res, v. 1046, n. 1-2, p. 137-144, 2005.

ROSSI, C.; ANGELUCCI, A.; COSTANTIN, L.; BRASCHI, C.; MAZZANTINI, M.; BABBINI, F.; FABBRI, M. E.; TESSAROLLO, L.; MAFFEI, L.; BERARDI, N.; CALEO, M. Brain-derived neurotrophic factor (BDNF) is required for the enhancement of hippocampal neurogenesis following environmental enrichment. Eur J Neurosci, v. 24, n. 7, p. 1850-1856, 2006.

ROTH, T. C., 2ND; LESKU, J. A.; AMLANER, C. J.; LIMA, S. L. A phylogenetic analysis of the correlates of sleep in birds. J Sleep Res, v. 15, n. 4, p. 395-402, 2006.

SAHA, S.; DATTA, S. Two-way active avoidance training-specific increases in phosphorylated cAMP response element-binding protein in the dorsal hippocampus, amygdala, and hypothalamus. Eur J Neurosci, v. 21, n. 12, p. 3403-3414, 2005.

SAPER, C. B.; SCAMMELL, T. E.; LU, J. Hypothalamic regulation of sleep and circadian rhythms. Nature, v. 437, n. 7063, p. 1257-1263, 2005.

SATHYANARAYANAN, S.; ZHENG, X.; XIAO, R.; SEHGAL, A. Posttranslational regulation of Drosophila PERIOD protein by protein phosphatase $2 \mathrm{~A}$. Cell, v. 116, n. 4, p. 603-615, 2004.

SAWTELL, N. B.; FRENKEL, M. Y.; PHILPOT, B. D.; NAKAZAWA, K.; TONEGAWA, S.; BEAR, M. F. NMDA receptor-dependent ocular dominance plasticity in adult visual cortex. Neuron, v. 38, n. 6, p. 977-985, 2003.

SCHABUS, M. Still missing some significant ingredients. Sleep, v. 32, n. 3, p. 291-293, 2009.

SCHILTZ, C. A.; BREMER, Q. Z.; LANDRY, C. F.; KELLEY, A. E. Food-associated cues alter forebrain functional connectivity as assessed with immediate early gene and proenkephalin expression. BMC Biol, v. 5, n., p. 16, 2007.

SCOVILLE, W. B.; MILNER, B. Loss of recent memory after bilateral hippocampal lesions. J Neurol Neurosurg Psychiatry, v. 20, n. 1, p. 11-21, 1957.

SEI, H.; FUJIHARA, H.; UETA, Y.; MORITA, K.; KITAHAMA, K.; MORITA, Y. Single eight-hour shift of light-dark cycle increases brain-derived neurotrophic factor protein levels in the rat hippocampus. Life Sci, v. 73, n. 1, p. 53-59, 2003.

SGAMBATO, V.; PAGES, C.; ROGARD, M.; BESSON, M. J.; CABOCHE, J. Extracellular signal-regulated kinase (ERK) controls immediate early gene induction on corticostriatal stimulation. J Neurosci, v. 18, n. 21, p. 8814-8825, 1998. 
SHAFFERY, J. P.; ROFFWARG, H. P.; SPECIALE, S. G.; MARKS, G. A. Ponto-geniculooccipital-wave suppression amplifies lateral geniculate nucleus cell-size changes in monocularly deprived kittens. Brain Res Dev Brain Res, v. 114, n. 1, p. 109-119, 1999.

SHAPIRO, C.; GIRDWOOD, P. Protein synthesis in rat brain during sleep. Neuropharmacology, v. 20, n. 5, p. 457-460, 1981.

SHIROMANI, P. J.; BASHEER, R.; THAKKAR, J.; WAGNER, D.; GRECO, M. A.; CHARNESS, M. E. Sleep and wakefulness in c-fos and fos B gene knockout mice. Brain Res Mol Brain Res, v. 80, n. 1, p. 75-87, 2000.

SIEGEL, J. M. The REM sleep-memory consolidation hypothesis. Science, v. 294, n. 5544, p. 1058-1063., 2001.

SIEGEL, J. M. Clues to the functions of mammalian sleep. Nature, v. 437, n. 7063, p. 1264$1271,2005$.

SIEGEL, J. M. Do all animals sleep? Trends Neurosci, v. 31, n. 4, p. 208-213, 2008.

SIEGEL, J. M.; MANGER, P. R.; NIENHUIS, R.; FAHRINGER, H. M.; SHALITA, T.; PETTIGREW, J. D. Sleep in the platypus. Neuroscience, v. 91, n. 1, p. 391-400, 1999.

SIMPSON, C. S.; MORRIS, B. J. Induction of c-fos and zif/268 gene expression in rat striatal neurons, following stimulation of D1-like dopamine receptors, involves protein kinase A and protein kinase C. Neuroscience, v. 68, n. 1, p. 97-106, 1995.

SJOSTROM, P. J.; TURRIGIANO, G. G.; NELSON, S. B. Rate, timing, and cooperativity jointly determine cortical synaptic plasticity. Neuron, v. 32, n. 6, p. 1149-1164, 2001.

SMITH, C.; BUTLER, S. Paradoxical sleep at selective times following training is necessary for learning. Physiol Behav, v. 29, n. 3, p. 469-473., 1982.

SMITH, C.; ROSE, G. M. Evidence for a paradoxical sleep window for place learning in the Morris water maze. Physiol. Behav., v. 59, n. 1, p. 93-97., 1996.

STEWARD, O.; WALLACE, C. S.; LYFORD, G. L.; WORLEY, P. F. Synaptic activation causes the mRNA for the IEG Arc to localize selectively near activated postsynaptic sites on dendrites. Neuron, v. 21, n. 4, p. 741-751, 1998.

STICKGOLD, R.; HOBSON, J. A.; FOSSE, R.; FOSSE, M. Sleep, learning, and dreams: offline memory reprocessing. Science, v. 294, n. 5544, p. 1052-1057., 2001.

STICKGOLD, R.; JAMES, L.; HOBSON, J. A. Visual discrimination learning requires sleep after training. Nat Neurosci, v. 3, n. 12, p. 1237-1238., 2000 a.

STICKGOLD, R.; WHIDBEE, D.; SCHIRMER, B.; PATEL, V.; HOBSON, J. A. Visual discrimination task improvement: A multi-step process occurring during sleep. J Cogn Neurosci, v. 12, n. 2, p. 246-254., 2000 b. 
SUNAHORI, K.; JUANG, Y. T.; TSOKOS, G. C. Methylation status of CpG islands flanking a cAMP response element motif on the protein phosphatase 2Ac alpha promoter determines CREB binding and activity. J Immunol, v. 182, n. 3, p. 1500-1508, 2009.

TAISHI, P.; SANCHEZ, C.; WANG, Y.; FANG, J.; HARDING, J. W.; KRUEGER, J. M. Conditions that affect sleep alter the expression of molecules associated with synaptic plasticity. Am J Physiol Regul Integr Comp Physiol, v. 281, n. 3, p. R839-845, 2001.

TASHIRO, A.; MAKINO, H.; GAGE, F. H. Experience-specific functional modification of the dentate gyrus through adult neurogenesis: a critical period during an immature stage. J Neurosci, v. 27, n. 12, p. 3252-3259, 2007.

TERAO, A.; HUANG, Z. L.; WISOR, J. P.; MOCHIZUKI, T.; GERASHCHENKO, D.; URADE, Y.; KILDUFF, T. S. Gene expression in the rat brain during prostaglandin D2 and adenosinergically-induced sleep. J Neurochem, v. 105, n. 4, p. 1480-1498, 2008.

TERAO, A.; WISOR, J. P.; PEYRON, C.; APTE-DESHPANDE, A.; WURTS, S. W.; EDGAR, D. M.; KILDUFF, T. S. Gene expression in the rat brain during sleep deprivation and recovery sleep: an Affymetrix GeneChip study. Neuroscience, v. 137, n. 2, p. 593-605, 2006.

THIELS, E.; KANTEREWICZ, B. I.; KNAPP, L. T.; BARRIONUEVO, G.; KLANN, E. Protein phosphatase-mediated regulation of protein kinase $\mathrm{C}$ during long-term depression in the adult hippocampus in vivo. J Neurosci, v. 20, n. 19, p. 7199-7207, 2000.

THIELS, E.; NORMAN, E. D.; BARRIONUEVO, G.; KLANN, E. Transient and persistent increases in protein phosphatase activity during long-term depression in the adult hippocampus in vivo. Neuroscience, v. 86, n. 4, p. 1023-1029, 1998.

TIMO-IARIA, C.; NEGRAO, N.; SCHMIDEK, W. R.; HOSHINO, K.; LOBATO DE MENEZES, C. E.; LEME DA ROCHA, T. Phases and states of sleep in the rat. Physiol Behav, v. 5, n. 9, p. 1057-1062., 1970.

TOBLER, I. Is sleep fundamentally different between mammalian species? Behav Brain Res, v. 69, n. 1-2, p. 35-41, 1995.

TOKUYAMA, W.; OKUNO, H.; HASHIMOTO, T.; LI, Y. X.; MIYASHITA, Y. Selective zif268 mRNA induction in the perirhinal cortex of macaque monkeys during formation of visual pair-association memory. J Neurochem, v. 81, n. 1, p. 60-70, 2002.

TONONI, G.; CIRELLI, C. Sleep and synaptic homeostasis: a hypothesis. Brain Res Bull, v. 62, n. 2, p. 143-150, 2003.

TONONI, G.; CIRELLI, C. Sleep function and synaptic homeostasis. Sleep Med Rev, v. 10, n. 1, p. 49-62, 2006.

TOSCANO, C. D.; MCGLOTHAN, J. L.; GUILARTE, T. R. Experience-dependent regulation of zif268 gene expression and spatial learning. Exp Neurol, v. 200, n. 1, p. 209215, 2006. 
TZINGOUNIS, A. V.; NICOLL, R. A. Arc/Arg3.1: linking gene expression to synaptic plasticity and memory. Neuron, v. 52, n. 3, p. 403-407, 2006.

ULLOOR, J.; DATTA, S. Spatio-temporal activation of cyclic AMP response elementbinding protein, activity-regulated cytoskeletal-associated protein and brain-derived nerve growth factor: a mechanism for pontine-wave generator activation-dependent two-way activeavoidance memory processing in the rat. J Neurochem, v. 95, n. 2, p. 418-428, 2005.

VAN DONGEN, H. P.; MAISLIN, G.; MUllingTON, J. M.; DINGES, D. F. The cumulative cost of additional wakefulness: dose-response effects on neurobehavioral functions and sleep physiology from chronic sleep restriction and total sleep deprivation. Sleep, v. 26, n. 2, p. 117-126, 2003.

VAN PRAAG, H.; KEMPERMANN, G.; GAGE, F. H. Neural consequences of environmental enrichment. Nat Rev Neurosci, v. 1, n. 3, p. 191-198, 2000.

VANDESOMPELE, J.; DE PRETER, K.; PATTYN, F.; POPPE, B.; VAN ROY, N.; DE PAEPE, A.; SPELEMAN, F. Accurate normalization of real-time quantitative RT-PCR data by geometric averaging of multiple internal control genes. Genome Biol, v. 3, n. 7, p. RESEARCH0034, 2002.

VASSALLI, A.; DIJK, D. J. Sleep function: current questions and new approaches. Eur J Neurosci, v. 29, n. 9, p. 1830-1841, 2009.

VECSEY, C. G.; HAWK, J. D.; LATTAL, K. M.; STEIN, J. M.; FABIAN, S. A.; ATTNER, M. A.; CABRERA, S. M.; MCDONOUGH, C. B.; BRINDLE, P. K.; ABEL, T.; WOOD, M. A. Histone deacetylase inhibitors enhance memory and synaptic plasticity via CREB:CBPdependent transcriptional activation. J Neurosci, v. 27, n. 23, p. 6128-6140, 2007.

VERTES, R. P.; EASTMAN, K. E. The case against memory consolidation in REM sleep. Behav Brain Sci, v. 23, n. 6, p. 867-876; discussion 904-1121, 2000.

VIQUEZ, N. M.; LI, C. R.; WAIRKAR, Y. P.; DIANTONIO, A. The B' protein phosphatase $2 \mathrm{~A}$ regulatory subunit well-rounded regulates synaptic growth and cytoskeletal stability at the Drosophila neuromuscular junction. J Neurosci, v. 26, n. 36, p. 9293-9303, 2006.

VON HERTZEN, L. S.; GIESE, K. P. Memory reconsolidation engages only a subset of immediate-early genes induced during consolidation. J Neurosci, v. 25, n. 8, p. 1935-1942, 2005.

WAGNER, U.; KASHYAP, N.; DIEKELMANN, S.; BORN, J. The impact of post-learning sleep vs. wakefulness on recognition memory for faces with different facial expressions. Neurobiol Learn Mem, v. 87, n. 4, p. 679-687, 2007.

WALKER, M. P.; BRAKEFIELD, T.; MORGAN, A.; HOBSON, J. A.; STICKGOLD, R. Practice with sleep makes perfect: sleep-dependent motor skill learning. Neuron, v. 35, n. 1, p. 205-211., 2002.

WINDER, D. G.; SWEATT, J. D. Roles of serine/threonine phosphatases in hippocampal synaptic plasticity. Nat Rev Neurosci, v. 2, n. 7, p. 461-474, 2001. 
WIRTH, M. J.; BRUN, A.; GRABERT, J.; PATZ, S.; WAHLE, P. Accelerated dendritic development of rat cortical pyramidal cells and interneurons after biolistic transfection with BDNF and NT4/5. Development, v. 130, n. 23, p. 5827-5838, 2003.

WOO, N. H.; NGUYEN, P. V. "Silent" metaplasticity of the late phase of long-term potentiation requires protein phosphatases. Learn Mem, v. 9, n. 4, p. 202-213, 2002.

WORLEY, P. F.; BHAT, R. V.; BARABAN, J. M.; ERICKSON, C. A.; MCNAUGHTON, B. L.; BARNES, C. A. Thresholds for synaptic activation of transcription factors in hippocampus: correlation with long-term enhancement. J Neurosci, v. 13, n. 11, p. 47764786, 1993.

XIA, M.; HUANG, R.; GUO, V.; SOUTHALL, N.; CHO, M. H.; INGLESE, J.; AUSTIN, C. P.; NIRENBERG, M. Identification of compounds that potentiate CREB signaling as possible enhancers of long-term memory. Proc Natl Acad Sci U S A, v. 106, n. 7, p. 2412-2417, 2009.

YOO, S. S.; HU, P. T.; GUJAR, N.; JOLESZ, F. A.; WALKER, M. P. A deficit in the ability to form new human memories without sleep. Nat Neurosci, v. 10, n. 3, p. 385-392, 2007.

YU, L.; HAVERTY, P. M.; MARIANI, J.; WANG, Y.; SHEN, H. Y.; SCHWARZSCHILD, M. A.; WENG, Z.; CHEN, J. F. Genetic and pharmacological inactivation of adenosine A2A receptor reveals an Egr-2-mediated transcriptional regulatory network in the mouse striatum. Physiol Genomics, v. 23, n. 1, p. 89-102, 2005.

ZHU, S. W.; CODITA, A.; BOGDANOVIC, N.; HJERLING-LEFFLER, J.; ERNFORS, P.; WINBLAD, B.; DICKINS, D. W.; MOHAMMED, A. H. Influence of environmental manipulation on exploratory behaviour in male BDNF knockout mice. Behav Brain Res, v. 197, n. 2, p. 339-346, 2009.

ZOLA-MORGAN, S.; SQUIRE, L. R. Neuroanatomy of memory. Annu Rev Neurosci, v. 16, n., p. 547-563, 1993. 


\section{Anexos}

ANEXO A - Aprovação do Comitê de Ética em Pesquisa Animal 


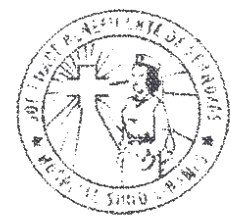

\section{Hospilal
Síriolibançs}

IMSTIUTO DE RNSINO E PESOUSA

São Paulo, 06 de novembro de 2006.

Ilmo. Sr. Julien Braga Calais Correia Pinto

Pesquisador Responsável

Registro CEUA2006/19

Pesquisa: "Expressão gênica durante o sono após exposição a um ambiente enriquecido".

Prezado Pesquisador,

O Comitê de Ética em Pesquisa da Sociedade Beneficente de Senhoras do Hospital Sírio Libanês analisou e APROVOU o Protocolo de Pesquisa Animal nº. CEUA2006/19 na reunião realizada em 06 de novembro de 2006.

Atenciosamente,

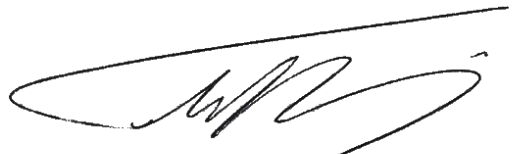

Prof. Dr. Francisco Huntberto de Abreu Maffei

Coordenador da Comissão de Ética no Uso de Animais - CEUA

Sociedade Beneficente Hospital Sírio Libanês

Rua Coronel Nicolau dos Santos. 69 - CEP: 01308-060 - São Paulo - SP 